\title{
Strengthening Higher Agricultural Education in Africa
}

June 2019

Agriculture Global Practice

Document of the World Bank 
(C) 2019 The World Bank

1818 H Street NW, Washington DC 20433

Telephone: 202-473-1000; Internet: www.worldbank.org

Some rights reserved

This work is a product of the staff of The World Bank. The findings, interpretations, and conclusions expressed in this work do not necessarily reflect the views of the Executive Directors of The World Bank or the governments they represent. The World Bank does not guarantee the accuracy of the data included in this work. The boundaries, colors, denominations, and other information shown on any map in this work do not imply any judgment on the part of The World Bank concerning the legal status of any territory or the endorsement or acceptance of such boundaries.

\section{Rights and Permissions}

The material in this work is subject to copyright. Because The World Bank encourages dissemination of its knowledge, this work may be reproduced, in whole or in part, for noncommercial purposes as long as full attribution to this work is given.

Attribution-Please cite the work as follows: "World Bank. 2019. Strengthening Higher Agricultural Education in Africa (c) World Bank."

All queries on rights and licenses, including subsidiary rights, should be addressed to World Bank Publications, The World Bank Group, 1818 H Street NW, Washington, DC 20433, USA; fax: 202-522-2625; e-mail: pubrights@worldbank.org. 


\section{Acknowledgements}

This report was prepared by a team including David Kraybill (consultant, co-author), Thomas Jayne (consultant, co-author), John Bonnell (consultant), Amy Jamison (consultant), Suresh Babu (IFPRI) and led by Peter Goodman (Senior Agriculture Economist, Task Team Leader). Irina Klytchnikova (Senior Agriculture Economist), Joanne Gaskell (Senior Agriculture Economist), Xiaonan Cao (Senior Education Specialist) and Mark Cackler (Practice Manager, Agriculture), provided valuable guidance during the study. Peer reviewers for the report were, Francisco Marmolejo (Lead Education Specialist), Willem Janssen (Lead Agricultural Economist), Irina Klytchnikova (Senior Agricultural Economist, GFADR) and Riikka Rajalahti (Consultant).

The World Bank gratefully acknowledges the financial contribution to this study from the Korea World Bank Group Partnership Facility 


\section{Table of Contents}

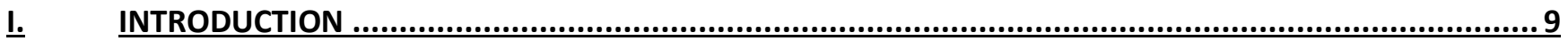

1. BACKGROUND 9

2. OBJECTIVES AND APPROACH OF THIS STUDY 9

II. CONCEPTUAL FRAMEWORK: THE ROLE OF UNIVERSITIES IN TRANSFORMING AGRI-FOOD SYSTEMS 10

III. REGIONAL CHALLENGES AND TRENDS INFLUENCING THE DESIGN OF AGRICULTURAL HIGHER EDUCATION IN AFRICAN UNIVERSITIES: IMPLICATIONS FOR SKILLS AND KNOWLEDGE NEEDS.......................14

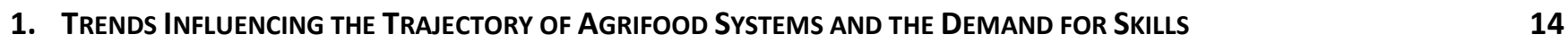

2. Implications of Trends in Agriculture for KNOWLedge AND SKILLS NeEdS IN the Agri-Food Sector 21

IV. CORE CHALLENGES TO DEVELOPMENT OF HIGHER AGRICULTURAL EDUCATION .........................23

1. National level Challenges $r$

RISING DEMAND FOR ENROLLMENT AND FUNDING CONSTRAINTS 23

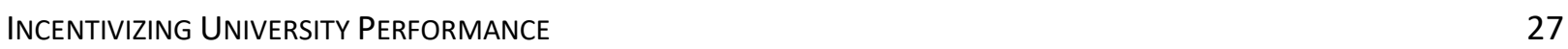

REGULATION AND QUALITY ASSURANCE 28

The NeEd for Greater InClusion In Higher Education $\quad 30$

2. UNIVERSity LEADERSHIP AND MANAGEMENT $\quad 3$

APPROACH TO UNIVERSITY TRANSFORMATION - A SHIFT TO ORGANIZATIONAL LEARNING 30

PERFoRMANCE BASED STAFF CONTRACTS

INFRASTRUCTURE INVESTMENT

3. ReleVANCE AND Quality of Teaching AND ReSEARCH 32

TEACHING

RESEARCH

4. Collaboration $\quad 35$

Africa Region Collaboration on Teaching ANd ReSEarCH

NORTH-SOUTH COLLABORATION ON RESEARCH

local Collaboration With Agricultural Policy ResearCh Institutes 38 


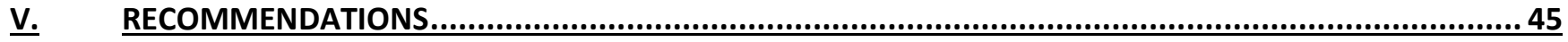

1. ReCommendation Theme 1: NAtional LeVel Reforms 4

VISION/STRATEGY

THEMATIC SCOPE OF Higher Agricultural Education

INSTITUTIONAL ARCHITECTURE $\quad 45$

FUNDING SOURCES $\quad 46$

INCENTIVES - PERFORMANCE-BASED FUNDING

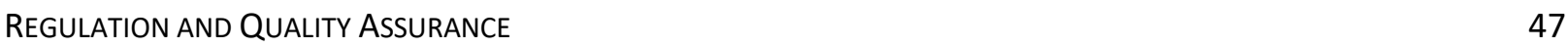

2. ReCOMMENDATION THEME 2: LEADERSHIP AND MANAGEMENT 4

$\begin{array}{ll}\text { LEADERSHIP TRAINING } & 48\end{array}$

INVESTMENT AND FINANCIAL MANAGEMENT $\quad 49$

INCENTIVES FOR STAFF $\quad 49$

QUALITY ASSURANCE AND ACCREDITATION

3. ReCOMmendation Theme 3: ReleVANCE AND Quality $5 \mathbf{5 0}$

RELEVANCE ENHANCEMENT IN TEACHING AND LEARNING $\quad 50$

RELEVANCE ENHANCEMENT IN RESEARCH AND EXTENSION

4. Recommendation Theme 4: Collaboration $\quad 57$

Regional Collaboration $\quad 57$

TYPES OF COLLABORATION WITH NATIONAL, REGIONAL, AND CONTINENTAL UNIVERSITIES

COlLABORATION WITH GOVERNMENT MINISTRIES

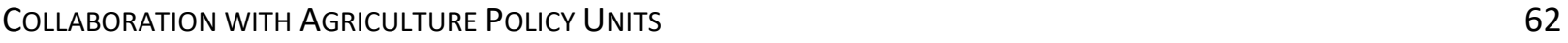

COLLABORATION WITH ATVET

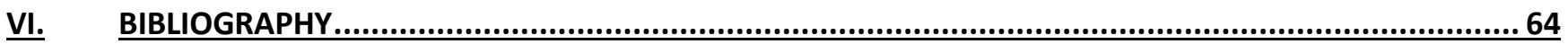

ANNEX 1 CORE DEVELOPMENT CHALLENGES IN HIGHER EDUCATION IN AFRICA: SUMMARY OF FINDINGS

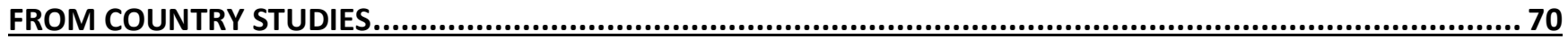

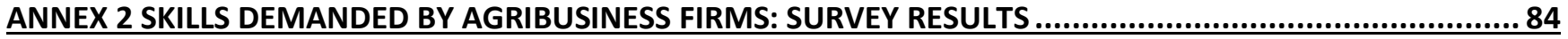

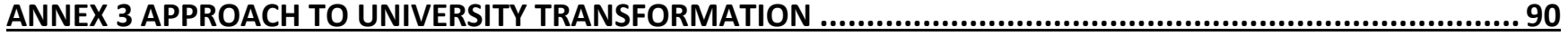

ANNEX 4 INTERNATIONALIZATION AND SHIFTS IN THE DYNAMICS OF NORTH-SOUTH PARTNERSHIPS DRIVING THE DEMAND FOR AFRICAN-LED SOLUTIONS.. 


\section{List of Figures}

\begin{tabular}{|c|c|c|}
\hline Figure 1 & $\begin{array}{l}\text { Foundational role of universities in influencing the performance of other public actors } \\
\text { in agrifood systems }\end{array}$ & 12 \\
\hline Figure 2 & Projected Population Aged Less Than 15 Years & 14 \\
\hline Figure 3 & Change in the distribution of labor in the agri-food sector with country income status & 15 \\
\hline Figure 4 & $\begin{array}{l}\text { Opportunities Across Digital Agriculture Development Continuum (Nascent, } \\
\text { Transitional, Advanced Systems) }\end{array}$ & 16 \\
\hline Figure 5 & $\begin{array}{l}\text { Prevalence of stunting among children under } 5 \text { years of age in the WHO African } \\
\text { Region }\end{array}$ & 17 \\
\hline Figure 6 & $\begin{array}{l}\text { Prevalence of overweight among children under } 5 \text { years of age in the WHO African } \\
\text { Region }\end{array}$ & 17 \\
\hline Figure 7 & Climate change risks and or impacts for specific natural, managed and human systems & 18 \\
\hline Figure 8 & Degradation Map & 19 \\
\hline Figure 9 & $\begin{array}{l}\text { Average female scientist shares in professional staff, by degree in } 64 \text { developing } \\
\text { countries, 2001-08 }\end{array}$ & 20 \\
\hline Figure 10 & Directions for Diversification of Higher Agricultural Education & 21 \\
\hline Figure 11 & Government Expenditure on Education, total (\% of GDP) & 23 \\
\hline Figure 12 & Expenditure On Tertiary Education (\% Of Government Expenditure On Education) & 24 \\
\hline Figure 13 & $\begin{array}{l}\text { The share of the population with completed tertiary education in SSA is and has } \\
\text { remained very low compared to other regions of the world }\end{array}$ & 24 \\
\hline Figure 14 & The Majority of Tertiary Education Enrollment in SSA is in non-STEM fields & 25 \\
\hline Figure 15 & Three Leadership Styles in Higher Education & 30 \\
\hline Figure 16 & $\begin{array}{l}\text { Level of international collaboration for SSA regions (2012) and percentage of non- } \\
\text { local, transitory researchers for SSA regions, 1996-2013. }\end{array}$ & 37 \\
\hline Figure 17 & Three Leadership Styles in Higher Education & 92 \\
\hline Figure 18 & $\begin{array}{l}\text { Percentage of total article output by subject groupings for Africa regions and } \\
\text { comparator countries } 2012\end{array}$ & 100 \\
\hline Figure 19 & $\begin{array}{l}\text { Downloads per article by subject grouping relative to regional averages for SSA } \\
\text { regions and comparator countries, } 2008-2012\end{array}$ & 100 \\
\hline Figure 20 & $\begin{array}{l}\text { Level of international collaboration for SSA regions and comparator countries, 2003- } \\
2012\end{array}$ & 101 \\
\hline Figure 21 & $\begin{array}{l}\text { Adjusted Field Weighted Citation Index associated with different types of collaboration } \\
\text { (e.g., FWCI for single-authored, intra-regional, and international collaboration } \\
\text { normalized against FWCI of institutional collaboration) for SSA regions and } \\
\text { comparator countries, } 2012 \text {. }\end{array}$ & 101 \\
\hline
\end{tabular}




\section{List of Text Boxes}

\begin{tabular}{|c|c|c|}
\hline Text Box 1 & $\begin{array}{l}\text { IPCC } 2018 \text { 1.5OC Report: Climate Change Impact on Access to and Availability of } \\
\text { Nutrients }\end{array}$ & 17 \\
\hline Text Box 2 & IPCC 2018 1.5OC Report: Climate Change Impact on Water Stress. & 18 \\
\hline Text Box 3 & Country Approaches to Responding to Increased Demand for Enrolment & 26 \\
\hline Text Box 4 & The Role of Private Universities in Kenya & 26 \\
\hline Text Box 5 & Performance Based Funding in Côte D'Ivoire and Senegal & 27 \\
\hline Text Box 6 & Challenges of Quality Assurance in Kenya & 28 \\
\hline Text Box 7 & Country Examples of Quality Assurance & 29 \\
\hline Text Box 8 & Quality Assurance, African Centers of Excellence (ACE) & 29 \\
\hline Text Box 9 & Performance Based Staff Contracts in Cote D'Ivoire & 31 \\
\hline Text Box 10 & Performance Based Staff Contracts in Malawi & 31 \\
\hline Text Box 11 & Country Availability of Labor Market Information. & 33 \\
\hline Text Box 12 & Non-traditional academic engagement in Kenya & 33 \\
\hline Text Box 13 & EARTH University, Costa Rica: A New Kind of Agricultural University & 34 \\
\hline Text Box 14 & Examples of Africa Region Collaboration on Teaching and Research & 36 \\
\hline Text Box 15 & The Role of Egerton University in the Development of the Tegemeo Institute & 39 \\
\hline Text Box 16 & The Indaba Agricultural Policy Research Institute of Zambia & 40 \\
\hline Text Box 17 & From University to Industry: Technology Transfer at Unicamp in Brazil & 41 \\
\hline Text Box 18 & Reforming Higher Agricultural Education in China, 1990-2000 & $42-43$ \\
\hline Text Box 19 & Reforming India's State Agricultural Universities & 43 \\
\hline Text Box 20 & Transforming Wageningen Agricultural University & 44 \\
\hline Text Box 21 & $\begin{array}{l}\text { Brazil's National Agricultural Research Program Benefits from Long-Term } \\
\text { Investments in Human Resources }\end{array}$ & 44 \\
\hline Text Box 22 & The Potential of ICT for AET and Its Role in an Innovation System & 46 \\
\hline Text Box 23 & Sustainable Financing of Policy Research Institutes & 62 \\
\hline Text Box 24 & Non-traditional academic engagement in Kenya & 79 \\
\hline Text Box 25 & Improving Student Internships in Agrifood Industry & 81 \\
\hline Text Box 26 & Innovative Scholars Program - Malawi & 95 \\
\hline
\end{tabular}




\section{List of Tables}

\begin{tabular}{|l|l|c|}
\hline Table 1 & Implications of Trends in Agriculture for Skills Needs & 22 \\
\hline Table 2 & Composition of businesses surveyed & 84 \\
\hline Table 3 & $\begin{array}{l}\text { Agribusiness firm respondent's ranking of importance to the question: "Over the } \\
\text { next decade, which kind of employee skills will be most highly valued by your } \\
\text { business?" }\end{array}$ & 85 \\
\hline Table 4 & $\begin{array}{l}\text { Over the next decade, which kind of employee skills will be most highly valued by } \\
\text { your business? }\end{array}$ & 86 \\
\hline Table 5 & $\begin{array}{l}\text { Which specific knowledge competency areas would you like to see more emphasis } \\
\text { placed on in higher education to prepare graduates to work in your business? }\end{array}$ & 87 \\
\hline Table 6 & $\begin{array}{l}\text { Which specific knowledge competency areas would you like to see more emphasis } \\
\text { placed on in higher education to prepare graduates to work in your business? }\end{array}$ & 88 \\
\hline Table 7 & $\begin{array}{l}\text { Please rate the importance of the following ways of developing a work force with } \\
\text { the skills most valued by your business. }\end{array}$ & 89 \\
\hline Table 8 & \begin{tabular}{l} 
Protocol for an Organizational Experiment \\
\hline
\end{tabular} & 100 \\
\hline
\end{tabular}




\section{Acronyms and Abbreviations}

\begin{tabular}{|c|c|}
\hline AAU & Association of African Universities \\
\hline ACE & African Centres of Excellence \\
\hline AGRA & Alliance for Green Revolution in Africa \\
\hline AGORA & Access to Global Online Research in Agriculture \\
\hline AfDB & African Development Bank \\
\hline AIS & Agricultural Innovation Systems \\
\hline AKIS & Agricultural Knowledge and Information system \\
\hline ALU & African Leadership University \\
\hline AIMS & African Institute for Mathematical Sciences \\
\hline ANADER & Agricultural Extension Agency Mozambique \\
\hline ATVET & Agricultural and Technical Vocation Educational Institutes \\
\hline BMZ & German Federal Ministry for Economic Cooperation and Development \\
\hline CAADP & Comprehensive African Agricultural Development Programme \\
\hline CNRA & National Center for Agricultural Research \\
\hline CAMES & African and Malagasy Council for Higher Education \\
\hline CODESRIA & Council for Development of Social Science Research in Africa \\
\hline CPUT & Cape Peninsula University of Technology in South Africa \\
\hline DACUM & Developing a Curriculum \\
\hline DRIC & Directorate of Research, Innovation and Consultancy \\
\hline DTAC & Departmental Teaching Assessment Committee \\
\hline EMBRAPA & Brazilian Agricultural Research Corporation \\
\hline ESA & École Supérieure d'Agronomie \\
\hline FOHCREC & Forest and Horticultural Crops Research Center \\
\hline GDP & Gross Domestic Product \\
\hline GIS & Geographical Information Systems \\
\hline HAE & Higher Agricultural Education \\
\hline HAQAA & Harmonization of African Higher Education Quality Assurance and Accreditation \\
\hline HELB & Higher Education Loans Board \\
\hline HEST & Higher Education, Science and Technology \\
\hline IAGRI & Innovative Agricultural Research Initiative \\
\hline IAPRI & Indaba Agricultural Policy Research Institute \\
\hline ICT & Information Communication Technology \\
\hline IICD & International Institute for Communication and Development \\
\hline INPHB & National Polytechnic Institute Félix Houphouet-Boigny \\
\hline IOT & Internet of Things \\
\hline IPBES & Inter-Governmental Science-Policy on Biodiversity and Ecosystem Services \\
\hline IPCC & Intergovernmental Panel on Climate Change \\
\hline IUCEA & Inter-University Council for East Africa \\
\hline KNUST & Kwame Nkrumah University of Science and Technology \\
\hline
\end{tabular}




\begin{tabular}{|l|l|}
\hline LUANAR & Lilongwe University of Agriculture and Natural Resources \\
\hline LIPREC & Livestock and Poultry Research Center \\
\hline LMD & Licence-Masters-Doctoral \\
\hline MESRS & Ministry of Higher Education and Scientific Research \\
\hline M\&E & Monitoring and Evaluation \\
\hline MSU & Michigan State University \\
\hline NAB & National Accreditation Board \\
\hline NAIP & National Action Plans \\
\hline NARS & National Agricultural Research System \\
\hline NCTE & National Council for Tertiary Education \\
\hline NRC & Natural Resource College \\
\hline PANGEA & Partnership for Africa's Next Generation of Academics \\
\hline PBCs & Performance-based Contracts \\
\hline PBF & Performance-based funding \\
\hline PDIA & Problem-driven Incremental Change \\
\hline QA & Quality Assurance \\
\hline RIMA & Research and Innovation Management Associations \\
\hline R\&D & Research and Development \\
\hline RUFORUM & Regional Universities Forum for Capacity Building in Agriculture \\
\hline SARChI & South African Research Chairs Initiative \\
\hline SDG & Sustainable Development Goals \\
\hline SIREC & and Soil and Irrigation Research Center \\
\hline TOT & Training-of-trainer \\
\hline TVET & Technical and Vocational Education and Training \\
\hline UCC & University of Cape Coast \\
\hline UEM & Universidad Eduardo Mondlane \\
\hline UFHB & University Felix Houphouet-Boigny \\
\hline UNA, & University Nangui Abrogoua \\
\hline UNESCO & United Nations Educational Scientific and Cultural Organisation \\
\hline UNICAMP & Universidade Estadual de Campinas \\
\hline UNZA & University of Zambia \\
\hline USAID & United States Agency for International Development \\
\hline USIU & United States International University \\
\hline & \\
\hline
\end{tabular}




\section{INTRODUCTION}

\section{BACKGROUND}

1. Over the last decade African governments' and regional economic organizations have increasingly recognized the need to reshape higher agricultural education to meet the changing needs of the agri-food sector. There is a strong appetite for change but a need for a better understanding of the challenges that universities face in transforming into institutions that can be more dynamic and responsive, especially to the needs of the private sector, that can be seen as more relevant by the public sector and meet the rapidly growing demand for university places.

2. The study is being prepared at a time when the World Bank along with other development partners are considering possible approaches to address these challenges. It follows regional dialogue on this theme in Africa in recent years involving African governments, regional agro-innovation and education networks including Regional Universities Forum for Capacity Building in Agriculture (RUFORUM), under the umbrella of the African Union Comprehensive African Agricultural Development Programme. (CAADP).

\section{OBJectives AND APPROACH OF ThIS STUdy}

3. The objective of the study is to identify reforms and investments needed to strengthen higher agricultural education in Africa and to inform the design and implementation of future investments and related regional dialogue.

4. The analysis in this study is drawn from several sources. The study team undertook one-two week country studies in five countries, Cote d'Ivoire, Ghana, Kenya, Malawi and Mozambique, conducting interviews with university leaders, members of departmental faculty in agriculturallyrelated disciplines, private sector representatives, government officials in ministries of agriculture and related public sector units. The team conducted a short skill needs survey with 44 agri-enterprises. The team also conducted 14 interviews of key informants with longstanding experience in agricultural higher education systems. The report's conclusions and recommendations are drawn from these varied sources as well as from a review of the literature on institutional capacity development.

5. The study is structured as follows: section II describes the role of higher agricultural education in the wider agro-innovation system and the means through which higher education can drive transformation of the agri-food sector and economic development in Africa; section III describes global trends in agriculture that will drive changes in employers' knowledge and skills needs; section IV describes the implications of these trends for skill and knowledge needs; section $\mathrm{V}$ describes the core challenges that universities face in transforming to be more responsive to needs; and the final section VI provides recommendations on reforms and investments to strengthen higher education in Africa.

6. The World Bank gratefully acknowledges the support provided to this study from the Korea World Bank Group Partnership Facility. 


\section{CONCEPTUAL FRAMEWORK: THE ROLE OF UNIVERSITIES IN TRANSFORMING AGRI-FOOD SYSTEMS.}

\section{Role of Higher Agricultural Education in Economic Transformation}

7. The Importance of Higher Education in Economic Transformation: Universities engaged in agriculture are part of an Agricultural Education System that includes universities or departments that are specialized in agriculture and universities or departments that are not specialized in agriculture but deliver education and research that is directly part of agricultural education and research or relevant to it. The system also includes Technical and Vocational Education and Training (TVET), training colleges, other African and overseas universities.

8. The supply of highly effective human resources profoundly influences the pace of a country's economic development. African universities contribute by far the greatest numbers of undergraduate and Master's-level workers in most African countries' labor forces. The workers graduating from African universities then influence the quality of the rest of their country's workforce, through the training that they provide to others -- in primary and secondary schools, in agricultural training colleges, in technical and vocational education training schools, in public sector jobs, in civil society, and in the private sector.

9. Returns to investments in higher education in Africa are estimated at 21 percent - the highest in the world (Africa-American Institute, 2015). A one-year increase in average tertiary education levels is estimated to raise annual Gross Domestic Product (GDP) growth in Africa by 0.39 percentage points, and eventually yield up to a 12 percent increase in GDP (UNESCO, World Bank). Universities also play an important role in creating knowledge-based goods and services that have diffuse and potentially transformational impact. For example, the activities of universities may have important effects on government policy, practices of private sector firms, a more informed citizenry, and the democratic process (Shulock, 1999).

10. Growing evidence shows that indicators of educational achievement are highly correlated with long-term per capita economic growth rates (e.g., Altinok, Angrist, and Patrinos, 2017). Economic development in Africa is likely to co-evolve together with the upgrading of African countries' workforce. Fortunately, in recognition of the strong correlation between education and socio-economic development, Sub-Saharan African governments have gradually increased public spending on education by more than 6 percent each year since 2000 .

11. The Importance of the Agrifood Sector and Higher Agricultural Education in Economic Transformation: Agricultural higher education institutions will be called upon to play a central role in promoting Africa's economic transformation (Altbach 2013; Altbach et al. 2010; Bloom et al. 2006; Rivera 2008). Even though the majority of workers in African agrifood systems will never step foot on a university campus, they are still likely to receive training from and be influenced by university graduates in the form of primary or secondary school teachers, private sector training programs, 
agricultural training, vocational and extension schools, family members, friends, colleagues, and mentors. Through their diffuse effect on workforce quality, higher education institutions exert a profound effect on the pace of a country's development (World Bank 2009).

12. Even with rapid economic diversification and non-farm employment expansion, recent analysis reconfirms the foundational role of agri-food systems in enabling and driving economic diversification and transformation (Christiaensen and Martin, 2018; Jayne et al., 2018). Because the economies of Sub-Saharan Africa strongly depend on agriculture and allied agri-food systems, African governments may contribute to achieving their economic growth objectives by strengthening their higher education capacity related to agri-food systems.

\section{Role of Higher Agricultural Education in the Agro-Innovation System}

13. The agricultural education system is part of a broader innovation ecosystem that includes extension systems, research and development (R\&D) institutes, agricultural policy research institutes, regional network organizations that support advocacy and sharing of knowledge, civil society organizations, private sector foundations, organizations and innovation hubs, as well as farmers and agribusinesses.

14. These organizations interact within this ecosystem influenced by power relations, control over resources, and the individual goals and objectives of the participants involved. Through its own decisions and the behavior of its management, the university can influence how the ecosystem functions and can influence the performance of other actors in the ecosystem. In turn the allied parts of the ecosystem can affect the performance of universities and their impact on development outcomes.

15. Figure 1 describes part of the ecosystem, the way in which universities influence the performance of government ministries, public agricultural research and development (R\&D), agricultural extension systems, policy analysis institutes, and the generation of data to provide evidence-based guidance to agrifood systems development. The quality of university education influences the effectiveness of workers in all of these types of organizations. The quality of research undertaken by the university may usefully guide and orient the activities of the other organizations. For example, research has documented how agrifood systems transformation is raising the demand for labor-saving agricultural technologies in some areas where labor wages are rising rapidly, and landsaving technologies in other areas where land scarcity is becoming an acute problem (Wineman et al., 2018). University research on how agricultural land and labor prices are evolving in different parts of a country can usefully orient public agricultural R\&D programs toward labor-saving or labor-saving forms of technical innovation appropriate to specific areas. University-led initiatives can help coordinate the activities of agricultural R\&D units, extension systems, ministries of agriculture, and policy institutes to achieve greater integration and synergies from their activities. And universities have a major role to play in anticipating and coordinating with the private sector to ensure that the skills sets of university graduates are meeting the demands of the rapidly evolving firms in Africa's agrifood systems. 


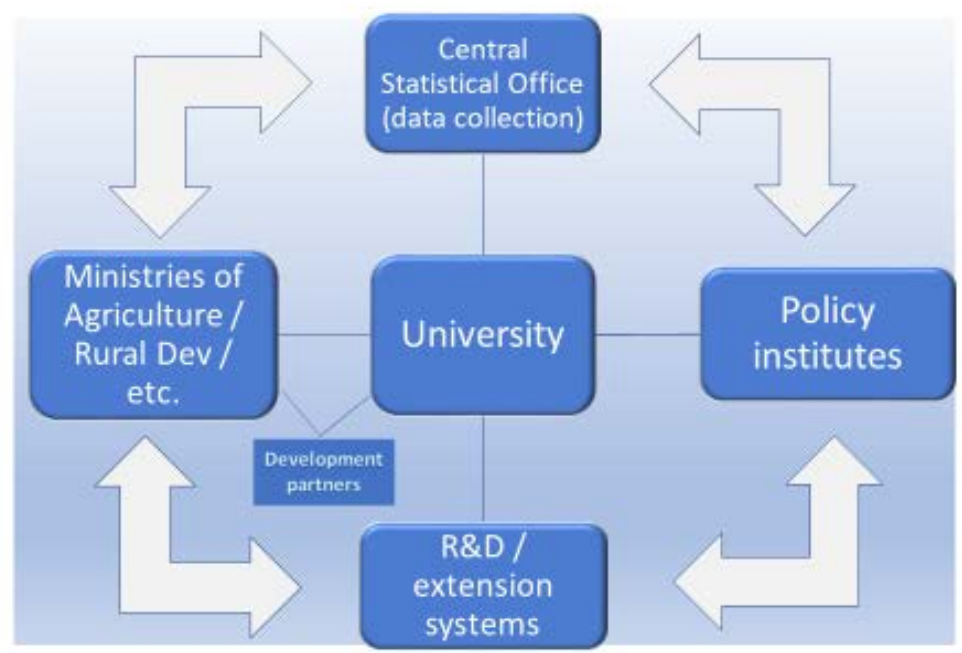

16. Figure 1 depicts only a partial picture of how agricultural universities influence the performance of other actors in agrifood systems, with a focus on public sector institutions. The private sector, civil society and TVET systems are likewise fundamentally influenced by agricultural universities. It is sometimes perceived that agricultural universities are having little impact on the private sector, but this view fails to recognize how underperformance of the university results in impacts that must be adjusted to by the private sector, including the need for on-the-job training that could have otherwise been effectively provided by universities or by university graduates employed in TVET systems. The foregone or underperforming activities of universities create impacts - such as the need for adjustments by others in the system, foregone private investments in the food system that might have otherwise occurred in environments with a better trained workforce, or foregone coordination between actors in the system that may have resulted in more rapid agrifood systems transformation.

17. African universities are at the foundation of "education value chains". The productivity of millions of individuals working in the agri-food system (in farming, trading, agribusiness, processing, farm finance, insurance, policy analysis, etc.) receive their training, formally or informally, directly or indirectly, from people in farm extension, technical, vocational education and training programs, and informal groups, who in turn received their training from faculty in the colleges of agriculture in local universities. Even though most workers in African agrifood systems do not attend universities, they are still likely to receive training from and be influenced by university graduates in their roles as primary or secondary school teachers, trainers in private sector training programs, teachers in vocational schools, agricultural extension agents, family members, friends, colleagues, and mentors. Through their diffused impact on workforce quality, therefore, higher education institutions can profoundly catalyze a country's development (World Bank 2009). 
18. Given the complexity of agricultural education and training and workforce development in Africa, a systems perspective is necessary to both understand what is currently occurring in regions and to successfully implement reforms. A system is defined as a collection of "actors, activities, and settings" that interact in various ways and "that are directly or indirectly perceived to have influence on or be affected by a given problem situation" (Foster-Fishman, Nowell, \& Yang, 2007, p.198). To successfully bring about desired change, Senge (1990) argued that individuals and organizations must adopt a new mindset and approach, one that views the larger interactions of the system instead of a narrow focus on particular system components. From this lens, transformative change is a dynamic ongoing and iterative process that is dependent upon stakeholder involvement in defining problems, identifying root causes of those problems, and locating effective change leverage points (FosterFishman et al., 2007).

19. The benefits of system perspectives is gaining momentum for reform efforts to improve agricultural education systems in Africa, particularly for creating environments that enable innovation. To conceptualize the intricacy and nonlinearity in AET, some have proposed to view agricultural development within the frame of Agricultural Innovation Systems (AIS) (Davis et al., 2007; Rivera, 2008; Spielman, Ekboir, Davis, \& Ochieng, 2008), which follows a trajectory of related ideas about system innovation (World Bank, 2006), including the National Agricultural Research System (NARS) and the Agricultural Knowledge and Information system (AKIS). The World Bank (2006) defined an innovation system as "a network of organizations, enterprises, and individuals focused on bringing new products, new processes, and new forms of organization into economic use, together with the institutions and policies that affect their behavior and performance". This system includes informal as well as formal rules and looks more like "a spider web of related individuals and organizations, all of whom contribute something to the application of new or existing information and knowledge" (Davis et al., 2008, p. 39).

20. Drawing upon systems perspective, this study identifies regional trends and challenges affecting agricultural higher education systems and outlines necessary responses to the changing landscape of African agrifood systems. Findings from country studies offer further guidance to design contextually appropriate solutions designed and implemented via stakeholder collaboration. 


\section{REGIONAL CHALLENGES AND TRENDS INFLUENCING THE DESIGN OF AGRICULTURAL HIGHER EDUCATION IN AFRICAN UNIVERSITIES: IMPLICATIONS FOR SKILLS AND KNOWLEDGE NEEDS}

21. This chapter discusses trends that will increasingly drive knowledge and skills needs from the private and public sector that Africa's higher agricultural education must respond to. Table 1 (page 21) summarizes the trends' resulting knowledge and skills needs.

22. Sub-Saharan African agrifood systems are developing rapidly. Anticipating the needs of firms and organizations in Africa's agrifood systems requires an understanding of how agrifood systems are transforming and what these changes mean for needed skills in the labor force.

23. These changes - in technologies, institutions, climates, and the importance of globalization and relationships between local and international firms - are expanding and changing the emphasis of the skill sets demanded by private and public sector workers in agrifood systems. Africa also continues to face fundamental and longstanding challenges of low agricultural productivity, food insecurity, and poverty, which highlight the enduring (and often latent) demand for knowledge and skilled people to address these chronic challenges.

24. This section aims to highlight both the enduring and evolving economic, demographic and education trends affecting African agrifood systems and the implications for the evolving skill sets of the labor force. These skill sets are identified through (1) key informant interviews of 52 public sector, private sector and academic experts in the five case study countries (Cote d'Ivoire, Ghana, Kenya, Malawi, and Mozambique); (2) peer-reviewed scholarship; (3) a survey of agribusiness stakeholders ( $n=44$ respondents). After identifying these evolving needs, subsequent sections of the paper will consider how higher agricultural education systems can respond to meet these needs.

\section{Trends Influencing The Trajectory of Agrifood Systems And THE} DEMAND FOR SKILLS

\section{Trend 1 Demographic Change -} Driving an Overall Increase in Demand for Higher Education: Africa is the only region of the world where the population of under-15s is continuing to grow (Figure 2). Africans between 15 and 35 years of age now account for $55 \%$ of the region's labor force. Every year, roughly 11 million young Africans are entering the labor force. In parallel, enrollment in secondary education has increased from 26 to 43 percent in

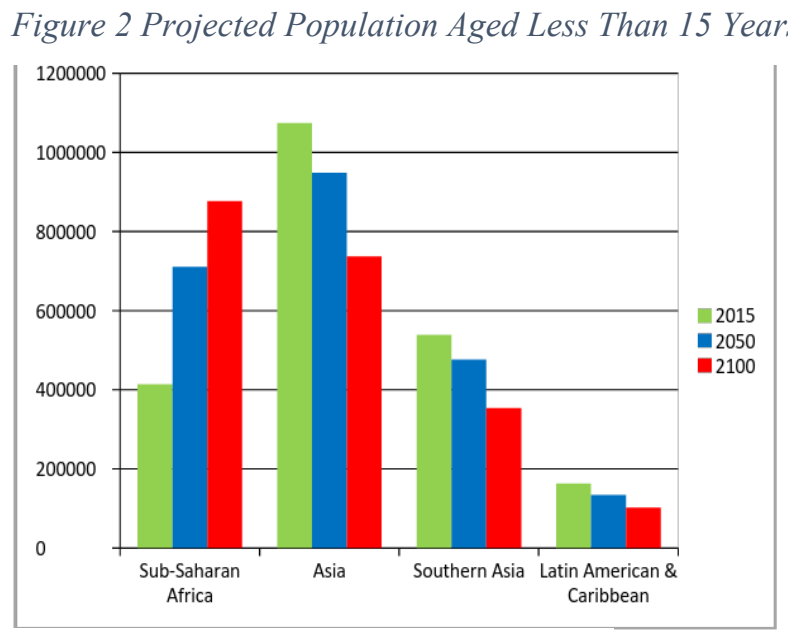

Source: United Nations 2016 
Sub Saharan Africa since 2000. In combination these factors have resulted in sharp increases in demand for university enrollment.

26. The demand for higher education in agriculture will rise tremendously over the next two decades. In Ethiopia, the numbers of students graduating with undergraduate degrees annually has risen from 3,000 in the 1990s to over 105,000 today (Jayne, Kabaghe, and Minde, 2017). African universities and technical schools must anticipate and make plans to absorb this rapid rise in demand for university education without compromising on teaching quality.

27. Relatedly, the number of private sector wage jobs is rising rapidly in many African countries, more rapidly than public sector jobs (Yeboah and Jayne, 2018).

\section{Trend 2 Structural Evolution of Value Chains - Driving Demand for Downstream Job}

Skills: Over the next 40 years, the food system of Africa will continue its transition along a similar trajectory as experienced in other regions. Generation of employment and valuation addition will shift from farms to off-farm agro-food industries such as distribution, packaging, processing, finance, technology development and dissemination, insurance, technical analysis and later to food services (Minde 2012; Hill et al., 2015, Tschirley et al 2015) (Figure 3). This shift requires new kinds of workers in the private sector. Most of Africa's workers in agri-food systems will be running farms or small businesses or be employees on farms or in small businesses in the informal economy and they may especially benefit from the availability of practical technical services produced by TVETs. The skills required for success in these businesses are diverse and involve soft skills as well as technical and problem-solving skills. Higher education institutions in Africa need to position themselves to effectively train those who will be providing the training to these millions of workers in African agrifood systems.

Figure 3 Change in the distribution of labor in the agri-food sector with country income status

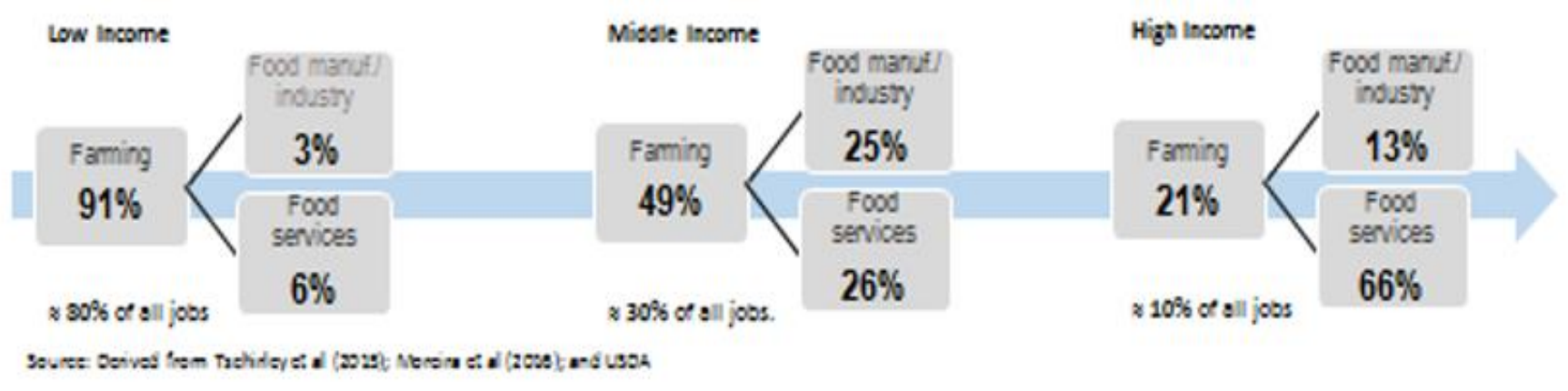




\section{Trend 3 Technological Revolution - Driving}

\section{Demand for Skills in Application of Digital}

Technology and Biotechnology to Agri-Food Value

Chains: The fourth industrial revolution driven by digitization and parallel advances in automation, precision technology, geographic information systems (GIS) is rapidly changing the way agri-food value chains operate.

The agricultural sector is a late adopter of digital

Figure 4 Opportunities Across Digital Agriculture Development Continuum (Nascent, Transitional, Advanced Systems)

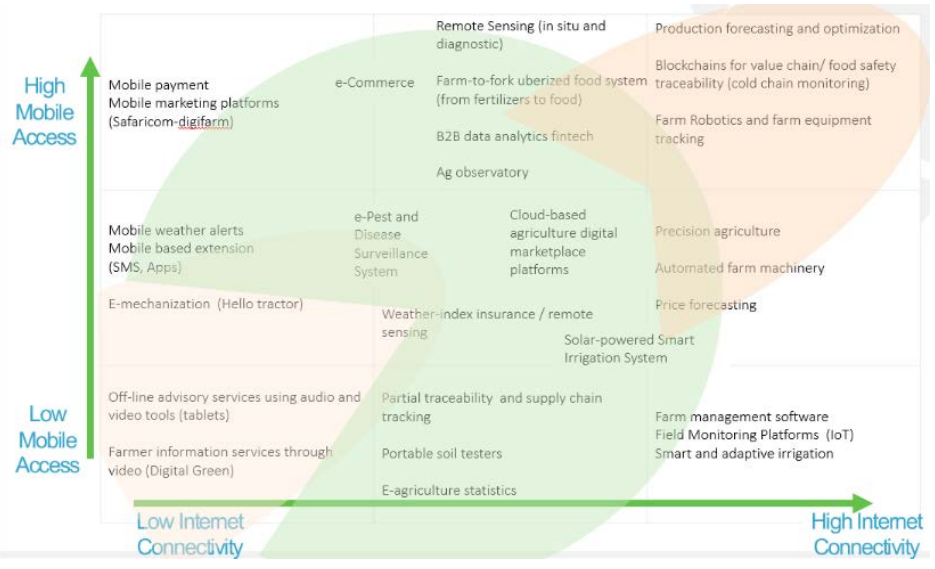

Source: Africa Digital Agricultural Moonshot Presentation. World Bank May 2019

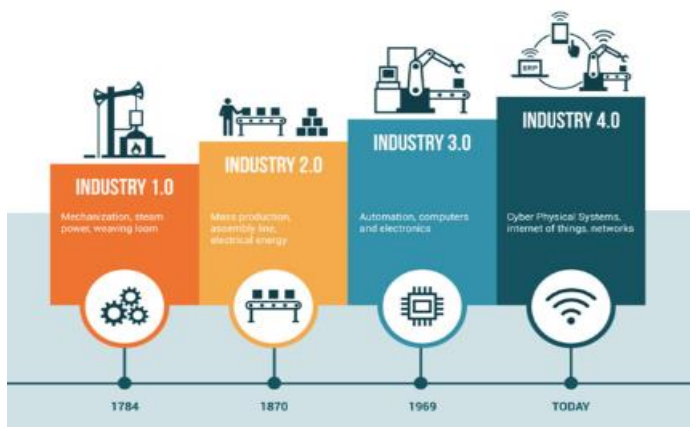

technology compared to other sectors but the scope for its application is enormous (Figure 4). Improved weather modeling, GIS, advanced capacity to analyze climate, agricultural production mega-data and mobile technology can now provide widespread access to high accuracy early warning and production advice; blockchain and mobile connectivity can respond to increasing demand for fast delivery of perishable produce to market and traceability from farm to fork; and automation and precision agriculture can dramatically improve the efficiency of water and input use. Human capital development needs to keep pace with technology.

30. If food demand in 2030 is to be met by productivity gains alone, cereal yields in Sub-Saharan Africa will need to increase at 3 percent per year, which is over 40 percent higher than the 2.1 percent gains achieved from 2000 to 2013 (World Bank, 2015; van Ittersum et al., 2016). Increased output over the last 30 years has been primarily met through land expansion rather than technological adoption. Cereal yields have hardly increased in the last four decades. Food production growth in SubSaharan Africa will need to shift from reliance on area expansion to increased output per unit land, or else there will be major natural resource and biodiversity costs to be borne. Moreover, as a higher proportion of Africa's labor force derive their livelihoods from off-farm sources, there will be a growing demand for labor-saving agricultural technologies. Both of these developments hold major implications for agricultural engineering, agronomy and agricultural extension programs in African universities. The rapidly falling cost of technology will make it easier for small farmers to overcome technological barriers to participation in formal value chains and change some of the characteristics of agricultural transformation observed in other countries over the last 40 years.

\section{Trend 4 Urbanization, Rising Incomes and Dietary Change- Driving Demand for Better}

Nutritional Skills: While addressing under-nutrition and malnutrition, including as a result of deficiencies in specific micronutrients, is still a major challenge for large parts of Africa (Figure 5). 
Over the next 20 years, Africa will experience a dietary transformation driven by rising incomes and urbanization. In light of these trends, African diets are already changing toward processed foods (Minde et al., 2014; Tschirley et al., 2015). Africa's dietary transformation is causing an increased prevalence of health conditions noted in "Western diets" such as obesity (Figure 6)and cardio-vascular disease. Food science and technology and nutritional expertise will have an increasingly critical role to play. However, a snapshot survey of curricula in African universities revealed that there is insufficient non-degree extension training and nutrition education is very deficient (Minnar et al., 2013).

Figure 5 Prevalence of stunting among children under 5 years of age in the WHO African Region

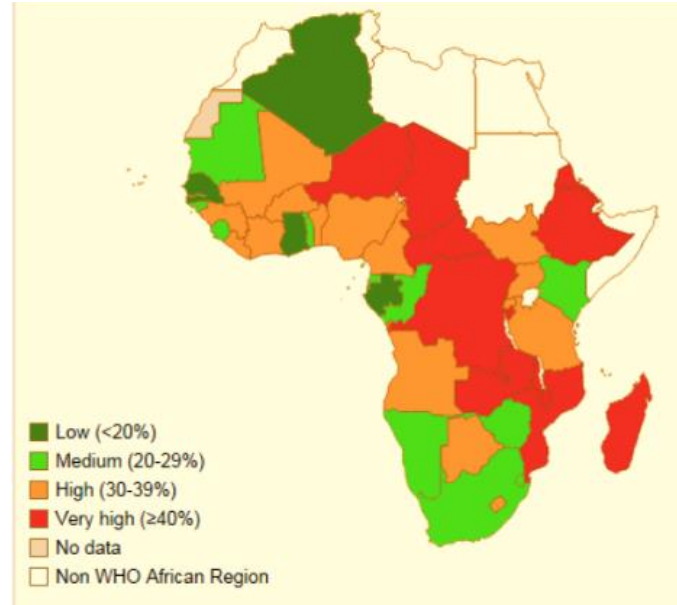

Figure 6 Prevalence of overweight among children under 5 years of age in the WHO African Region

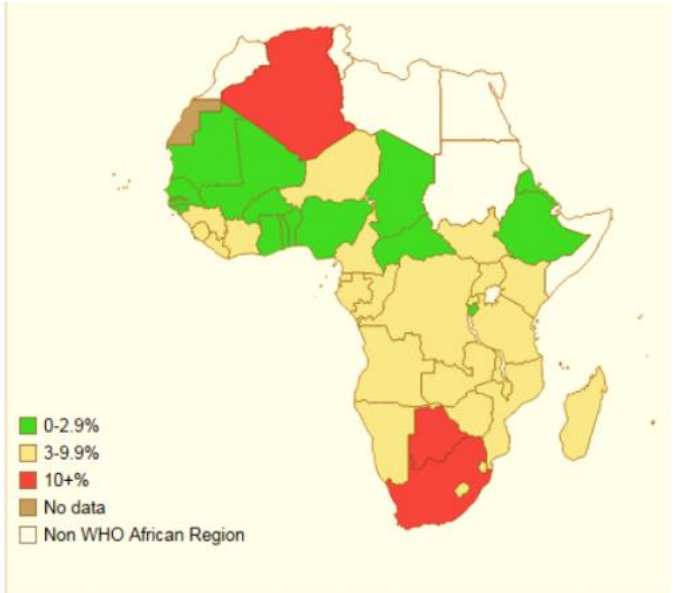

Source: Nutrition in the WHO Africa Region, World Health Organisation
32. Trend 5 Climate Change - Driving Demand for Skills in (i) Risk Management; (ii) Climate Change Mitigation and Resilience Technology: IPCC 2018 predicts that an increase in global warming from $+1.5^{\circ} \mathrm{C}$ to $+2^{\circ} \mathrm{C}$ would cause moderate to high impact on crop yields but with large regional differences (Figure 7). Climate change threatens the achievement of the SDG 2 goal to end hunger by 2050 and many other related SDGs. Impacts on protein availability may bring as many as 150 million people into protein deficiency by 2050 (Text Box 1).

33. The global population exposed to water stress could increase by 50 percent if global warming increases from $+1.5^{\circ} \mathrm{C}$ to $+2^{\circ} \mathrm{C}$ (Text Box 2). The consequences of a $+2^{\circ} \mathrm{C}$ world on crop yields could be reduced substantially with appropriate investment in climate smart agriculture.
Text Box 1 IPCC 2018 1.5OC Report: Climate Change Impact on Access to and Availability of Nutrients. "Climate change impacts on dietary and weightrelated risk factors are projected to increase mortality, owing to global reductions in food availability and consumption of fruit, vegetables and red meat (Springmann et al., 2016). Further, temperature increases are projected to reduce the protein and micronutrient content of major cereal crops, which is expected to further affect food and nutritional security (Myers et al., 2017; Zhu et al., 2018)". "Impacts on protein availability may bring as many as 150 million people into protein deficiency by 2050 (Medek et al., 2017)". "Changes in temperature and precipitation are projected to increase global food prices by $3-84 \%$ by 2050 (IPCC, 2013)".

34. African countries are particularly vulnerable to climate-related shocks due to the region's reliance on rain-fed production systems, transport systems that often cannot efficiently handle the 
region's food import needs during years of major food production shortfalls in the region, and the limited coping abilities of a large fraction of the region's population who live in poverty. Sources of biotic stress will become more prevalent and serious.

35. Climate change and variability is causing major challenges for maintaining agricultural productivity. These challenges create an urgent need for Africa to develop and implement agricultural, water and land management practices that promote sustainable productivity and resilience. Effective responses to climate-related threats will require significant investment in growing capacities of individuals and institutions within African systems. So far, almost all strategies for addressing climate change, sustainability and resilience issues are led by organizations outside of Africa. African-led initiatives and networks are needed to build the local ownership and commitment to developing effective strategies. African universities will be central sectors in producing the necessary research for climate change response and in attracting and training professionals and workers in livestock and crop science and agronomy, food science and technology, agricultural economics, and management who will have the incentives to generate sustainable and resilient responses to the region's challenges associated with climate change.

Figure 7 Climate change risks and or impacts for specific natural, managed and human systems

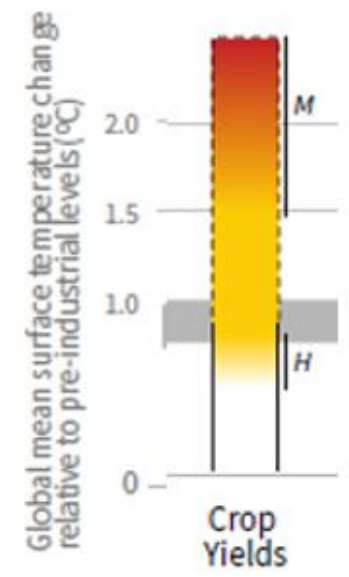

Source: Adapted from IPCC 2018

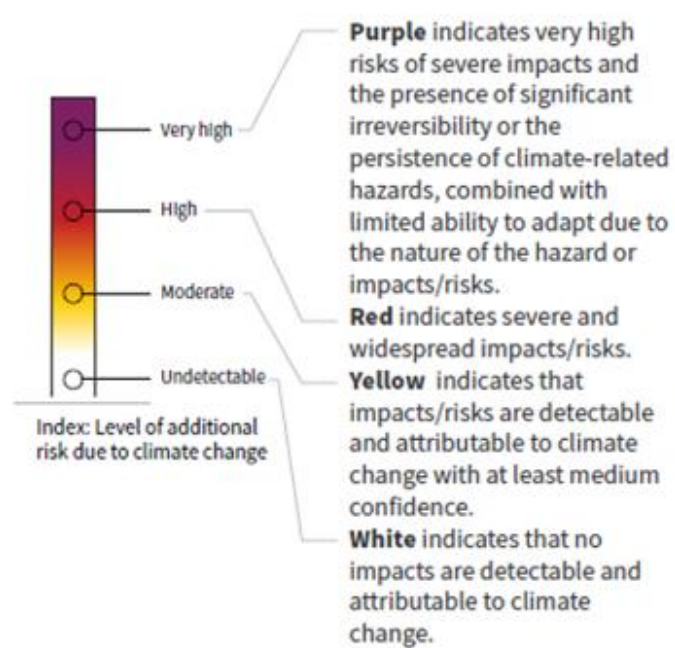

change.

\footnotetext{
Text Box 2 IPCC 2018 1.5OC Report: Climate Change Impact on Water Stress. Depending on future socio-economic conditions, limiting global warming to $1.5^{\circ} \mathrm{C}$, compared to $2^{\circ} \mathrm{C}$, may reduce the proportion of the world population exposed to a climate changeinduced increase in water stress by up to $50 \%$, although there is considerable variability between regions (medium confidence).
} 


\section{Trend 6 Land Degradation and Biodiversity Degradation - Driving Demand for Skills in Soil Water and Ecosystem Management (both scientific and economic):}

37. The 2018 Inter-Governmental

Science-Policy on Biodiversity and Ecosystem Services (IPBES)

Assessment Report on Land

Degradation and Restoration, the first ever global assessment report on land degradation, concludes that "Currently, degradation of the Earth's land surface through human activities is negatively impacting the well-being of at least 3.2 billion people, pushing the planet towards a sixth mass species extinction, and costing more than 10 per cent of the annual global gross product in loss of biodiversity and ecosystem services". Figure 8 shows the vast areas of Africa experiencing decreasing soil health.

38. When land is degraded, soil carbon can be released into the atmosphere, along with nitrous oxide. An increase of just $1 \%$ of the carbon stocks in the top metre of soils would be higher than the amount corresponding to the annual anthropogenic $\mathrm{CO} 2$ emissions from fossil fuel burning. The global loss of ecosystem services (including carbon sequestration and water storage) due to land degradation and desertification are between US\$ 6.3 and 10.6 trillion annually. (International Union for Conservation of Nature Issues Brief 2015).

39. The percentage of rural Africans living on degrading land has risen between 2000 and 2010 from 18 to 26 percent (Sitko and Jayne, 2018). Redressing this problem will require major new investment in agricultural soil scientists, agronomists, agricultural economists, and sustainabilityoriented land management departments. There is an urgent need to establish programs now that will produce the next generation of African scientists incentivized to work in rural areas to arrest the land degradation problem. Higher level technical training should also be broadened to investigating biotic and abiotic stressors, which are both likely to become more prevalent and serious with greater climate variability. African agriculture higher education institutions must address the question of how Africa can develop the capacity to anticipate and respond effectively to these challenges. 
40. Trend 7 Recognition of Gender as a Driver of Equitable Economic Development Driving Demand for Greater Gender Balance in University Enrollment: Inclusion of women in agri-food sector decision making is more than an equity issue; it also has the potential to raise productivity. The International Food Policy Research Institute (IFPRI) "Gender in Agriculture. Closing the Knowledge Gap” Report 2014 quantifies the potential of greater gender inclusion in agriculture and concludes that "Closing the gender gap in agriculture would generate significant gains for the agricultural sector and for society. If women had the same access to productive resources as men, they could increase yields on their farms by $20-30 \%$.
Figure 9 Average female scientist shares in professional staff, by degree in 64 developing countries, 2001-08



Source: "Gender in Agriculture. Closing the Knowledge Gap" IFPRI Report 2014

Note: Full Time Equivalent (FTE)

This could raise total agricultural output in developing countries by $2.5-4 \%$, which could, in turn, reduce the number of hungry people in the world by 12-17\%". There are good reasons to expect that inclusion of women higher up agrifood value chains would reap benefits. A study of research and development teams at more than 4,000 companies found that gender diversity "generates dynamics that lend themselves to radical innovation." Yet women's enrollment in University in Africa in general is low compared to Europe for example (Figure 9).

41. Trend 8 Rising demand for African-led agricultural policy processes and solutions. African governments and pan-African organizations are increasingly seeking to develop and implement their national and regional strategies based on qualified African agricultural policy analysis, providing an "African voice" to agricultural initiatives on the continent. The demand for competent African strategic thinkers, managers, technical analysts and visionaries is growing rapidly - both to shape the agenda as well as to respond to the demand for technical and policy guidance from national governments, regional economic consortia, and pan-African development organizations. The demand for effective agricultural policy think tanks and research institutes is likely to grow especially rapidly over the coming decade as the center of gravity of policy discussion shifts from international capitals to Africa. International and bilateral development partners are also shifting the emphasis of their programs to put greater priority on building programs in Africa around African-led organizations that can shape the agenda for agricultural transformation in the region and provide guidance to African governments. Inputs from international universities are increasingly needed to build capacity of African agricultural policy institutes.

42. In conclusion, the extent to which Africa can compete in a rapidly evolving and increasingly sophisticated global agri-food sector and realize the full potential of the sector to contribute to job 
creation and reduced climate change impact, will be greatly influenced by its success in delivering appropriate knowledge and skills to the future agri-food labor force.

\section{Implications of Trends in Agriculture FOR KNOWLEDGe AND SKILlS NeEDS IN THE AGRI-FoOd SECTOR}

43. The trends described in this section imply the need for more skills in five key thematic areas and one cross-cutting theme:

(i) Agribusiness and Food Industry Management: business management, finance, marketing and consumer behavior, commodity market analysis, food technology and regulation;

(ii) Human Health and Nutrition: human nutrition, food science, nutrition smart agriculture, food safety regulation, globalization, trade and zoonotic disease risks, consumer behavior;

(iii) Climate Change, Agriculture and Ecosystem Management: (a) Agricultural Science (b); integrated Natural Resource and Ecosystem Management;

(iv) Agricultural Risk Management Tools: finance, insurance and commodity market tools for risk management;

(v) Digital Technology (and related technologies in geographic information systems, automation, precision agriculture)

(vi) Soft Skills (cross cutting): communication, team work and approaches to problem solving, research skills and information management, work ethics.

44. These are not new disciplines but greater emphasis on combinations of disciplines and interactions between disciplines may be needed to address new challenges and structural change in the agri-food sector. High agricultural education may need to be broadened or reconfigure in several directions (Figure ): (i) along value chains (to address issues from farm to retail and their interrelationships); (ii) across elements of the ecosystem (e.g. across a watershed rather than only the production area); (iii) across scientific disciplines (genetics, soil science, nutrition, hydrology ...) and (iv) across markets (e.g. greater attention beyond agricultural markets to water markets and carbon markets for example).
Figure 10 Directions for Diversification of Higher Agricultural Education

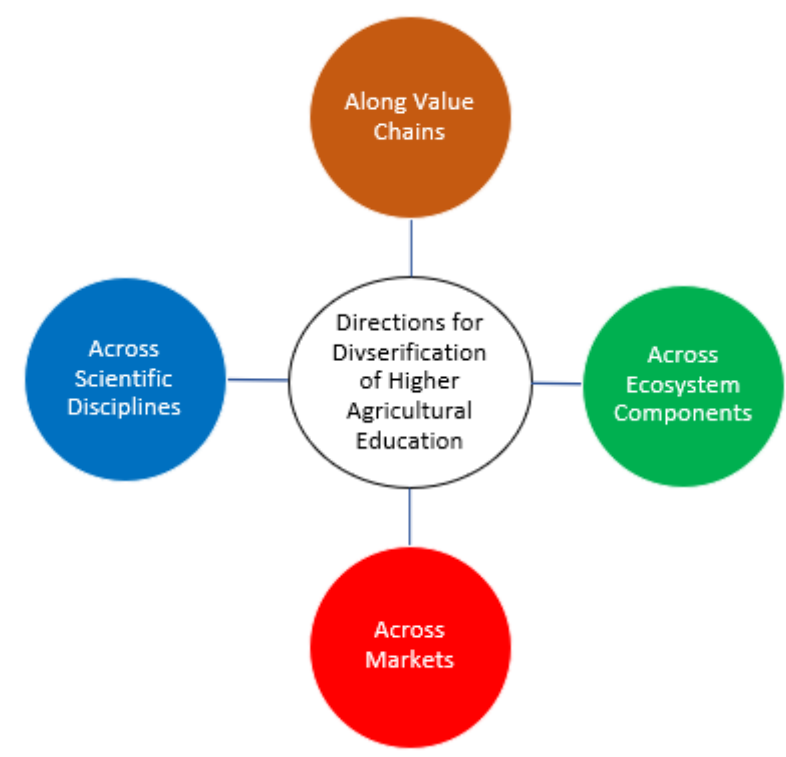




\begin{tabular}{|l|}
\hline \multicolumn{1}{|c|}{ TREND } \\
\hline $\begin{array}{l}\text { Structural Evolution of Value } \\
\text { Chains }\end{array}$ \\
\hline $\begin{array}{l}\text { Urbanization, Rising Incomes } \\
\text { and Dietary Change }\end{array}$ \\
\hline
\end{tabular}

\section{Climate Change}

Land Degradation

Technological Revolution

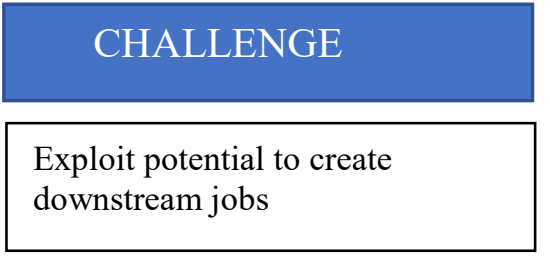

Address threat to human health from inadequate diets

Increase resilience of \& mitigate GHG emissions from agriculture

Address threat to climate change resilience, water availability and biodiversity

Exploit potential for next revolution in agricultural productivity and address risks of exclusion from technology

\section{SKILLS NEEDED}

Agribusiness and Food Industry Management

Human Health and Nutrition

Climate Change, Agriculture and Ecosystem Management

Agricultural Risk Management Tools

Digital Technology 


\section{CORE CHALLENGES TO DEVELOPMENT OF HIGHER AGRICULTURAL EDUCATION}

49. This chapter explores the challenges that African countries face in changing higher agricultural education to deliver the evolving knowledge and skills needs of the agri-food sector in response to changing needs, to meet rising demand for enrollment and facilitate greater inclusion of women in higher education and discusses how they are responding to these challenges.

\section{National Level Challenges}

\section{Rising Demand for Enrollment and Funding Constraints}

Universities are responding to rapidly expanding demand in a limited-resource environment. Funding increases are not keeping pace with increased demand for enrollment. Institutions often face a difficult choice between expanding student numbers in response to rising demand but sacrificing quality or restricting student intake to maintain quality of student teaching. Universities need the flexibility to adopt innovative sources of revenue generation to raise sufficient funding to meet rising demand.

50. While spending on education as a share of GDP and the share of total education spending on tertiary education (Figure 11 and 12) in Africa has increased to reach a similar share of GDP as the global average (Figure 13), tertiary education enrollment in Africa is increasing albeit from a very low base and not as fast as other regions. While the majority of enrollment is in education and social science subjects rather than STEM or agriculture (Figure 14), agricultural universities are also facing increasing enrollment pressures. In this environment of increased pressure on financial resources countries are adopting different approaches to dealing with pressure on resources.

Figure 11 Government Expenditure on Education, total (\% of GDP)

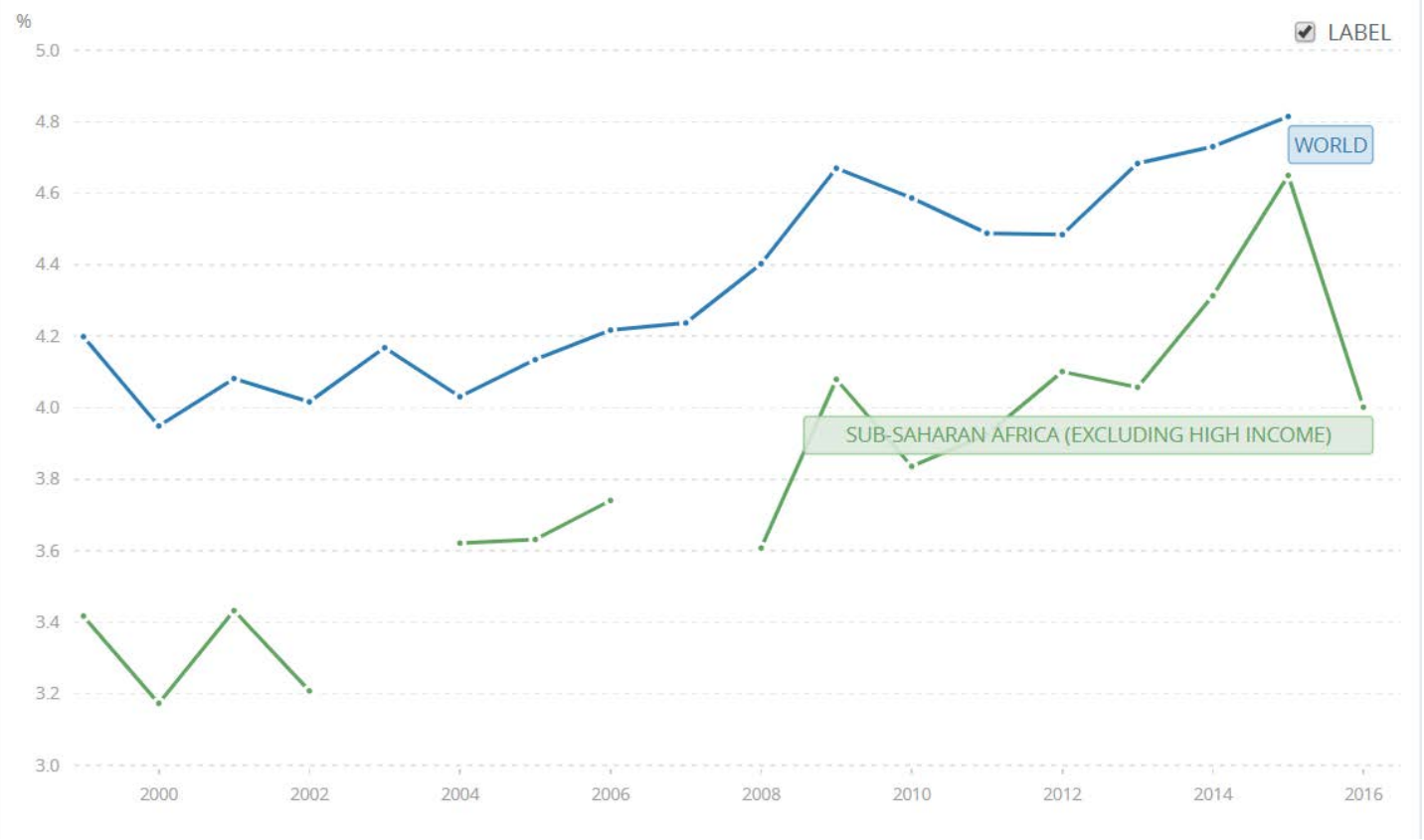


Figure 12 Expenditure On Tertiary Education (\% Of Government Expenditure On Education)

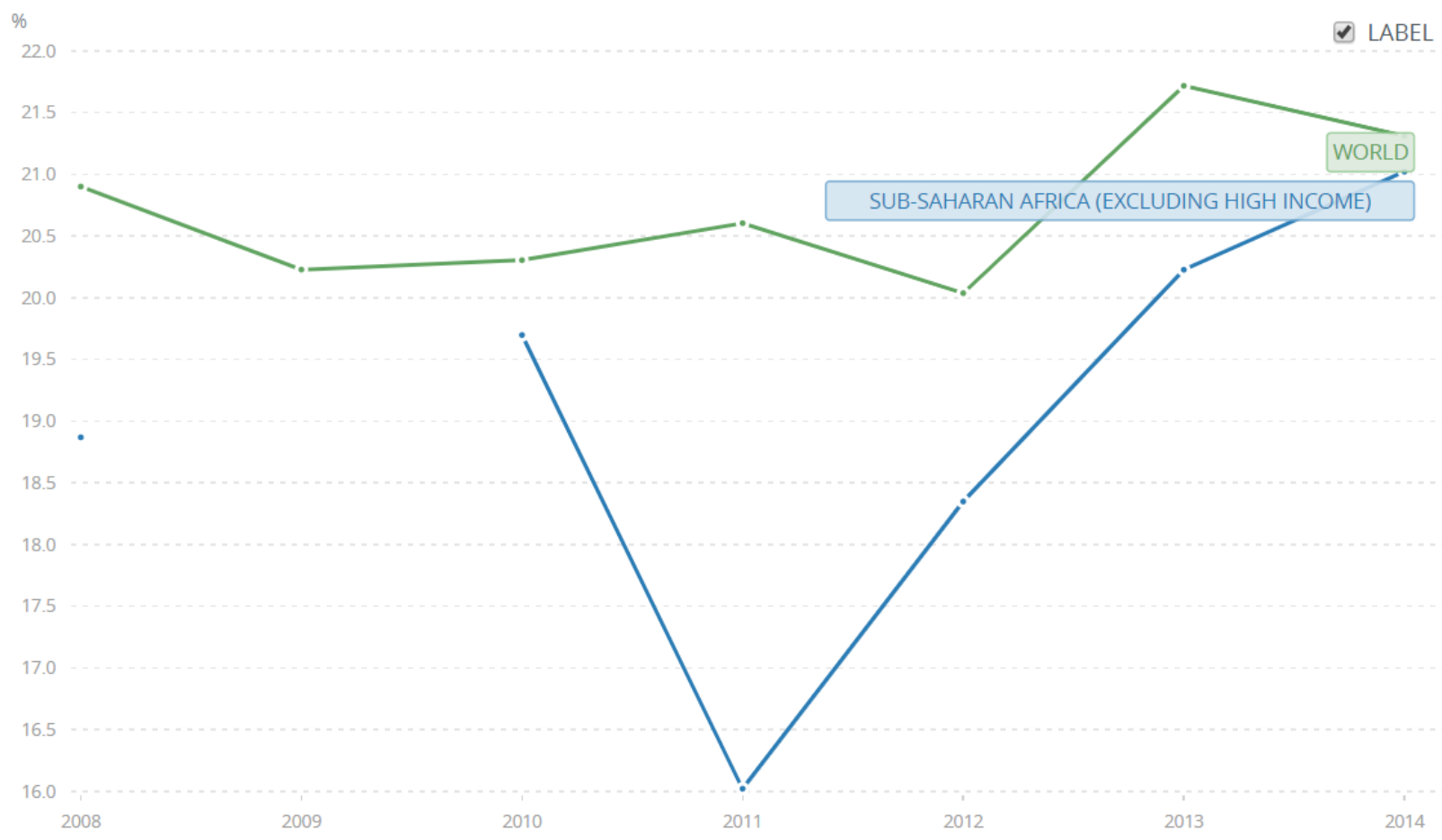

Figure 13 The share of the population with completed tertiary education in SSA is and has remained very low compared to other regions of the world

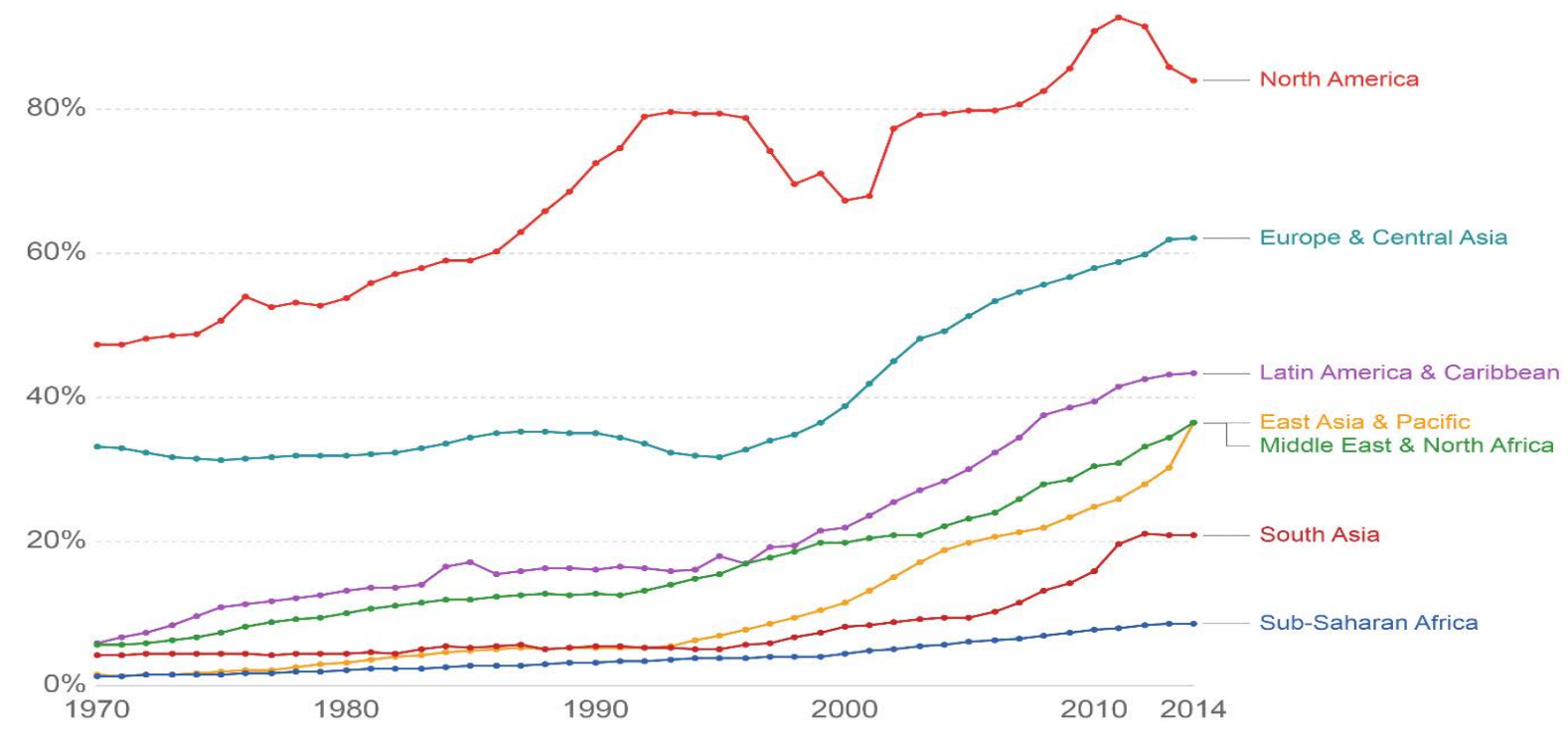

Source: One World in Data : https://ourworldindata.org/tertiary-education 9/4/2019 in The Future of Work in Africa. Draft Report. World Bank. June 2019 


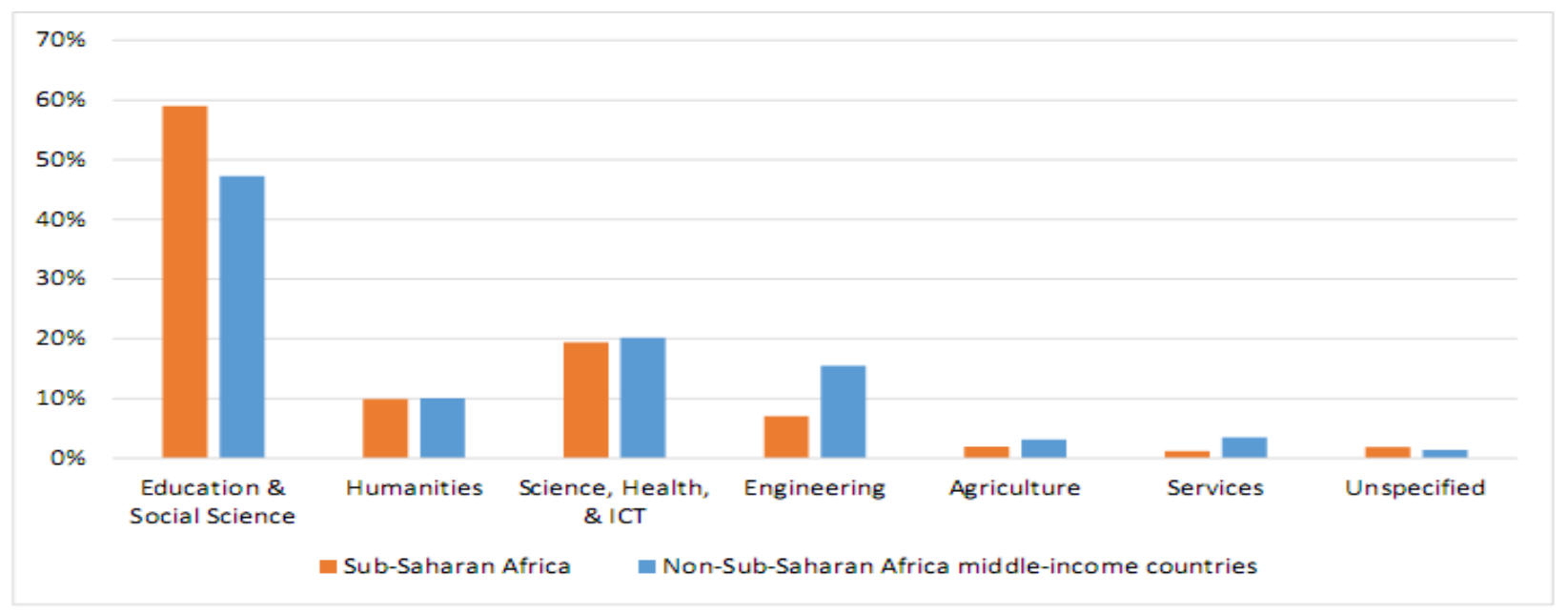

Source: Evans, Arias, \& Santos (n.d) in The Future of Work in Africa. Draft Report. World Bank. June 2019

51. Between 1970 and 2013, higher education enrollments grew faster in Africa than in any other region (Zeleza, 2016). Enrollment rates were at an extremely low level to begin with, and Africa still lags far behind in terms of overall enrollment compared to other regions. "Sub-Saharan Africa has the lowest tertiary gross enrollment ratio globally, significantly lower than South Asia, which is second to last. This trend is primarily due to sub-Saharan Africa's low base in 1970, when fewer than 400,000 students were in a tertiary education program" (World Bank, 2017).

52. Increasing pressure on resources has led to a push for diversification of revenue sources such as increased tuition/student fees, implementation of dual-track tuition fee policies (where some students are subsidized and others are charged fees), access to student loans, fundraising from donors and other private sources, investment in financial markets, encouraging faculty and institutional entrepreneurship, privatizing certain functions of the university, and offering revenue generating services (Zeleza 2018; Jacob \& Gokbel, 2018).

53. Current higher education funding levels are far from adequate and must be increased for higher education to contribute to economic growth up to its potential. The result is inadequate numbers of qualified academic staff, decreasing staff-to-student ratios, overcrowded classrooms, and insufficient laboratory space. Under these circumstances, it is difficult for universities to implement active learning strategies that supplement the traditional lecture with experiential learning. Poor funding diminishes research quality and relevance because of lack of equipment and facilities (Bloom, Canning, and Chan 2006). Current funding levels for higher education are well below the levels requested by university administrators in most African countries. In Nigeria, for instance, universities have been funded at $70 \%$ of the requested level on average over the past four decades (Okebukola 2015b).

54. Pressure on resources has reflected in deterioration of instructional resources and facilities and loss of secure faculty positions which has contributed to the casualization of the faculty labor and loss 
of morale, an upsurge in student loan debt and an increase of institutional debt (Zeleza 2018; Jacob \& Gokbel, 2018). Under these circumstances, it is difficult for universities to implement active learning strategies that supplement the traditional lecture with experiential learning.

Text Box 3. Country Approaches to Responding to Increased Demand for Enrollment: Countries have taken different approaches to addressing this challenge. Ethiopia adopted the former approach and expanded the number of undergraduate students by 30 -fold over the past two years, which has unsurprisingly resulted in a serious deterioration of the quality of instruction and supervision. Malawi adopted the latter approach and student intake has been severely restricted. Every year, approximately 15,000 students qualify for postsecondary education, however due to capacity constraints only 4,000 are accepted into higher education. Kenya partly responded to increased demand by adopting a policy that supported the creation of parallel universities with distinct mandates within the higher education system (Ng'ethe, Subotzky, \& Afeti, 2007). The strategy supported the upgrading of polytechnics to technical universities offering "skills degrees" and training programs to the highest level possible. Traditional universities would then focus on research and the awarding of "knowledge degrees".

55. The Role of Private Universities in Meeting Rising Demand: Privatization in the higher education sector has been one way of dealing both with decreasing public resources and the increasing demand for enrollment. Levy (2009b) found that private institutions now constitute a majority in Africa and serve a key, though limited, role in absorbing demand. Adapting to competitive markets, private institutions often specialize in commercial fields (e.g. accounting, communication, computer science) that are inexpensive to teach and promise quick, gainful employment. Thus, private institutions typically approach education more as a private commodity than a public good (Levy, 2009a). Oketch (2004, 2003

56. The Role of Non-Agricultural Universities in Meeting Rising Demand: Another approach has been to utilize the capacity of non-agricultural universities to deliver parts of agricultural education. There are both advantages and disadvantages in having agriculture as an agricultural focus versus a science focus. An advantage is that agriculture remains central to the academic mission, making it relatively easy both administratively and intellectually to collaborate with external agricultural stakeholders and external agricultural universities and institutes. A major disadvantage is that agricultural teachers and researchers may be isolated from scientific developments in nonagricultural fields of knowledge that have potential relevance for the increasingly complex challenges faced by the agricultural sector.

Text Box 4. The Role of Private Universities in Kenya. In Kenya, as a result of the 2012 Higher Education Act, the Higher Education Loans Board (HELB) allows students to apply for government-funded loans to private institutions. Kenya private universities have been scrutinized since 1985 by the country's quality assurance agency. As a result, the country boasts some of the most reputable private universities in the region such as Strathmore University and United States International University. 


\section{Incentivizing University Performance}

Performance-based contracting can yield positive results but only when accompanied by change to improve management.

57. The desirability of greater accountability of universities for outputs was expressed by representatives of both the public and private sectors during interviews conducted for the country background studies. Performance-based funding (PBF) is an incentive-based funding mechanism used by some governments to improve the quality of public services. PBF is currently used for funding of public universities in Kenya, Senegal, and South Africa (Bomett 2015; Okebukola 2015a).

58. Empirical evidence on the effects of performance contracting on public program outcomes is mixed and almost all were conducted outside of Africa. A study of the effect of performance contracting on the quality of administrative and support services at Kenyatta University concluded it had a large and positive effect, including shorter wait times for services, greater attention paid to strategic plans, better delegation of duties, more transparent promotions, more staff development, more teamwork, and better monitoring of service quality (Nguthuri, Maringa, and George 2013).

59. In a meta-analysis of 46 studies in non-African countries, researchers found evidence of a small positive average effect on educational program outcomes (Mcguire and Gerrish 2016). However, when controls for quality of performance management were included, the size effect for most types of services increased considerably. The implication of this finding is that performance contracting systems may produce little positive effect on outcomes unless, at the same time, the quality of management also improves.

\footnotetext{
Text Box 5. Performance Based Funding in Cote D'Ivoire and Senegal: In Cote D'Ivoire, the government has not implemented performance-based contracts (PBCs) with higher education institutions, though the idea has been under discussion for several years. MESRS is now in the process of developing plans and procedures for PBCs. If implemented, the new system would require institutions to negotiate performance targets with the government and funding of higher education institutions would be based on the extent to which the institution achieves its targets.

In Senegal, funding for universities is tied to a lengthy list of performance indicators including the pass rate for undergraduate students, number of university computers per student, percentage of teachers trained in the LMD (Licence-Masters-Doctoral) system, number of courses that are accredited, percentage of administrative staff trained in performance contract management, implementation of a functional quality assurance mechanism, and implementation of an improved registration system (Toguebaye 2015).
} 


\section{Regulation and Quality Assurance}

To be effective, regulation must be accompanied by sufficient funding for universities to implement the changes need to meet standards. Regional organizations are leading the harmonization and expansion of quality assurance in higher agricultural education in Africa.

60. The increase of government and public scrutiny of the quality of higher education world-wide beginning in the late 1980s is widely recognized (Brennan \& Shah, 2000a; Mundial, 1994; Neave \& van Vught, 1994; UNESCO, 1998) especially across sub-Saharan Africa (Materu, 2007). This era marked a shift in policy makers' attention away from traditional concerns about access and cost to concerns for quality.

61. Increasing numbers of African governments have created national quality assurance agencies in just the last thirty years. The African Quality Assurance Network, established by the Association of African Universities, now lists quality assurance bodies in 34 countries, including Cameroon, Ghana, Kenya, Malawi, Mozambique (AfriQAN, 2018). These bodies set minimum academic standards for higher education, approve establishment of new institutions and programs, accredit institutions and programs, and monitor performance of institutions and programs. In some countries, these agencies regulate not only private, but also public universities such as in Kenya. In many of these countries, governments require universities to adopt a quality assurance policy and to create a unit to implement it.

62. At regional level, harmonization of higher education

Text Box 6. Challenges of Quality Assurance in Kenya: In Kenya, stakeholders underlined the importance of understanding the center-university-national context in higher education. National quality assurance standards seem to them to be prioritized over center-level standards. When a center's goals, processes, and especially monitoring and evaluation plans are not aligned with the broader expectations from Kenya's Commission for Higher Education for the host university, then ongoing center assessment is challenging. across countries is a major goal of quality assurance initiatives (Shabani, Okebukola, and Oyewole 2014). The African Union (2015) has called on African governments to harmonize higher education systems and programs to facilitate collaboration among universities, mobility of students and faculty, and transfer of academic credit. Two regional associations focus on quality assurance: The African and Malagasy Council for Higher Education (CAMES) with 19-member countries, mainly in West Africa, and the Inter-University Council for East Africa (IUCEA) which has grown from 33 in 2000 to 127 at present. At the continental level, the Association of African Universities and the African Union Commission jointly promote quality assurance through an effort known as Harmonization of African Higher Education Quality Assurance and Accreditation (HAQAA) and released The African Standards and Guidelines for Quality Assurance in Higher Education (African Union Commission 2018). 
63. While there is widespread agreement that more attention must be paid to quality in higher education in Africa, setting standards is not enough. An institutional culture of improvement and adequate financial resources are also essential. Quality assurance mandates typically provide no incremental funding for either measurement or improvement of quality. Consequently, many of the university quality assurance initiatives are limited to measurement and reporting, with little or no effect on quality.

Text Box 7. Country Examples of Quality Assurance: In Cote, D’Ivoire, MESRS created a Quality Assurance Department in 2016 but operation was begun only recently. Universities are required to have quality assurance units though most institutions in the country do not have a functioning unit yet. In Malawi, The National Council for Higher Education in Malawi oversees quality assurance at the national level for tertiary institutions. LUANAR has its own quality assurance unit. In Ghana, universities have implemented efforts to improve quality. At the University of Ghana, a Departmental Teaching Assessment Committee (DTAC) assesses and evaluates the performance of lecturers in conformity with international standards. In Mozambique, The Higher Education, Science and Technology (HEST) project funded by The World Bank has sought to address these challenges. It helped to streamline the accreditation process and to create policies related to research quality, managing higher education statistics, and managing monitoring and evaluation (M\&E) system for higher education.

\section{Text Box 8 Quality Assurance, African Centers of Excellence (ACE)}

The World Bank in collaboration with West and Central African countries in 2014 launched the African Center of Excellence (ACE) initiative. Through an open, rigorous, transparent and merit-based assessment procedure, ACE selects and invests in beneficiary well-performing universities "Centers of Excellence" in disciplines related to STEM, agriculture, and health. ACE seeks to increase the quality and quantity of STEM graduates by establishing high quality specialized, well-resourced centers in selected universities to train students in STEM-related fields (applied mathematics in Benin, ICT in Cameroon, statistics in Cote d'Ivoire, mathematics, informatics and ICT in Senegal, etc.) to increase knowledge production that will create knowledge-based competitive advantages. By 2018, about 8100 students have been enrolled under the ACE project, of which 25 percent are female, 6500 are master's students and $1600 \mathrm{Ph}$.D. students. The Association of African Universities (AAU) has been very effective in coordinating and checking the quality of the various ACE (World Bank 2019 - Work in Africa, Draft Final Report)

Findings from this study suggest this is an important line of inquiry for leaders, managers, and implementers of future investment projects in higher education in agriculture. For example, in terms of quality assurance, World Bank officials in Kenya observed the importance of the relationship between center-university-national context. National QA standards seem to them to be prioritized over center-level standards. When an ACE's goals, processes, and especially monitoring and evaluation plans were not aligned with the broader expectations from Kenya's Commission for Higher Education for the host university, then ongoing center assessment is challenging. Thus, the future reform initiatives are more likely to be successful if they design evaluation and quality assurance mechanisms that complement the demands, trends, metrics, and political dynamics of national and regional quality.

The ACE's evidence that the national Quality Assurance (QA) standards are powerful levers of change and retrofitting brings undesired complexities; hence, RAUs should engage quality assurance agencies from an early stage in project conceptualization and throughout implementation. University leaders in Malawi, reflecting on LUANAR's ACE, encouraged integration and communication between research institutes and programs and their home institutions rather than creating parallel systems (for research, accounting, etc.). Quality assurance calls for such reinforcement of good practices across the institution. Such efforts are likely to increase buy-in and impact at various institutional levels and across partners. 


\section{The Need for Greater Inclusion in Higher Education}

High female attrition rates are undermining the potential impact of increased female enrollment.

64. Massification of higher education has led to increased opportunities for marginalized groups such as women and rural populations to access higher education. Student bodies are (slowly) becoming more diverse. Universities and higher education systems have implemented interventions such as affirmative action policies, targeted financial aid, to improve gender diversity although these have not gone uncontested (Zeleza, 2016). The focus has been on equity in enrollment but less attention has been paid to ensuring equity in success of enrolled students (Mohamedbhai, 2014). Attrition rates among women remain extremely high and Africa has the lowest female enrollment rate overall globally. It has remained one of the only regions where women's enrollment continues to lag behind men (Zeleza, 2016).

\section{UNIVERSITY LEADERSHIP AND MANAGEMENT}

\section{Approach to University Transformation - A Shift to Organizational Learning}

To adapt to continually changing agricultural sector needs, universities must adopt an organizational learning leadership style that encourages experiment and change and rewards the relevance of teaching and learning.

Figure 15 Three Leadership Styles in Higher Education. Source: David Kraybill

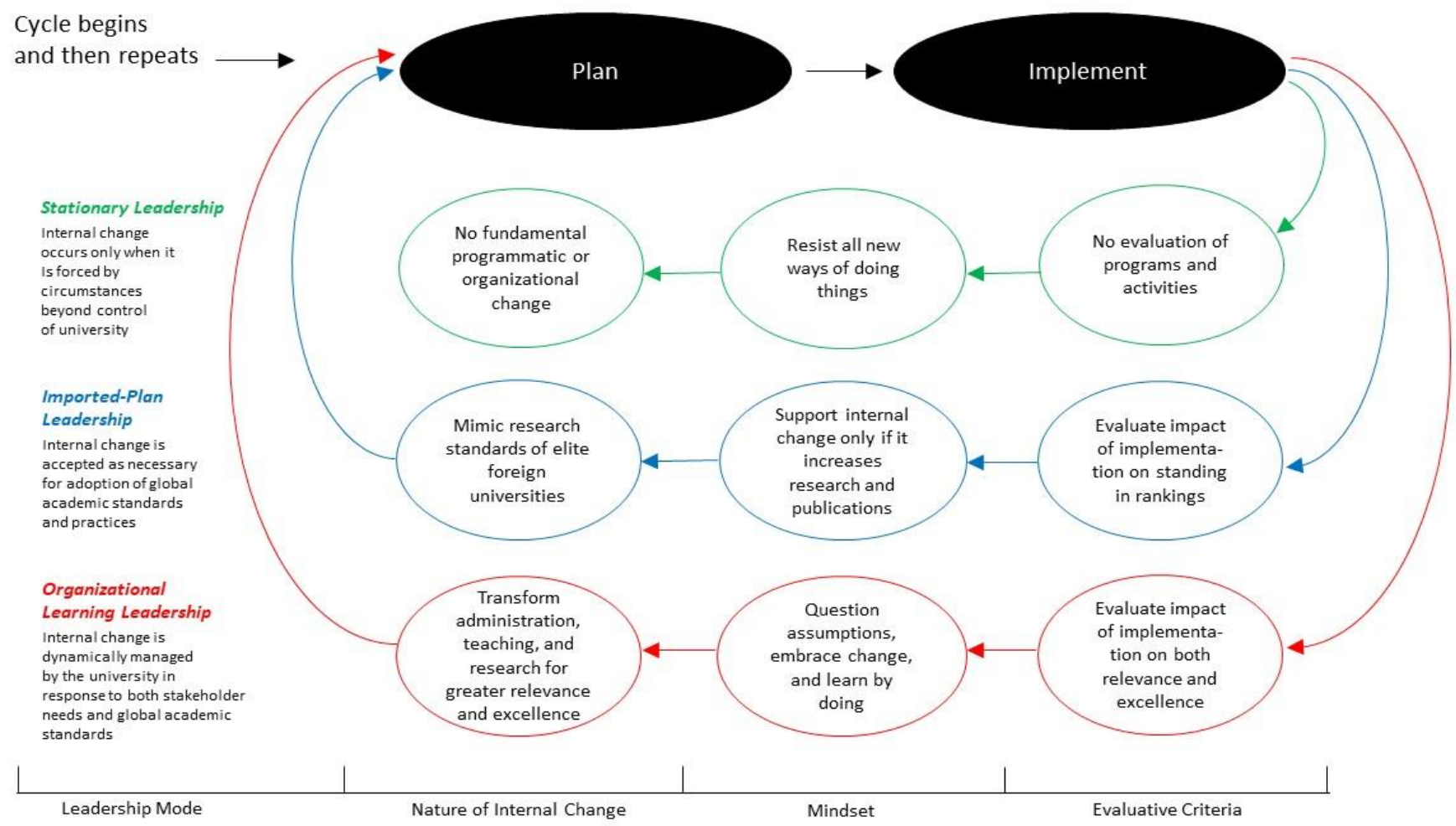

65. The rapidly evolving challenges of the agricultural sector and exponential changes in technology mean that universities must be able to continually learn about changing sector needs and 
adapt teaching and research accordingly. This requires that universities become learning organizations. Stationary or imported styles of leadership will fail to keep pace with change so a shift to leadership based on organizational learning is needed (Figure 15). Organizational learning, is defined as a continuous process of adapting systemically to internal and external forces that stand in the way of a university achieving economic relevance and academic excellence in its programs. A university that strives to be a learning organization no longer adopts the traditional approach to classroom instruction in which curricular planning and class preparation is teacher-centric, focusing on "what teachers teach". Instead, instructional planning by both the university and the individual instructors is learner-centric, focusing on "what students learn". Practical guidance on how to implement this change, including the use of organization learning experiments, is provided in the main report.

\section{Performance Based Staff Contracts}

Stronger faculty incentives are needed to drive change. The use of performance-based staff contracts is in its infancy in higher agricultural education in Africa but can help address weak staff motivation and loss of staff time to supplemental income earning activities.

66. Universities are burdened by the pursuit of supplemental income by members of academic staff from other sources which is a major diversion from core teaching and research responsibilities in some countries. Performance based staff contracts could help address this but are in their infancy in the countries studied. Potentially they provide an important incentive for faculty staff to align their efforts with university objectives. They could for example provide the necessary incentive for staff to refocus their efforts from research, which has traditionally driven promotion, to delivering high quality teaching which has reaped fewer rewards for staff in the past.

Text Box 9. Performance Based Staff Contracts in Cote D'Ivoire: One of the barriers to adoption of performance-based contracts in Cote D'Ivoire is that members of academic staff in Côte d'Ivoire's public universities, including UFHB and INPHB, are employees of the Ministry of Higher Education and Scientific Research and are represented by one or more unions, thus giving them substantial independence from university deans, directors, and presidents. This independence weakens the capacity of university administrators to bring about change. However, performance-based contracting, if implemented, can help overcome the weak commitment of university employees to their own institution and its goals and thus provide a compelling rationale for change in organizational culture, or mindset.

Text Box 10. Performance Based Staff Contracts in Malawi: In Malawi, LUANAR has recently adopted a performance management system and it is in its first year of rolling out. Under this new system, they are beginning to institute performance-based salaries, but this is not yet in place. There is currently a general evaluation of performance on contributions to science (publications and outreach), resource mobilization, and seniority which influences salary decisions. The new performance evaluation system at LUANAR would require staff to set performance targets in the areas of teaching, research, outreach, and resource mobilization for each semester which include specific deliverables. These would be negotiated by the staff member and their manager. Staff will be evaluated every six months through a participatory appraisal process (between the staff member and their manager) with results being submitted to human resources for review. 


\section{Infrastructure Investment}

Inadequate investment in basic utilities and infrastructure is undermining universities' potential to conduct scientific research and adopt ICT in teaching and research.

67. Infrastructure was identified as an important area of investment by university personnel in all five countries studied. This has been a longstanding problem - a World Bank report on tertiary education (Yusuf, Saint, and Nabeshima 2009) in 2009 observed that African universities had a large backlog of investment in laboratories, classroom and office buildings, dormitories, and ICT facilities.

68. For training in agriculture and STEM disciplines, scientific laboratories are particularly important but the number and size of laboratories is grossly inadequate in many African universities, given the large increases in enrollment over the past decade. Many more classrooms are needed but existing classrooms also need renovation to facilitate the use of ICT in teaching and learning.

69. Some universities visited during the country background studies reported inadequate water and electricity services. Solar power generation may be a viable option, particularly for universities in locations not serviced by the national electrical grid or where power from the grid is unreliable. ICT infrastructure, including adequate Internet bandwidth, servers, computers, and help desks, must be available. Other infrastructure needs include facilities that meet national health and safety requirements and that provide accessible for persons with disabilities.

\section{Relevance And Quality of TeACHing And ReSEARCH}

\section{Teaching}

Designing More Relevant Courses

The use of analytical tools such as use of labor market information, graduate tracer studies and occupational analysis is not widespread and must be adopted to improve the relevance of teaching.

Labor market information and occupational analysis

70. There is a consensus among alumni and agribusiness companies that current university agriculture education tends to be overly theoretical, unapplied, and/or outdated. In the countries studied, these are well recognized challenges and efforts have been made to respond to them. Nevertheless, the systematic use of analytical tools to assess agri-food sector skills needs and feedback into the design of curricula and research programs is inadequate. Tracer studies that track where students are employed when they graduate and occupational studies to provide a detailed understanding of the task involved in specific jobs would greatly inform efforts to increase the relevance of higher agricultural education but such a rigorous approach appears to be uncommon. 
Text Box 11. Country Availability of Labor Market Information. Labor observatories have been established in Ghana (Ghana Ministry of Employment and Social Relations, n.d.) Ivory Coast (Zito 2011), and Kenya (Kenya Ministry of Labour and Social Protection, n.d.). In Mozambique, the International Labor Organization is assisting the Ministry of Labor to create a labor market observatory, though data from the system are not yet available to the public (Mozambique Ministry of Labor, n.d.). Malawi conducts periodic labor market surveys but it does not appear to have a labor market observatory. While worthwhile examining if it is available, labor market observatory data often comes from low-response surveys and does not provide much occupational detail (Johanson and Adams 2004).

\section{Curricula Revision}

There are serious bureaucratic barriers to changing curricula. While regulation of quality is important, universities must be given sufficient flexibility to change curricula design.

71. If teaching is to improve in African universities, it is essential that leaders and funders be mindful of the bureaucratic and personnel constraints that stand in the way of curricular reform. One constraint is the bureaucratic cycle of curricular change. Most of the universities visited during the country background studies reported that curricula are reviewed every 3-6 years. In general, universities do not make official revisions in curricula outside this cycle, which is mandated in most cases by the government ministry or agency that regulates higher education. Another constraint on curricular reform arises from heavy faculty workloads and the absence of incentives to change. Curricular revision is nearly always done by the faculty members who teach the courses under review, who already have a heavy teaching load and view curricular revision as additional work with little benefit to them.

\section{Text Box 12 Non-traditional academic engagement in Kenya}

Private universities in Kenya are using new mechanisms to make education more relevant to communities who may not otherwise access their campuses. Many of these individuals are involved in agri-food businesses.

Strathmore University: Faculty from Strathmore's renowned business school recently launched a 'Street MBA' program. The program contextualizes business theory and entrepreneurial practices for small-business owners in the informal markets of the Kibera neighborhood just nearby campus. English curriculum was translated in Kiswahili, contextualized with local illustrations, and taught by faculty and advanced grad students. Many of the street MBA participants operate agri-food businesses. Program evaluation shows significantly improved business productivity for program participants.

United States International University: USIU recently launched an interdisciplinary capacity building program for medium and small microenterprise owners. The program was designed with government partnership so as to provide evidence for policy, which is presented via periodic 'Evidence to Action' workshops with policymakers. Also, in partnership with the World Bank, USIU recently launched the Kenya Youth Employment Opportunities project, which provides out-of-school youth training in life skills and business skills, and provides seed funding for start-up ventures, many of which are agribusiness. To incentivize support in this non-traditional academic engagement, USIU leaders are 'retooling' faculty and developing a new faculty evaluation framework that includes more targeted metrics and higher weight for industry and civil society engagement and supporting applied research opportunities 


\section{Text Box 13. EARTH University, Costa Rica: A New Kind of Agricultural University}

EARTH University, an autonomous educational entity, was newly designed and established in Costa Rica in 1990. Although a significant part of the plan of study focuses on agriculture and natural resource management, the university's core purpose is to prepare leaders capable of promoting sustainable development in the tropics. EARTH is a private, non-profit, international university, autonomous and independent of political pressure. It has an international faculty, a student body originating from 25 Latin American and Caribbean countries, a small number of students from Africa, and is small, with 400 students and 40 faculty. The university's 3,300-hectare farm is used for training as well as commercial, income-generating crop production.

EARTH's unique educational model is based on technical and scientific knowledge, entrepreneurial mentality, values and ethics, and social and environmental commitment. In addition to inculcating practical skills that benefit interactions at many levels throughout the AIS, EARTH's experiential curriculum balances theory and practice through work experience, community development, the academic program, entrepreneurial projects, and internships. The emphasis on entrepreneurial skills equips graduates with a greater range of career choices, and exposure to rural communities is vital for producing graduates dedicated to serving the sector and rural people. A major lesson is that the development of robust rural economies requires individuals capable of applying knowledge and skills from across disciplines, often in very practical and applied ways. Faculty must engage directly with their students in production, processing, and marketing as well as in research and extension. Reward and promotion criteria must be designed to encourage innovative teaching and engagement as well as research. Assured funding combined with continuous fund raising enable the university to maintain high academic and infrastructure standards.

\section{Providing Experiential Learning}

Experiential learning such as internships are common but they tend to be under-resourced and suffer from limited participation of employers in planning, supervision and career follow up and incentives for businesses to fully participate and benefit from such programs.

72. Inadequate practical internship opportunities has been cited by higher agricultural educationists as the major reason for weak university-private sector linkages. Two types of work-integrated learning were observed by the country background study teams: internships and fieldwork. Both should be expanded but, to make the expansion worthwhile, the quality of the work-integrated learning programs must be improved. In the universities observed in the country background studies, there is need for stronger relationships with businesses, better design of student work programs, and more funding for supervision and program support. In most African countries, the use of internships by businesses as a means of employee recruitment is not widespread, and managers tend to regard internships as a bother and unjustified expense. Consequently, universities have difficulty finding an adequate number of internship slots for their students (Reinhard et al. 2016). A related problem is that companies that accept interns tend to relegate them to the status of observers and assign them tasks peripheral to core business functions. Rarely, in most African countries, are interns treated as employees in the businesses where they are placed. Ideas for improving work-integrated learning can be obtained from universities of technology in South Africa, which has some of the best on the continent (Reinhard et al. 2016). There is also inadequate supervision of internships due to the high associated costs. Text Box 13 describes one example of an experiential curriculum developed in Costa Rica. 


\section{Research}

The staff incentive and support system is not conducive to maintaining a long-term team of senior researchers in universities.

73. There is a need for stronger incentives and support systems to build strong research teams and portfolios. The proportion of academic staff who hold senior rank is far less than the proportion who hold junior or middle rank in many African universities, and efforts to increase the relative size of the senior staff are often unsuccessful. This imbalance has important implications for the research productivity of universities since the pursuit of promotion through a series of well-defined steps is an important motivator of research activity and scientific publication (Tien 2000). Instead of building their research portfolios for promotion, many junior academic staff teach the required load of courses without devoting much time and serious effort to research. They spend the rest of their work time on remunerative consultancies, for which affiliation with a university enhances their visibility until they have developed an independent reputation. At that point in their career, many leave the university for jobs with NGOs, businesses, government, or self-employment. A World Bank study of staff retention in five African universities found that junior staff often leave the university because they regard the promotion process to be obscure, unfair, too long, or overly taxing and the salary level to be unattractive (Tettey 2006).

74. Among the ranks of junior academic staff who remain and advance to the middle level, many ultimately experience "retirement income anxiety" as they approach their final decade of work and leave the university for higher-paid employment and a work environment with a later mandatory retirement age.

\section{Collaboration}

\section{Africa Region Collaboration on Teaching and Research}

There are strong financial, technical and human capital related rationale for collaboration between universities in the Africa region on higher agricultural education and research. While good examples of cooperation exist, the arrangements for cooperation are somewhat ad-hoc and there is an opportunity for more systematic cooperation that could be supported by regional network organizations.

75. Collaboration between universities in the Africa region is a much under-utilized opportunity to build the regions collective capacity for higher education. Reasons for collaboration may include learning about the process of organizational transformation, learning about degree programs, developing joint degree programs or courses, engaging in joint research, exchanging students or faculty, or building the capacity of a weaker university. There are a number of good examples of collaboration between universities across the region (Text Box 14) that demonstrate the potential for collaboration in these areas within the region. 
76. There is a strong rationale for regional collaboration:

(i) A certain degree of specialization (in topics most relevant to each country) in each country and mutual sharing with other countries can potential generate regional cost savings;

(ii) Small countries in particular benefit because if they operate in isolation they incur a high share of overhead costs in trying to deliver teaching and research on a small scale for a broad range of themes.

(iii) Exchange of information and contacts yields mutual benefits for collaborating countries and joint research efforts may have greater credibility and application than those conducted individually.

77. The challenge is to determine what the institutional architecture for such collaboration should look like so that collaboration can be organized in a proactive and systematic way rather than on an adhoc basis. Here, regional organizations such as RUFORUM already play a strong role and their continued leadership will be important.

\section{Text Box 14. Examples of Africa Region Collaboration on Teaching and Research}

- The Collaborative Master's Program in Agricultural Economics, operates as a joint effort of eight universities in eastern and southern Africa (African Economic Research Consortium, n.d.). Distinguished international faculty reside at one of the universities for periods of time ranging from a few weeks to a few years to teach graduate classes, undertake curriculum review for other courses at the anchor university, mentor junior faculty at the anchor university, build joint research programs with faculty and students at the anchor university, and promote south-south cooperation.

- The Plant breeding sandwich program is implemented jointly by University of Cape Coast and the University of Kwazulu-Natal.

- The Partnership for Africa's Next Generation of Academics (PANGEA), a doctoral training and skills development program involving eight partner universities in Ghana, Botswana, Kenya, Tanzania, Malawi, South Africa, Uganda and Cameroon (Nakkazi 2016). PANGEA conducts short courses and workshops across the eight-member campuses on technical and soft skills for research.

- The Research and Innovation Management for Africa and the Caribbean linked universities in southern, eastern, central, and western part of the continent with partners in the United Kingdom and Belgium (Kirkland and Ajai-Ajagbe 2013). The initiative trained research management officers and assisted in the launching of Research and Innovation Management Associations (RIMAs) for East and Central Africa for on-going research management capacity development.

- Degree program development through the Africa Tuning, a large network of African universities, initially focused on development of undergraduate and post-graduate degrees and curricula in the disciplines of medicine, teacher education, agricultural sciences, mechanical engineering, and civil engineering (Hahn and Teferra 2013). The program, which is sponsored by the European Union, has broadened to include higher education management. 


\section{North-South Collaboration on Research}

International support for research should increasingly focus on African-led solutions. Although the flow of researchers in and out of the continent is instrumental in strengthening skills and maintaining the exchange of ideas and practice, its transient nature hinders local capacity-building and the development of sustainable local partnerships. West Africa has been notably more isolated in terms of North South research collaboration than the rest of the continent.

78. A joint report by the World Bank and Elsevier, "A decade of development in Sub-Saharan African Science, technology, engineering \& mathematics research" published in 2014, gives interesting pointers to the underlying issues affecting development of STEM and agricultural research in the different regions of SSA. While Sub-Saharan Africa's share of the global research output is significantly increasing, more than doubling from 2003 to 2012, health research still accounts for almost half of this output. Science, Technology, Engineering and Mathematics (STEM) and agricultural research lag behind both in quantity and impact, and in interest - and hence potential funding - from the corporate sector. The key drivers of the region's research are international collaboration and targeted national and international funding which tend to privilege North-South partnerships to the detriment of inter-African collaboration and stifle local initiatives. Researcher mobility follows a similar pattern with a high percentage of Sub-Saharan Africa's researchers being non-local and transitory. Although the flow of researchers in and out of the continent is instrumental in strengthening skills and maintaining the exchange of ideas and practice, its transient nature hinders local capacity-building and the development of sustainable local partnerships (Figure 15). The fragmentation of current research and academic infrastructure across the region, particularly in STEM, is a further obstacle to the development of African-led technical solutions. West Africa has been notably more isolated in terms of North South research collaboration than the rest of the continent.

Figure 16 Level of international collaboration for SSA regions (2012) and percentage of non-local, transitory researchers for SSA regions, 1996-2013.

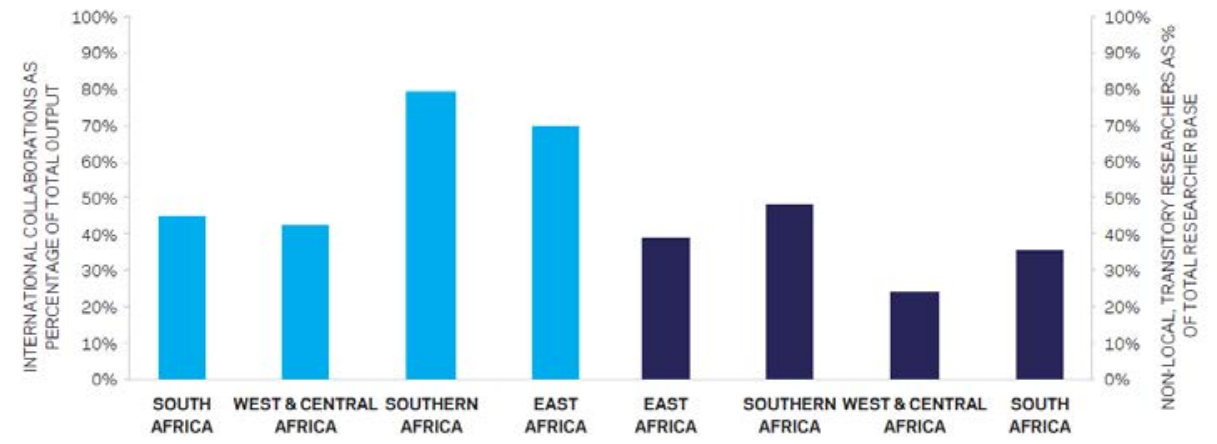

Source: A Decade of Development In Sub-Saharan African Science, Technology, Engineering \& Mathematics Research. World Bank, Elsevier. 2014. 


\section{Local Collaboration with Agricultural Policy Research Institutes}

Collaboration between universities and agricultural policy research institutes is mutually beneficial. While policy research institutes should maintain their independence, a strong association with universities can help ensure the survival of such policy research institutes which are often dependent on external project funding.

79. Experience in development of agricultural policy research institutes underlines the importance of the collaboration between universities and policy research institutes in terms of (i) the university providing a supply of highly qualified researchers to the policy research institutions; (ii) the use of policy research institute data for university research; (iii) creation of opportunities for university academics to apply their academic knowledge to the policy issues of the day and (iv) the important role of the university in advocating for the policy research institutes interests to government and donors and securing funding. They also draw attention to some of the challenges of such collaboration including: (i) achieving independent policy research while being affiliated with a public university; and (ii) dealing with tensions created by pay differentials between the two organizations sometimes driven by donor funding on policy research institutes and short-term consulting opportunities.

80. Affiliations between universities and African agricultural policy research institutes is a mutually beneficial collaboration that can considerably enhance both organizations operations. Household surveys and other data bases collected and shared by agricultural policy research institutes can enhance the quality of research carried out by faculty and students of the affiliated universities and the exchange of researchers between university departments and policy institutes can contribute exchange of ideas and methods to the programs of both organizations.

81. In Ghana, the Institute of Social Science and Economic Research is affiliated with the University of Ghana; in Kenya the Tegemeo Institute, is affiliated with Egerton University; and in Malawi the Center for Agricultural and Rural Development is affiliated with LUANAR. Figure 15 and Figure 16 provide insight into some of the challenges of establishing such collaboration with reference to examples in Kenya and Zambia that followed different collaboration models: Tegemeo Institute in Kenya, that was initially established within Egerton University and the Indaba Agricultural Policy Research Institute in Zambia, that was established as an autonomous organization but collaborating closely with UNZA. Text boxes 17-21 provide examples of how other countries have addressed these challenges. 


\section{Text Box 15 The Role of Egerton University in the Development of the Tegemeo Institute}

Kenya also has a longstanding local agricultural policy institute, the Tegemeo Institute for Agricultural Policy and Development, but it has followed a very different model than that of Zambia. In the late 1990s, USAID chose to discontinue a policy project headed by Stanford and Arizona State University and encouraged the Kenyan research staff to form a policy analysis unit located within Egerton University, one of Kenya's main agricultural universities. This structure provided immediate locally-led policy guidance to government, as the Institute received both financial and in-kind support through the publicly funded Egerton University.

But as an arm of a public university, Tegemeo was also accountable to Egerton, which exerted control over its finances, pay scales (which were substantially lower than market rates), and selection of research staff. USAID/Kenya provided long term support directly to Tegemeo, starting in 1997, but the institute had trouble retaining excellent researchers who typically left for higher-paying jobs with international development organizations or the private sector. Sustained USAID support made it possible for continuous staff development training, with over 10 Egerton staff receiving MS or Ph.D. degrees at international universities. Bonding requirements ensured that these scholarship recipients would return to Tegemeo. However, very few of these internationally trained staff would stay long because of the discrepancies between local and international salary scales. Over time this problem has been rectified, but new problems emerged. With a movement toward international remuneration and emoluments, some staff at Tegemeo were paid more than the highest leadership positions of Egerton University and far more than faculty in allied departments at the university. The relative benefits afforded to Tegemeo staff, while contributing to staff retention, eventually created frictions with agricultural departments at Egerton that could have otherwise been strong partners. Egerton authority over new hires to the Institute often introduced ethnic and political considerations and at times Tegemeo was a microcosm of the broader political battles occurring in Kenya. All of these problems impeded the productivity of the institute despite over 20 years of continuous funding from USAID and other donors.

In spite of these challenges, Tegemeo produced some important policy work, collaborated with international universities, produced quality outputs, organized well-attended policy conferences in Kenya, and contributed substantively to Government of Kenya agricultural plans, and was valued by both donors and by Egerton, which benefited from the $15 \%$ indirect cost recovery of grants to Tegemeo.

Tegemeo also had to deal with the common challenge of its staff being approached for individual consulting work. Donors unwittingly contributed to a free-rider problem: While USAID funded the long-term costs of building the institution - a core team of researchers, the costs of data collection necessary to carry out evidence-based analysis, and long-term graduate training to build qualified staff -- other donors liaised with Tegemeo through hiring their researchers as consultants for specific analyses. To the extent that Tegemeo research staff with full-time responsibilities to their core funding mission were diverted by short-term consulting opportunities, the ability of the Institute to deliver on its core mission was compromised. Over time, USAID started to complain about getting inadequate value for money and failure of the institute to sustainably cover its full costs of operation, which eventually led USAID to terminate its support to Tegemeo in 2017.

Key challenges and lessons learned from the Tegemeo experience in Kenya: (i) how to strike an effective balance between affiliation with public universities and institutions to promote a sense of government ownership while retaining sufficient independence to make competitive hires and carry out its analysis without sense of interference and control over the findings; (ii) how to provide staff compensation sufficient to retain internationally-competitive Kenyan research staff within a public university system; and (iii) how to address the free rider problem of donors seeking valued local policy analysis who are not willing or able to contribute to the costs of maintaining the institute's longterm viability and sustainability 


\section{Text Box 16 The Indaba Agricultural Policy Research Institute of Zambia}

Zambia has made great progress in developing African-led agricultural policy capacity and arguably has one of the region's strongest agricultural policy research institutes, the Indaba Agricultural Policy Research Institute (IAPRI).

A major lesson from Zambia is that it is possible to develop local policy analysis capacity within a decade if development agencies, international universities, local universities, and governments effectively work together for a sustained period. In 1990, agricultural policy analysis capacity in Zambia was among the lowest in the region. In 1999, USAID initiated an agricultural policy project headed by Michigan State University, which over a course of 12 years sent four Zambians for MS or Ph.D. training at MSU and hired several other Ph.D. researchers from other US and European universities upon graduation to join the project in Lusaka. Slowly the project built up a core team of Zambian agricultural policy analysts working together with senior MSU faculty based long-term in Lusaka based on long-term funding support from USAID. Staff retention was high over this period because the project provided a competitive remuneration package, enabled local researchers to build an international-quality research program of their own, featured strong mentoring, and provided scope for upward mobility. The project benefited from the collaboration of numerous faculty at the University of Zambia.

By 2010, USAID and SIDA missions in Lusaka worked together with MSU to transform the project into an autonomous, Zambian-managed policy institute. The full transition still took two additional years to erect the institutional structure, identify effective leadership, and build government support for this independent think tank, the Indaba Agricultural Policy Research Institute (IAPRI). Today, IAPRI works with UNZA, numerous international universities and development organizations, including MSU, which continues to mentor and provide hard and soft skills training to junior staff.

USAID deserves great credit for its sustained support of IAPRI's data collection activities. Because there was little or no farm survey evidence in the 1990s from which to draw upon in Zambia, the data needed to be assembled in order for IAPRI to provide evidence-based policy analysis.

Several important lessons emerge regarding the role of the national university in supporting IAPRI's development. First, IAPRI faced a number of crucial challenges through its initial years, and if the institution had not maintained strong support and institutional affiliation with UNZA, it might not have survived. Second, most of IAPRI's current research staff came out of the national university system, obtaining either undergraduate or MS degrees at the University of Zambia). The stock of qualified Zambians for PhD training internationally depended greatly on UNZA's ability to produce qualified undergraduate and MS degree holders. An unresolved third question is how closely IAPRI management wished to be tied to UNZA. Senior Zambian leadership resisted formal affiliation, citing concerns over autonomy, ability to nimbly respond to opportunities without depending on University apparatus to access funds and/or staff, and worries over fitting into university salary structures that were far below international market rates. These problems have been avoided under IAPRI's current status as a private company. Because its staff adhere to an internationally competitive salary structure, its staff have for the most part made long-term commitments to the organization and have rarely been bid away to join international organizations. An internationally competitive salary structure has certainly promoted IAPRI's sustainability and quality of analysis, even though within Zambia, it is sometimes spoken of as a relatively high-cost supplier of policy analysis support. What might be considered optimal from the standpoint of the policy institute is reasonable autonomy in personnel, remuneration, and financial management, while retaining formal affiliation with the university and support from senior university leadership for the institute's development. 


\section{Text Box 17. From University to Industry: Technology Transfer at Unicamp in Brazil}

Brazil has dramatically increased technology transfer and innovation through Inova, the technology transfer office established by the State University of Campinas (Unicamp) in 2003 and the first technology transfer office established in a Brazilian university. A multidisciplinary university with more than 31,000 students and 20 research units, Unicamp pursues a variety of technologies in many fields. By 2007, Inova had become the most frequent patentor and licensor in Brazil. In only two-and-a-half years it signed 128 technology transfer agreements, licensed 45 technologies to private companies and the government, and applied for 153 new patents, 22 trademarks, and 24 software registrations. Its technology transfer agreements will last for more than ten years, and they have already generated royalties for the university ranging from 1.5 percent to 10 percent of the net income from the licensed technology. Unicamp grants inventors 33 percent of royalty and licensing income. The greatest contributor to the patent and licensing portfolio is the Chemistry Institute (48 percent); the corresponding figure for agribusiness and food is 16 percent. Inova's patent database is available online.

Under Brazilian law, Unicamp owns 100 percent of its professors' and researchers' results. The law permits public institutions to give up ownership to the inventor, but Inova has not taken this route; its inventors lack commercial expertise and find it more attractive for Inova to commercialize the technology and give the inventor part of the licensing fee. Unicamp also commonly practices sponsored research. In such cases, ownership rights are normally split 50/50.

Factors in Inova's success include:

- Inova is driven by market demand. Instead of selecting Unicamp's technologies and offering them to the market, Inova examines market demand and seeks solutions inside the university.

- The technology transfer team comes from private institutions and has business skills. They are not researchers.

- The government provides many incentives to companies, such as tax benefits to companies that pay royalties; tax benefits to companies that invest in research and development, within or outside the company; compensation for taxes on royalties paid abroad during the execution of technology transfer contracts; tax exemptions for fees paid to maintain patents, trademarks, and cultivar registrations abroad; and sponsorship/subsidy of 60 percent of the salary of a scientist hired by a company.

These coordinated efforts will increase patenting and technology transfer in Brazil, strengthen the relationship between public institutions (where Brazilian research is mainly concentrated) and private companies, and contribute strongly to innovation. Other public universities and research centers have been studying Inova's model to emulate it.

Source: Di Giorgio 2007 


\section{Text Box 18. Reforming Higher Agricultural Education in China, 1990-2000}

By the late 1980s, as China gained momentum in moving toward a market economy, the higher education system for agriculture (created in the 1950s in the image of the Soviet system) recognized that its graduates would not have the skills to perform well in the changing labor market. Developed for a planned economy and operating under a centralized administrative system, China's institutions of higher agricultural education had little autonomy. They had no control over staff recruitment and finances. They struggled to accommodate to the changes brought about by the market economy.

Catalysts of reform. External and internal factors catalyzed the decision to reform China's higher agricultural education system. The three principal external factors were: (1) better-qualified, better-skilled graduates were needed to solve emerging technical and managerial problems in the agricultural sector; (2) government pressure to improve the efficiency of investments in education and reduce costs; and (3) lessons from reforms in other countries. Internal pressure for reform included: (1) demand from higher education institutions to gain greater authority to plan agricultural education, develop curricula, and manage personnel; (2) the need to rationalize the use of academic staff and bring about efficiencies in teaching and research; (3) the realization that teaching staff and institutions had to merge if they were to deliver graduates with the desired skills; (4) the need to use agricultural education infrastructure more efficiently; and (5) the need to reduce staff and personnel costs.

Steps in the reform process. Reform began toward the end of the 1980s with an analysis of internal and external problems and constraints that emerged from implementing reforms in the national economic system. This processinitiated mainly internally by the agricultural education institutions and the Ministry of Agriculture (MOA) - was informed by the outcomes of a conference and several meetings. Reforms were implemented in four main steps. The first was to formulate a reform strategy, concept, and guidelines to address the problems and constraints identified and integrate them with national institutional reform. This step was taken jointly in 1993 by MOA and the Ministry of Education (MOE), with support from central government. The second step, undertaken from 1993 to 1995, was to initiate pilot reforms at some universities. These pilots, which focused on internal structural reform and merging institutions, tested the reform concept and contributed to an action plan for large-scale reform in higher agricultural education. In the third step, the agricultural education institutions, MOA, and MOE synthesized their experiences with the pilots. Based on the outcome of this learning exercise, MOA formulated an action plan for launching the national reform in higher agricultural education in 1996. The fourth step was to implement the reform throughout China from 1996 to 2000. That process was guided by MOA and MOE in cooperation with provincial governments. In some cases, the reform process continues.

Stakeholders and their contribution or involvement. Many institutions collaborated and cooperated in the reform. The MOA helped formulate the reform strategy and action plan. The MOE was involved in designing and implementing the curriculum reform and merging institutions. Central government participated in the earlier stages, and provincial governments participated in merging institutions. Employers supported curriculum and employment reform, and students and their parents pressured the higher agricultural education institutions to improve internal education management and bring about financial reform. Staff of agricultural education institutions participated in planning and implementing internal structural reforms, and education research institutions provided concepts and guidance with regard to the reform.

Changes emerging from the reform. The major changes emerging from the reform included:

- decentralizing the administrative structure to the provincial government level and giving more decision-making responsibility to higher agricultural education institutions;

- changing curricula and pedagogical approaches; changing student enrollment; aligning employment patterns more closely with labor-market expectations;

- changing internal administrative structures to enable better recruitment and motivate staff; and reforming logistical systems (leading to efficiency and financial savings).

(Box continues on the following page) 


\section{Text Box 18. Reforming Higher Agricultural Education in China, 1990-2000 (continued)}

Other results of reform. Institutions involved in higher agricultural education gained more autonomy in implementing and managing education and research and in balancing agricultural market needs with national education guidelines. A performance-linked staff recruitment and remuneration system was integrated into the management system for these institutions. Education efficiency improved significantly. Funding also improved, because student fees were raised and enrollment rose by 10-15 percent. Curricula and teaching methods are better, more flexible, and more student friendly since the reforms took place. The establishment of a Rural Development section (faculty) has contributed to meeting the challenges of rural development. New teaching methods introduced by the College of Rural Development set a good example for further reforms in teaching methods for other faculty.

Lessons learned. Some aspects of the reforms were very specific to the national context. For example, once reform was agreed upon, it proceeded according to plan. All key actors cooperated in meeting a major economic challenge that demanded better-educated and trained graduates from higher agricultural education institutions.

Even amid strong collaboration and support, the reforms took a decade to achieve their main objectives, and the process continues to evolve. The lesson is that if higher agricultural education is to be reformed in a comprehensive way, the investment in time and continued support will be substantial. In China, even with strong agreement over the reforms, the reforms did not always work smoothly, especially when institutions were merged and the rapid rise in enrolment placed high pressure on teachers and on space.

Reforms had winners and losers among educational institutions and staff as the entire system was made more cost-effective. Notably, reforms in student enrolment and placement systems did not seem to improve employment among graduates, who found it more difficult to gain employment owing to greater competition for jobs. Government funding is still less than required, especially for higher agricultural education institutions in poorer areas.

Source: Liu and Zhang 2004.

\section{Text Box 19. Reforming India's State Agricultural Universities}

A major, systemwide reform of India's state agricultural universities (SAUs) aimed to modernize administration and management, update curricula and pedagogical approaches, upgrade teaching materials and laboratories, set new norms and standards for higher agricultural education, and improve human resource management in state line departments working closely with the agricultural universities. The process, initiated with four universities, was viewed as a ten-year effort but confined to a project of six years (1995-2001). The project improved the quality and relevance of India's SAUs by establishing an Accreditation Board, demand-oriented curriculum reforms, and complementary investments in staff training and educational infrastructure.

The quality and diversity of student intake and the quality of faculty improved. In hindsight, however, it is clear that the process could have been introduced more slowly, with fewer objectives and a longer time frame to institutionalize the reforms. The capacity, readiness, and commitment of project actors could have been better assessed. The project might have done better to focus on higher education alone, reserving human resource management in line agencies for a separate project. Donor coordination should have been emphasized to prevent universities from attaining funds that made it possible to delay reforms.

At the national level, the agricultural university system is coordinated by the Indian Council of Agricultural Research (ICAR), which is also a source of research funding for the universities. 


\section{Text Box 20. Transforming Wageningen Agricultural University}

A Ministry of Agriculture decision to make a major investment in the knowledge infrastructure for agriculture, strengthen research, and make research more accountable to its clients induced Wageningen Agricultural University to change its focus and work with a wider research network and with stakeholders. The change process began in 1997 when the university merged with the Ministry of Agriculture's research department to create the Wageningen University and Research Center. The vision for education at Wageningen University and Research Center is to create a content-inspired international learning environment based on (1) an orientation to competencies (knowledge, skills, and attitude), (2) professional and academic education, and (3) diverse, dynamic, and flexible learning tracks. To achieve this vision, the university has undertaken major administrative, staffing, and program changes, in the course of which it has merged with other education and research entities. A better balance was attained between discipline-oriented and integrated courses and between a focus on the development of knowledge and skills and on the competencies needed to use knowledge in society. Students were expected to understand the synergy between natural and social sciences to increase the societal relevance of the university's programs. As it continues to evolve, the new organization has attracted more students and funding, become more client oriented, and expanded its international cooperation network with academic institutions.

The reform was a total reorganization that involved budget cutting, staff reductions, rationalization of course offerings, and a public relations campaign to inform future students and the public of new and revised academic programs. The university also reached out to partner with other education institutions, private sector clients, and the European and world network of academic agricultural education and research institutions. More specifically, 24 academic chairs were eliminated, several education programs closed, and 280 staff positions cut. A strategic plan developed and introduced in 1999 helped bring about desired improvements in organizational relevance and enrolment. A key element in the strategic plan was that the university abandoned the generalized "agricultural" track to focus on "life and social sciences," given that health, food, nutrition, lifestyles, and livelihoods had gained importance.

Research institutes that were under the Ministry of Agriculture, Nature, and Food Quality merged with the university and now operate in so-called Science Groups on animal, environmental, food, plant, and social sciences. Van Hall Larenstein, a college of higher agricultural and vocational education, joined Wageningen, and the former tropical school for higher vocational education relocated to Wageningen from Deventer.

\section{Text Box 21. Brazil's National Agricultural Research Program Benefits from Long-Term Investments in} Human Resources

In 1963, the Brazilian government took a high-level decision to build a human capital base for a modern agricultural sector. With financing from the United States Agency for International Development, four American land-grant universities assisted four Brazilian universities in strengthening BSc level training for a decade followed by another four years of support for postgraduate education. In 1971-72 more than 900 Brazilian graduate students were studying agricultural sciences in United States universities. This experience with building human capital in programs in agriculture is directly linked to political decisions by the Federal Government and the Ministry of Education to pass the University Reform Act of 1968, which linked promotions to higher graduate degrees and required academic staff to work full time. In 1972, when the government established the Brazilian Agricultural Research Corporation (EMBRAPA) to coordinate its national agricultural research program, EMBRAPA continued to invest in human resources. It launched a massive human capital improvement program that sent 500 agricultural researchers for $\mathrm{PhD}$ programs and spent 20 percent of its budget from 1974 to 1982 on training in Brazil and abroad (World Bank 2007a, 39). Today, one-third of EMBRAPA scientists have a PhD, half have an MSc, and the balance have a BSc or equivalent. The most important lesson from this experience is that Brazil did not reduce public expenditure on its core agricultural institutions some 40 years ago when foreign investment waned. Instead, by mobilizing high-level political support, Brazil built a strong human capital base to sustain a globally competitive agricultural research and extension base.

Source: Author.

Note: EMBRAPA = Empresa Brasileira de Pesquisa Agropecuária 


\section{RECOMMENDATIONS}

82. The section presents specific recommendations on each of the issues that were identified as challenges through the country studies in key informant interviews, including those relating to leadership and management, relevance and quality of teaching and research, and collaboration between universities and other actors in the AIS.

\section{RECOMMENDATION Theme 1: NATIONAL LEVEL REFORMS}

\section{Vision/ Strategy}

83. A National Vision or Strategy for Building Higher Agricultural Education or update of existing strategies, prepared in consultation with responsible public agencies, universities and the private sector, would provide useful direction to these institutions and a united approach going forward. The strategy could for example define; (i) objectives of reform; (ii) vision for necessary changes in the thematic scope of higher agricultural education to respond to changing knowledge and skills needs (further detail below); (iii) vision for enrollment (iv) vision for equity and diversification; (v) institutional strategy including the role of private universities, agricultural and non-agricultural universities; (vi) financial strategy; and (vii) regulatory strategy

\section{Thematic Scope of Higher Agricultural Education}

84. As part of the above strategy, in cooperation with the private sector, public sector and universities, countries should consider changes in thematic scope of higher education including to respond to skills needs in the areas of (i) agribusiness and food industry management; (ii) human health and nutrition; (iii) climate change, agriculture and ecosystem management; (iv) agricultural risk management tools; (v) digital technology in agri-food value chains (see Text Box 22), with a strong focus on broadening higher education to address issues and interactions across markets (agricultural, environmental, financial and risk markets), along value chains, throughout ecosystems and across disciplines.

\section{Institutional Architecture}

85. An important element of the above strategy would be to define the respective roles of agricultural universities/ departments; non-agricultural universities/ departments; and private universities, in delivering higher agricultural education (graduate numbers and thematic scope) and the source of funding for each. 


\section{Text Box 22. The Potential of ICT for AET and Its Role in an Innovation System}

Many AET systems in developing countries do not employ even low-level ICT in the teaching/learning process. Reasons for this include poorly trained teaching staff who have not been exposed to ICT in their training, lack of funds to purchase ICT, unreliable power access, and no supervisory pressure to adopt and use ICT. ICT can improve the quality of teaching and learning and raise the quality and relevance of AET for greater impact within the AIS through a number of means:

- Improved competencies among teachers. Teachers and trainers are trained in basic ICT skills and ICT-based teaching methods.

- Improved competencies among graduates. The effectiveness and employability of AET graduates improves because they possess ICT skills.

- Better educational materials. ICT enables teachers to access information sources and create, update, and share learning materials.

- Distance education and e-learning. ICT is integral to creating opportunities for distance and electronic teaching and learning.

- Improved education administration and management. Throughout the AET system, ICT enables more effective and efficient management of human and financial resources and monitoring of student performance.

The International Institute for Communication and Development (IICD), a non-profit foundation that specializes in ICT as a development tool, has helped to introduce a number of ICT solutions in the education sector, which indicate the potential for ICT within AET. For example, teachers in Burkina Faso learned to build websites, find materials on the web, and use video, web publishing, and other applications to improve their lessons. Social media training helped these teachers start an active online community for sharing teaching materials with schools across the country. In a similar project, Bolivian teachers learned to create videos and CD-ROMs to support lessons; its success inspired the Bolivian government to launch a national program to put computer labs in 1,000 schools. At the Copperbelt College of Education in Zambia, one initiative requires that all graduating teachers be able to prepare lessons digitally. ICT skills also benefit vocational training and help make youth more employable. In Zambia, IICD helped set up a computer lab in a youth center, where young people learn basic ICT skills and access the web. As users learned more about the potential of ICT, the computer lab began to offer additional services, including secretarial and marketing support. Now ICT is also used to support training for tailors, carpenters, and mechanics.

Source: Author and www.IICD.org.

\section{Funding Sources}

86. Regulations governing income generation by universities could be loosened to allow universities to retain all internally generated income. Currently, many governments require universities to remit such income to the national treasury, dampening the incentive for entrepreneurial activity in higher education. Income generated internally by African universities comes largely from tuition. Many universities have established new degree programs, sub-degree programs, and post-graduate programs that generate additional income. A few African universities generate income from patents, production and sale of goods or services, and consulting though the share of total university income from such sources is small. Universities should exercise care in choosing income generating activities to ensure 
they do not divert focus from their core mission. However, where income generation is a natural outcome or complement of teaching or research, it can make a net positive contribution to both the mission and budget of a university. For example, a commercial tissue-culture operation that sells banana plants can complement teaching and research on tissue culture technology by providing learning opportunities for students and research opportunities for scientists while, at the same time, generating income for the university.

\section{Incentives - Performance-based Funding}

87. It is recommended that African governments establish performance indicators and tie higher education funding to performance. Performance targets should be agreed upon jointly by the universities and the government, performance should be evaluated, and funding should be based on the extent to which targets are met. Worldwide, implementing effective performance contracting systems has proven to be fraught with measurement and management difficulties. Therefore, a phased approach is recommended so that the system can be adjusted and improved incrementally. An initial phase could focus on the quality of administrative and support services provided by universities to ensure that management issues are given top priority. A performance contract management team answerable to the Vice-Chancellor should be created in each university and staffed with a coordinator, a specialist in contracting, an accountant, and a monitoring-evaluation specialist.

88. A subsequent phase could then focus on other outcomes that are more difficult to measure and for which it is difficult to account for causal forces beyond the control of universities. The broader set of indicators could include employability of graduates, uptake of innovations, establishment of publicprivate partnerships, number of publicly-disseminated research or policy papers, the ratio of females graduates, the ratio of students from poor households (Larsen 2016).

89. Performance contracting requires a great deal of preparatory work to design valid and implementable indicators, put data gathering and analysis systems in place, and train university and ministry staff on the use of the indicators. In most countries, PBF requires design and implementation of new higher education funding models, a process that requires time, effort, and financial expertise (Okebukola 2015a).

\section{Regulation and Quality Assurance}

90. While regulation and quality assurance may primarily be intended to ensure the adoption of minimum standards by universities, a part of the process they should be encouraged to embrace quality assurance and use it as a tool to measure the impact of their transformation initiatives.

91. For universities to adapt successfully to changing circumstances, it is important for them to have autonomy for decision-making regarding enrollment, fees, pursuit of alternative sources of revenue, hiring, salaries, and expenditures. When governments set these decisions, universities are hampered in their efforts to provide the best quality training and research with the available funds. 
92. It is recommended that governments grant universities autonomy over a wide range of administrative decisions, including enrollment, fees, revenue generation, hiring, salaries, and expenditure. Instead, governments should hold universities responsible for academic outputs and outcomes. Governments have much at stake in higher education and should ensure a good return from the sector through the contracting process rather than through the maintenance of stultifying regulations and excessive centralized decision-making.

\section{RECOMMENDATION THEME 2: LEAdERShIP AND MANAGEMENT}

93. Leaders of African universities should be trained and coached in the principles of organizational change leadership to prepare them to introduce organizational learning into their universities. A detailed discussion of the use of an organizational learning approach to university leadership is presented in annex 3 .

\section{Leadership Training}

94. The initial phase of leadership training would help to build the dynamic capabilities of sensing, seizing, and transforming which are described in Annex 3 of this report. This part of the training should target senior management (e.g., Vice Chancellors, Deputy Vice Chancellors, and Deans). Suggested topics for this phase of leadership training are (1) theories of organizational change in the higher education environment, (2) how organizational experiments and other approaches can be used to transform the internal culture and curricula of universities, (3) developing or revitalizing organizational strategies in academic institutions, (4) effective approaches for involving internal and external stakeholders in university transformation initiatives, (5) ways of developing and promoting shared values and resolving conflicts within and between academic institutions, (6) best practices of internal and external communication during university transformation initiatives, (7) how to deal with resistance during the change process, and (8) measuring and monitoring institutional and individual performance in higher education.

95. A final activity in the training phase will be for top leaders to identify broad categories of academic and administrative problems to be tackled through organizational experiments. These could include curriculum and pedagogy, research and innovation, classroom and instructional support services, library services, planning and monitoring, financial management, revenue generation, external relations (business, government, alumni), inter-university collaboration, and other categories.

96. A second phase of training would focus on preparing the lead members of the organizational experiment teams. The focus of this training should be on the organizational experiment protocol and case studies of its implementation in other universities.

97. Periodically, universities could consider providing induction training workshops for all recently appointed leaders to introduce them to basic leadership principles and to help them understand their administrative duties. Most African universities currently provide no opportunities for induction training though both newly appointed leaders and top administrators see the need for it. 


\section{Incentives for Staff}

Performance-Based Salaries

\section{(1) Salaries tied to individual performance}

98. A system of individual accountability would help to motivate member of academic and nonacademic staff to play their part in transforming the university. Assuming that the university and the various units of the university each have work plans, it is recommended that employees each be required to develop an annual work plan identifying how they will contribute to the annual work plan of the unit to which they are assigned. In universities that have control over the salary levels of their staff, salary increases should be tied to performance with reference to the annual work plan. In universities where the government sets salaries, employee performance could be tied to the allocation of discretionary funding for bonuses, skill upgrading, conference travel, or sabbaticals.

\section{(2) Student evaluations of teaching}

99. Another tool to complement a performance-based incentives system is to bring student evaluations of teaching into the institutional and individual accountability systems of universities and use them to inform performance evaluation. Student evaluations could be used to curb negative teacher habits such as absenteeism, arranging for unauthorized individuals to serve as substitute teachers, sexual harassment, or buying of marks/grades. It should be noted, however, that the student evaluation process can be corrupted by teachers threatening students individually or as a group, and therefore care must be exercised in designing the system. It is recommended that the use of student evaluations be implemented as an organizational experiment before being introduced throughout the university.

\section{Investment and Financial Management}

\section{(1) Infrastructure investment}

100. Funding of higher education infrastructure will be increasingly important for universities, donors, and private investors. Priorities for infrastructure include scientific laboratories which are particularly for STEM disciplines, renovation of classrooms to facilitate the use of ICT in teaching and learning, ICT infrastructure, including adequate Internet bandwidth, servers, computers and help desks, solar power generation especially where power supply is inconsistent and renovation to improve accessibility for disabled students.

\section{(2) Financial management}

101. Strengthening financial management systems can help ensure that funds are utilized in a timely manner. In many African universities, researchers face long delays in accessing available funds because of bureaucratic inefficiencies, at times jeopardizing timely implementation of research protocols and plans. For capital projects, release of funds is delayed when due process requirements are not met in a timely manner because of limited capacity for project planning and implementation. Improving financial management requires an increase in human capacity, modernization of financial systems, and upgrading of ICT infrastructure and equipment. 
102. African university leaders can advance the case for funding of higher education by showing how university teaching, research, and outreach contribute to stated national development objectives. To make a convincing case, universities can best focus on their achievements rather than plans or intentions. South Korea is a compelling example of a country that provided broad access to education and adequate levels of education and research funding, transforming itself from a recipient to donor country over a period of 50 years (Marx and Soares 2013). Effective public messaging about the role of the university in national development is so important in garnering support for public and private funding that this task should be supported and supervised directly by Vice Chancellors. A university's communications office or staff should work closely with the monitoring and evaluation office to publicize measured impacts of the university on farmers, businesses, households, communities, and the nation.

\section{Quality Assurance and Accreditation}

103. African universities engaging in transformation initiatives can benefit from embracing quality assurance and make it a tool that serves their objective of greater relevance and excellence in teaching, research, and outreach. Instead of merely reporting, universities should use quality indicators as value information for organizational learning. Performance indicator levels can help identify programs, services, and activities of the university that are in need of improvement. Because quality standards are minimum standards, leaders of university transformation initiatives will want to go beyond the government-mandated indicators and develop their own indicators of quality, particularly with regard to student and external stakeholder evaluations.

\section{ReCOMmendation Theme 3: RELEVANCE AND QuAlity}

\section{Relevance Enhancement in Teaching and Learning}

104. The aim of curricular and pedagogical revision should be to close the gap between what is taught and learned within the university and the competencies (skills, knowledge, and attitudes) expected by employers or needed for sustainable self-employment. Changing curricula and teaching/learning methods to prepare graduates for specified competencies is a daunting task. Unfortunately, most university teachers have no formal training in pedagogy and are unaware of the evidence-based literature on effective methods of teaching and learning. The graduate-level training in sub-disciplines of agriculture prepares graduate students, some of whom will become teachers, to think of teaching as a process of scientific knowledge transfer with relatively little emphasis on skills. The standard way of transferring knowledge in traditional higher education is through lectures, which put students in a passive position in the learning process. Competency in skills and deep mastery of knowledge require active learning during which students teach themselves through experience with guidance from teachers.

105. For a university to instill a new mindset, new course content, and new pedagogy, it is necessary to train teachers, administrators, and support staff on how to do it and to make educational resources 
available to assist them. First, however, it will be important to gather and analyze data on the knowledge and skills that are needed by employers and entrepreneurs.

\section{Tools for Relevance Enhancement in Teaching and Learning}

\section{(1) Labor market information}

106. For information on labor market needs, African universities may consult their Ministry of Labor to find out whether it has a labor market observatory or labor market information system. Labor observatories have been established in Ghana (Ghana Ministry of Employment and Social Relations, n.d.) Ivory Coast (Zito 2011), and Kenya (Kenya Ministry of Labour and Social Protection, n.d.). In Mozambique, the International Labor Organization is assisting the Ministry of Labor to create a labor market observatory, though data from the system are not yet available to the public (Mozambique Ministry of Labor, n.d.). Malawi conducts periodic labor market surveys but it does not appear to have a labor market observatory. While worthwhile examining if it is available, labor market observatory data often comes from low-response surveys and does not provide much occupational detail (Johanson and Adams 2004). Therefore, universities will need to supplement it with data and analysis of their own.

\section{(2) Graduate tracer studies}

107. An excellent source of data for analysis of the competency gap is the university's alumni. Studies that gather and analyze information on an educational institution's graduates have come to be known as "graduate tracer studies". It is recommended that African universities conduct graduate tracer studies of their graduates. Tracer studies should not simply be one-time events but should be repeated on a periodic basis.

108. Understanding competencies needed by former students who are now employed is the most important purpose of graduate tracer studies but there are also other purposes. Tracer studies can be used as documentation needed for accrediting of academic programs, for identifying potential quality improvements in academic programs, facilities, and services, and to provide information for marketing of academic programs (Schomburg 2003). In addition, tracer studies can be used as a means of reconnecting the university with its graduates for the purpose of developing an alumni association. The graduate tracer study piloted at Moi University in Kenya (Badiru and Wahome 2016) could be utilized and adapted by other African universities.

\section{(3) Occupational analysis}

109. Graduate tracer studies provide valuable data on labor market outcomes and on broad competencies needed for successful employment or self-employment. However, for some of the most common occupations identified through a tracer study, it is recommended that an occupational analysis also be conducted on some of the most common professions. One of the most widely used frameworks for occupational analysis is Developing a Curriculum (DACUM) (Norton 2009). The aim is to gather task-level intelligence that will help the university close the competency gap for future graduates entering the occupations that are in highest demand. In face-to-face interviews, trained interviewers 
gather information about the tasks carried out by the interviewee during a specified period of time. To reduce reporting error, the interviewers can arrange in advance for interviewees to record tasks in a diary on a daily basis. The interview is structured to gather information that will be used in subsequent analysis of the skills, knowledge, and attitudes required for successfully carrying out each task. Though DACUM has been most widely used by TVET institutions, it has also been used by universities for developing undergraduate curricula on agricultural engineering, food safety, horticulture, and other disciplines (Brumm et al. 2006; Linton et al. 2011; Halbrooks 2003). Other approaches, such as the Delphi method of data analysis, have also been used for occupational analysis for university agricultural curriculum design (Simon et al. 2005).

Translation of Identified Gaps into Improved Curricula and Pedagogy

\section{(1) Curricula revision}

110. After the tracer study and occupational task interviews are completed, the next step is to use this information to make changes in course content and teaching/learning methods. The aim is to identify knowledge topics and skill sets that the university will now teach and that students are expected to master before graduation and to identify how they should be taught. Mastery requires active involvement of students, so lectures should be supplemented with experiential learning.

111. If teaching is to improve in African universities, it is essential that leaders and funders be mindful of the bureaucratic and personnel constraints that stand in the way of curricular reform. One constraint is the bureaucratic cycle of curricular change. Most of the universities visited during the country background studies reported that curricula are reviewed every 3-6 years. Thus, considerable time could pass before curricular changes can be made, approved, and implemented. In general, universities do not make official revisions in curricula outside this cycle, which is mandated in most cases by the government ministry or agency that regulates higher education. Another constraint on curricular reform arises from heavy faculty workloads and the absence of incentives to change.

Curricular revision is nearly always done by the faculty members who teach the courses under review. Typically, they already have a heavy teaching load and view curricular revision as additional work with little benefit to them unless the university has a system in place for student or expert evaluation of teaching and the evaluation results are used in promotion and salary decisions.

112. African universities may need to consider curricula revision, albeit informed by awareness that the incubation period for implementation will be much longer than for teaching-method reform. Curricular revision should be based on findings from labor market information reviews, tracer studies, occupational analyses, dialogue with employers, and lessons learned from implementation of the new teaching methods. The incubation time for curricular revision could be shortened if the Ministry of Education allows universities to revise curricula outside the regular cycle.

\section{(2) Pedagogical development}

113. Given the constraints on rapid curricular change, African universities are advised to focus, in the short run, on improving teaching methods, which are almost never regulated, and therefore can be 
changed much faster than curricula. In most universities, there are no bureaucratic constraints that would prevent pedagogical improvements from being introduced immediately. The classroom lecture is the only pedagogical method, aside from laboratory exercises, used by most of the instructors in African universities. Studies have shown that the lecture method of teaching leads to less cognitive processing by students and, consequently, inferior learning compared to active-learning methods of teaching (Freeman et al. 2014). A first and easy-to-implement step is to make lecturing more interactive, for example, by calling on individuals or groups randomly (Barkley and Major 2018). A widely-referenced study of alternative methods of teaching undergraduate physics in large-enrollment classes is relevant to African universities, where many classes have large enrollments and where instructors consequently tend to view alternatives to lecturing as infeasible (Deslauriers, Schelew, and Wieman 2012). The researchers compared learning outcomes in a class taught by an experienced instructor using traditional lectures with a class taught by an inexperienced instructor using instruction methods based on research from cognitive psychology and physics education. The hours and topics of instruction were the same but student learning, measured by attendance, student engagement, and content mastery, was greater in the class where instruction was more active. Beyond lecturing, there are many active learning strategies that can be used by instructors. For example, the "flipped classroom" approach requires students to learn content outside of class using resources provided or recommended by the instructor while classroom time is devoted to instructor-facilitated illustration and application of concepts. Many active learning methods have the dual advantage of increasing content mastery while, at the same time, improving students' critical thinking and communication abilities, which employers complained were lacking during the country background studies.

\section{(3) Support services for development of curricula and pedagogical development}

114. It is recommended that African universities create and staff a Teaching and Learning Center to provide training and coaching on active learning strategies and on curricular revision. This unit could also oversee graduate tracer studies and occupational analyses to guide curricular revision. Many South African universities have teaching and learning centers where other African universities could get ideas for setting up their own centers.

\section{Work-integrated Learning}

115. Work-integrated learning is "a strategy of applied learning (learning integrated with work) which involves a structured educational program that combines productive relevant work experience with academic study and professional reflection" (Du Pré 2010). This includes internships, fieldwork, job shadowing, and cooperative education.

116. Two types of work-integrated learning were observed by the country background study teams: internships and fieldwork. Both should be expanded but, to make the expansion worthwhile, the quality of the work-integrated learning programs must be improved.

117. A Teaching and Learning Center, recommended in the preceding section, could undertake planning and coordination of opportunities for practical learning through guest lectures, industrial 
exposure programs, internships, case study development, business-decision simulators, and innovation incubators. The center could also coordinate job fairs to match students and employers. A model worth examining is the Centre for Community Engagement and Work Integrated Learning at Cape Peninsula University of Technology in South Africa (CPUT). This Centre serves as a bridge between the university and businesses where students are placed for integrated-work learning experiences (Reinhard et al. 2016).

\section{Relevance Enhancement in Research and Extension}

$\underline{\text { Researcher and Research Chair Development }}$

\section{(1) Training for junior researchers}

118. To increase research activity, African universities could sponsor periodic workshops on research proposal preparation, logistical and financial management of research projects, communication with research sponsors, scientific publication of results, and public dissemination of findings. The training should target junior members of academic staff and post-graduate students. Universities should identify one or more of their most productive senior researchers to lead periodic research workshops and to serve as mentors to junior researchers. This approach avoids costly transportation and lodging expenses for presenters and participants while complementing a broader strategy of transforming the most productive and innovative faculty members into champions of change within the internal culture of the university. Higher education associations such as the African Association of Universities (AAU) or RUFORUM could offer training-of-trainer (TOT) workshops for senior researchers to prepare them for the workshop teaching, mentoring, and research productivity championing role.

\section{(2) Research chairs}

119. To attract and retain outstanding researchers, African universities and governments ministries and agencies could consider establishing Research Chairs with a long-term investment trajectory. The aim is to improve the capacity of universities to produce highly trained postgraduate students and to increase the volume of research and innovation outputs. Such an initiative brings new research leadership capacity into universities and helps retain highly productive researchers who are already at the universities.

120. The South African Research Chairs Initiative (SARChI) launched by the government of South Africa in 2006 (National Research Foundation 2018) is an example that could be followed. Since it began, the initiative has created 150 Research Chairs in 21 public universities with priority on science and technology for poverty alleviation. Initiative guidelines set a 60/40 target for external versus internal candidates to encourage recruitment from outside South African universities, including from local industry and from abroad. 
121. Most researchers, like employees in general, are motivated by multiple factors including public recognition, income, and an internal organizational environment that is supportive of employees. African universities can promote an internal culture of research productivity by giving annual awards for number and quality of publications, level of outside funds secured for research, or number of postgraduate students supervised. For example, Jomo Kenyatta University in Kenya gives an annual Chancellor's Research Merit Award to the researcher with the most leveraged funds. Award ceremonies are a way of publicly recognizing outstanding researchers. Cash awards can help keep researchers focused on scientific research rather than consultancies.

\section{(4) Retention and promotion of researchers}

122. For promotion systems to increase the research productivity of universities, promotion criteria must be clear, transparent, unbiased, and sufficiently demanding in terms of research and teaching outputs, but not excessively bureaucratic. Many universities could increase their academic staff retention rate and increase their research output by improving their promotion policies and procedures. For detailed suggestions on improvement of promotion systems in African universities, see Tettey (2006). Among the important components of an efficient promotion system is clear communication of requirements and deadlines for preparing and submitting promotion portfolios. Another important component is mentoring of junior staff by senior staff at the department level from the first day of employment so junior staff become aware of and comfortable with promotion requirements. Academic staff associations could also hire experienced specialists with thorough knowledge of promotion regulations, procedures, and processes to assist academic staff during the development and preparation of their promotion portfolios (Tettey 2006).

123. Another measure that would increase the proportion of senior academic staff in African universities is raising the mandatory age for retirement. In many African countries, retirement is mandated at age 60 , whereas researchers with an established track record can typically remain productive in research and teaching well beyond this age.

Research Collaboration

\section{(1) Collaboration with national agricultural research institutes}

124. African universities and agricultural research institutes can usefully collaborate in setting research priorities, seeking funding, conducting research, and disseminating findings. A country's total research output can be increased in volume and improved in quality through collaboration and sharing of equipment, facilities, and knowledge. Universities have students who can fulfill their degree requirements while participating in research programs of senior institute scientists, who supervise them. At the same time, research institutes often have superior laboratory facilities needed by university students and faculty to conduct their research.

Engagement of university faculty in the activities of agricultural research institutes bolsters universities' relevance to the public sector. Activities that result in recognition of universities' 
contribution to the performance of agricultural $R \& D$ and extension systems may result in greater funding for universities, both by government and by foundations and bilateral donors.

Farm management and input use survey data collected by agricultural policy research institutes could be usefully brought to bear for collaboration between researchers from agricultural R\&D units, universities, and policy institutes on research priority setting, impact assessment of particular agricultural technologies and innovations, sustainable intensification practices, resilience and climate smart agriculture, and other issues related to farm-level technology adoption and productivity issues. These areas are ripe for collaboration on funding proposals submitted to Alliance for Green Revolution in Africa (AGRA), Council for Development of Social Science Research in Africa (CODESRIA), bilateral donors, the World Bank, and foundations.

It is therefore recommended that agricultural university leadership promote faculty collaborations with local, national and regional agricultural research and development institutes, and/or extension systems to obtain external grant funds to promote research collaboration on issues relating to adoption of improved technologies and farmer management practices, sustainable intensification, community resilience, climate-smart agriculture and natural resource management.

\section{(2) Commodity value chain collaboration}

125. African universities can also benefit from collaboration with industry to develop, adapt, or refine industrial technologies or processes. An initial step is to meet with representatives from commodity networks, if they exist in the country, or with firms specializing in the major commodities. Value chain analysis can then be developed jointly by university researchers and commodity specialists, focused on issues of governance, coordination, process improvement, and enhancement of value addition. Value chain analysis can identify specific areas of inefficiency which could be targeted for improvement. Solutions are then developed jointly by the university and businesses in the commodity network.

\section{(3) University-industry collaboration}

126. Closing the gap between the research products that African universities produce and the technology and knowledge needs of external stakeholders is important. This can be done by establishing agricultural and food system innovation centers. The purpose is to serve as a listening ear in the link between the university and industry, generate new products, adapt cutting-edge technologies to local conditions, facilitate incubation, provide demonstrations, and work in collaboration with national agricultural R\&D organizations, extension systems, and private industry. The innovation center should initiate regular meetings for on-going dialogue on knowledge, technology, and skill needs within the agricultural sector. The center and private sector collaborators can share knowledge of emerging technologies and jointly implement research that would benefit industry. Undergraduate and graduate students in agricultural sciences can gain hands-on experience by working with academic supervisors in the center's labs. By conducting relevant research, faculty will be better able to bring cutting-edge knowledge, technologies, and skills training into the curricula. Valuable insights can be gleaned from Innovation labs currently funded by USAID and agricultural centers of excellence funded 
by the World Bank, particularly regarding how they link to the private sector, and how they collaborate with other universities and institutes in the regions where they are located.

\section{$\underline{\text { Research Support }}$}

\section{(1) Access to international journals and periodicals}

127. Research productivity requires ready access to international academic journals, most of which are now available online. During the country background studies, interviewees at universities visited by the teams identified the need for greater online access. Subscriptions to journal collections are expensive and prohibitive for some African universities. In such cases, universities should avail themselves of reduced rates for developing countries through Access to Global Online Research in Agriculture (AGORA), TEAL and other programs (USAIN, n.d.).

128. Practical knowledge of digital librarianship and the required ICT infrastructure are essential for universities to provide online access to journals. African universities could follow the model of Sokoine University of Agriculture (Tanzania), which provided training in digital librarianship for its own staff and then trained other universities throughout the country Innovative Agricultural Research Initiative (IAGRI,n.d.).

\section{(2) Support services for university-industry relations}

129. African universities wishing to strengthen their collaboration with industry should consider creating an office of university-industry relations within the university to nurture and expand applied joint research and development. Functions of the office would include case study-based training on university-industry relations for faculty and post-graduate students, development of industrial research proposals, organizing of researcher teams, convening industry-university conferences, supporting product prototyping, establishing intellectual property procedures, and application for copyrights and patents on intellectual property.

\section{(3) Sabbatical leaves}

130. Sabbatical leaves should be made available to university faculty in high priority areas. In the country background studies for the study, some of the priority areas identified were value chains, agribusiness, entrepreneurship, tissue culture, gene editing, plant breeding, and irrigation.

\section{Recommendation Theme 4: Collaboration}

\section{Regional Collaboration}

131. There is a strong rationale for delivering training and research at a regional level (e.g. West Africa, East Africa, Southern Africa or other country grouping) through collaboration between universities (and collaboration between universities and research institutes within a region) in several cases:

(i) Regional Public Good - where research or teaching addresses challenges that are of a regional nature because they are linked to regional resources, regional trade, reginal 
movement and regional policy (such as regional water, energy, climate change nexus issues; regional trade and food security issues; cross-border conflict, pastoralism or migration and transboundary diseases), the delivery of related teaching and research may fully or in part best be provided at a regional level. Such a regional approach nurtures a common understanding of the issues across affected countries, jointly created solutions and provides a natural platform for cross country collaboration at many levels.

(ii) Specialization - where a country is particularly well endowed with expertise, experience or resources that make it particularly well suited to delivering research and training on a particular theme;

(iii) Economies of Scale - where training is of a generic nature, not country specific and involving a relatively small number of participants, such as pedagogy or leadership training, there are cost savings from delivery at a regional level.

132. Regional network organizations such as RUFORUM and the Association of African Universities have a strong role to play in conceptualizing and facilitating such regional collaboration.

\section{Enhancing North-South Collaboration for African-Led Solutions}

133. International collaboration, as the main driver of African research, should continue to be nurtured but international programmes should include strong collaboration with local industry and government to help nurture local solutions and capacity.

134. Similarly, academic mobility in STEM and agricultural research should be encouraged as a way of strengthening skills and maintaining the exchange of ideas and practice. However, the mechanisms of mobility should favor the return of African researchers to build local capacity.

\section{Types of Collaboration with National, Regional, and Continental Universities}

135. African universities seeking to collaborate with other universities in the nation, region, or continent may wish to consider the purpose of the collaboration before identifying institutional partners. Reasons for collaboration may include learning about the process of organizational transformation, learning about degree programs, developing joint degree programs or courses, engaging in joint research, exchanging students or faculty, or building the capacity of a weaker university. A collaborative partnership with another university may include one or multiple purposes.

Collaboration on Organizational Transformation and Leadership

136. African universities seeking to transform themselves for relevance and excellence would benefit from collaboration with other African universities, public or private, that have transformed in innovative ways over the past 10-20 years. Examples of public universities that have undergone innovative transformation include Gulu University (Uganda), Jomo Kenyatta University of Agriculture and Technology (Kenya), Kenyatta University (Kenya), Makerere University (Uganda), and University of Abomey-Calavi (Benin). Examples of transformed private universities are Ashesi University 
(Ghana), Strathmore University (Kenya), and United States International University (Kenya). Other public and private universities could be added to this list.

137. Universities could also collaborate on leadership training. The universities could pool their resources and plan joint workshops or retreats for Department Chairs (Heads), Deans, or student leaders.

Collaboration to Learn About Degree Program Development

138. Degree program development is a fruitful focus of collaboration among African universities. An example of such an initiative is Africa Tuning, a large network of African universities established initially to focus on development of undergraduate and post-graduate degrees and curricula in the disciplines of medicine, teacher education, agricultural sciences, mechanical engineering, and civil engineering (Hahn and Teferra 2013). The program, which is sponsored by the European Union, has broadened to include higher education management.

139. In African countries where universities are changing to the Licence-Master-Doctoral (LMD) system, universities that have not yet completed this transformation would benefit from collaborating from those that have completed the conversion process. Universities seeking to launch degree programs in particular disciplines or subject matter areas may wish to collaborate with universities that already offer those programs to get ideas about scope of the program, curricula, teaching methods, experiential learning opportunities, and marketing. For example, in Côte d'Ivoire, the University of Grand Bassam, a private university, has sought the assistance of ESA, the oldest public agricultural university, to launch a new agriculture program.

\section{Collaboration to Develop Joint Degree Programs, Training Programs, or Courses}

140. Universities that seek to offer degree programs in particular disciplines or subject matter areas but lack the required staff or facilities can benefit by collaborating with one or more universities with which they pool resources to develop a high-quality program. An example of such as program is a plant breeding sandwich program implemented jointly by University of Cape Coast and the University of Kwazulu-Natal. Another example is the Collaborative Master's Program in Agricultural Economics, which operates as a joint effort of eight universities in eastern and southern Africa (African Economic Research Consortium, n.d.). Distinguished international faculty reside at one of the universities for periods of time ranging from a few weeks to a few years to teach graduate classes, undertake curriculum review for other courses at the anchor university, mentor junior faculty at the anchor university, build joint research programs with faculty and students at the anchor university, and promote south-south cooperation.

141. Another example of a collaborative network for post-graduate training is the Next Einstein Initiative of the African Institute for Mathematical Sciences (AIMS), a network of institutes in Cameroon, Ghana, Rwanda, South Africa, Tanzania, and Senegal (African Institute for Mathematical Sciences, n.d.). The aim of the network is to train post-graduate students in basic and applied 
mathematics and to build the human and infrastructural capacity of the institutes in the member countries.

142. Many African universities with post-graduate programs lack the human and financial resources to provide training on a wide range of research skills. These skill gaps in existing post-graduate programs can be addressed by short training courses offered in collaboration with other universities. An example of a collaborative network created for this purpose is the Partnership for Africa's Next Generation of Academics (PANGEA), a doctoral training and skills development program involving eight partner universities in Ghana, Botswana, Kenya, Tanzania, Malawi, South Africa, Uganda and Cameroon (Nakkazi 2016). PANGEA conducts short courses and workshops across the eight member campuses on technical and soft skills for research.

\section{Collaboration for Research}

143. A simple and relatively inexpensive form of collaborative research is to provide travel funds to researchers to consult or work with a scholar with whom they share a common research interest. Collaboration could also involve multiple researchers from two or more institutions. The joint activity could be team research on a topic of mutual interest, or it could be workshops to learn new research methods.

144. Collaboration can also focus on improving the capacity to manage research. For example, a four-year collaboration called Research and Innovation Management for Africa and the Caribbean linked universities in southern, eastern, central, and western parts of the continent with partners in the United Kingdom and Belgium (Kirkland and Ajai-Ajagbe 2013). The initiative trained research management officers and assisted in the launching of Research and Innovation Management Associations (RIMAs) for East and Central Africa for on-going research management capacity development.

\section{Collaboration to Exchange Students or Faculty}

145. Universities could provide opportunities for faculty to spend a semester or a year at another university. Post-graduate students would also benefit from spending a period of time at another university to take courses, work with a professor, or use laboratory facilities.

146. Visiting faculty members could come from other universities in the country, region, continent, or the rest of the world. Visiting faculty could also be recruited through the Carnegie African Diaspora Fellowship Program, which operates in five African countries (Ghana, Kenya, Nigeria, South Africa, Tanzania, and Uganda).

\section{Collaboration to Build the Capacity of a Weaker University}

147. African universities can build their reputation as a leader in higher education by mentoring the teaching staff of weaker universities, particularly those where a low percentage of the faculty have doctorates. For example, Mozambique has six private universities that offer agricultural courses and would benefit from assistance by Eduardo Mondlane Universidad, the major agricultural university. 


\section{Collaboration with Government Ministries}

148. Collaboration between universities with agricultural programs and government ministries is sporadic in most African countries. Nevertheless, universities have exerted a long run impact on public ministries through the training of $\mathrm{MSc}$ and $\mathrm{PhD}-$ level graduates who are hired by the ministries. National agricultural universities are the main suppliers of ministry of agricultural analysts and program managers, who tend to move up through the ranks and become division directors, permanent secretaries and ministers. Though private-sector demand for university graduates has grown, the ministries will continue to need well-trained university graduates. In planning curricula, universities should therefore continue to seek input from government ministries regarding their knowledge and skill needs.

149. African universities may consider promoting the engagement of faculty in national agricultural plans and strategies of the Ministries of Agriculture. Over the past decade, many African governments have produced national action plans (NAIPs), CAADP compacts, and related plans setting out government priorities for agricultural transformation. In most cases, formal university engagement in these government initiatives has been limited, although in some cases, university faculty have been involved as consultants. Activities that result in recognition of universities' contribution to national agricultural plans may result in greater funding for universities, both by government and by foundations and bilateral donors.

150. African universities would also benefit from collaboration with public data collection institutions. Strong alliances between African universities, local policy research institutes, data collection units, and ministries of agriculture can help create a more central role for the agricultural universities in national agricultural research. University leadership should provide incentives for department heads and individual faculty to collaborate with national statistical offices and agricultural policy institutes in the preparation and implementation of externally funded grant proposals to strengthen the databases on which evidence-based agricultural transformation policies depend. The effective utilization of agricultural statistics depends on the end-users being consulted in the preparation of data collection instruments and modalities. Doing so will increase the probability that the data collected can meaningfully inform important policy issues. For this reason, it is important that policy-engaged university faculty and researchers in agricultural policy research institutes are engaged with public statistical organizations in the conceptualization of national data collection activities.

151. A sustainable agricultural training and vocational program under the Comprehensive African Agriculture Development Programme (CAADP) supported by the German Federal Ministry for Economic Cooperation and Development (BMZ) may provide a model for consideration and potential expansion. The CAADP/BMZ program has four modules: (1) Policy analysis and guidance, (2) Climate change adaptation in Agriculture, (3) ATVET, and (4) women in ATVET. 


\section{Collaboration with Agriculture Policy Units}

152. There are synergistic mutual benefits between a well-functioning university-affiliated policy institute and the related disciplinary departments of the university. The research activities of agricultural policy institutes brings valued stature to the affiliated universities and supports universities' own efforts to attract external funding. The policy engagement activities of research institutes solidifies universities relevance in national agricultural policy discourse. Ensuring that these mutual benefits are realized constitutes an important role for universities. University management can concretely enhance the performance of affiliated agricultural policy research institutes in the two broad ways.

153. First, university leadership can provide incentives to attract and retain quality researchers within the research institute. This entails:

(i) offering remuneration packages that are close to market rates for salaries and benefits for staff of the affiliated research institute. Doing so will reduce the probability that valued staff may leave the institute.

(ii) making available research funds (when needed) to enable individual scholars to build a respected and impactful research program. When the research institute is adequately funded by external grants, this may not be necessary, but because of the funding cycles of external donors, there may be times when universities may need to provide bridging support for staff and research activities during hiatus or low-funding periods.

(iii) recognition of individuals' contribution to the institute through awards, endowments, salary increments, etc.,

(iv) continuous investment in individual capacity development, such as opportunities for continued professional development, training programs, and mentoring in the case of young research staff

(v) opportunities for promotion and upward mobility to leadership roles within the institute.

154. All of the points listed here require enlightened university leadership to ensure altruistic management of the institute. University oversight of the institute can influence the quality of leadership at the institute. One of the most important ways in which university leadership can promote the performance of its policy institutes is to insist on quality leadership of the institute.

155. A second category of ways in which university management may support the performance of their affiliated agricultural policy research institutes is to maintain and nurture close ties between the university and the affiliated research institute's funding partners. This is important for the following reasons:

(i) Funding partners are more likely to provide sustained support to the institute if the university demonstrates that maintaining funding is a major priority of the university. 
(ii) Universities can also encourage sustained donor commitment to the institute if the university contributes its own funding to the policy research institute

(iii) Universities can help policy research institutes to adopt sustainable financing models for their services and encourage donors to pay fees for services that ensure full cost recovery (see Text Box 23).

\section{Text Box 23 Sustainable Financing of Policy Research Institutes}

Universities can play a role in representing the interests of policy research institutes to donors and government and helping them to understand the importance of supporting a sustainable funding model for the policy research institute. A wellfunctioning policy institute must ensure that it has sufficient funding to properly perform its functions. These go beyond specific research activities and include regular household panel data surveys that essential data for not only for policy institute research but also for university; sabbaticals, re-tooling and training programs to ensure that research staff are familiar with cutting-edge research methods; and forging collaborations with other research institutes, regional and panAfrican organizations, and international partnerships. The dilemma that research institutes face is that its clients are often only willing to pay for the marginal costs of specific research assignment and not the overhead costs of conducting these other import activities. To ensure its sustainable funding the policy institute must either persuade its funding agencies and clients (typically donors and government) that they should fund these "overhead" activities directly, or alternatively including a sufficient overhead charge in their consultancy fees for specific assignments to cover these costs.

\section{Collaboration with ATVET Institutions}

156. The staff of Agricultural and Technical Vocation Educational Institutes (ATVETs) are often trained by a local university that has agricultural programs. Such universities should build their linkages with ATVETs and help them improve their human resources through workshops on technical topics and mentoring. Universities could also collaborate with ATVETs and use their campuses as satellites for degree or outreach programs of the university. 


\section{BIBLIOGRAPHY}

African Economic Research Consortium. n.d. "Collaborative Masters in Agricultural and Applied Economics." https://aercafrica.org/training/cmaae/.

African Institute for Mathematical Sciences. n.d. "Next Einstein Initiative." https://www.nexteinstein.org/. African Quality Assurance Network. (2018) [Webpage] Retrieved from: https://afriqan.aau.org/ African Union Commission. 2015. "Agenda 2063: The Africa We Want." Addis Ababa. - - - 2018. "African Standards and Guidelines for Quality Assurance in Higher Education."

African Union 2018. Inaugural Biennial Review Report of the African Union Commission on the Implementation of the Malabo Declaration on Accelerated Agricultural Growth and Transformation for Shared prosperity and Improved Livelihoods. Assembly Decision (Assembly/AU/2(XXIII)) of June 2014.

AGRA. (2017). Africa Agriculture Status Report: The Business of Smallholder Agriculture in Sub-Saharan Africa (Issue 5). Nairobi, Kenya: Alliance for a Green Revolution in Africa (AGRA), Nairobi, Kenya.

Altbach, P. G., Reisberg, L., \& Rumbley, L. E. (2010). Tracking a global academic revolution. Change, 42(2), 30-39. Altinok, N., Angrist, N. and Patrinos, H. 2017. Global Data Set on Education Quality (1965-2015). Policy Research Working Paper 8314, World Bank, Washington, DC.

Andrews, Matt. 2013. The Limits of Institutional Reform in Development: Changing Rules for Realistic Solutions. Cambridge University Press.

Andrews, Matt, Lant Pritchett, and Michael Woolcock. 2013. "Escaping Capability Traps Through Problem Driven Iterative Adaptation (PDIA)." World Development.

http://www.sciencedirect.com/science/article/pii/S0305750X13001320.

Badiru, Egesah Omar, and Mary Wahome. 2016. "Conducting Graduate Tracer Studies for Quality Assurance in East African Universities : A Focus on Graduate Students Voices on Quality Culture." Journal of Education and Practice 7 (6): 174-81.

Barkley, Elizabeth F, and Claire Howell Major. 2018. Interactive Lecturing: A Handbook for College Faculty.

Binka (2005) - ask Amy for this reference

Birnbaum, Robert. 1989. "The Cybernetic Institution: Toward an Integration of Governance Theories." Higher Education 18 (2): 239-53. https://doi.org/10.1007/BF00139183.

Bjarnason, S., Cheng, K. M., Fielden, J., Lemaitre, M. J., Levy, D. C., \& Varghese, N. V. (2009) (Eds.), A new dynamic: Private higher education. Paris, France: UNESCO.

Bloom, DE, David Canning, and Kevin Chan. 2006. Higher Education and Economic Development in Africa. Washington, DC: World Bank. http://www.arp.harvard.edu/AfricaHigherEducation/Reports/BloomAndCanning.pdf.

Bomett, Emily. 2015. "Performance Contract in Kenyan Public Universities: Implementation Issues and Strategies." British Journal of Education 3 (1): 90-105.

Brennan, J., \& Shah, T. (2000a). Managing quality in higher education: An international perspective on institutional assessment and change. Buckingham, England: Open University Press. 
Brennan, J., \& Shah, T. (2000b). Quality assessment and institutional change: Experiences from 14 countries. Higher Education, 40(3), 331-349.

Brookings: https://www.brookings.edu/blog/africa-in-focus/2018/09/20/figures-of-the-week-africas-growingyouth-population-and-human-capital-investments/

Brumm, Thomas J., Steven K. Mickelson, Brian L. Steward, and Amy L. Kaleita. 2006. "Competency-Based Outcomes Assessment for Agricultural Engineering Programs." International Journal of Engineering Education 22 (6): 1163-72. http://lib.dr.iastate.edu/abe_eng_pubs/13/.

Cheche, Stephen G, and Muathe Sma. 2014. "A Critical Review of Literature on Performance Contracting." Global Journal of Commerce and Management Perspective 3 (6): 65-70.

Cohen, Michael D, James G March, and Johan P Olsen. 1972. "A Garbage Can Model of Organizational Choice." Administrative Science Quarterly 17 (1): 1-25. https://doi.org/10.2307/2392088.

Davis, K., Ekboir, J., Mekasha, W., Ochieng, C., Spielman, D., \& Zerfu, E. (2007).Strengthening Agricultural Education and Training in Sub-Saharan Africa from an Innovation Systems Perspective (No. 00736). Washington, D.C.: International Food Policy Research Institute.

Davis et al (2017): Are African households (not) leaving agriculture? Patterns of households' income sources in rural Sub-Saharan Africa. Food Policy Volume 67, February 2017, Pages 153-174

Deslauriers, Louis, Ellen Schelew, and Carl Wieman. 2012. "Improved Learning in a Large-Enrollment Physics Class. Deslauriers. Schelew. Wieman.” Science 862 (2011): 862-64. https://doi.org/10.1126/science.1201783.

Dodgson, Mark. 1993. “Organizational Learning: A Review of Some Literatures.” Organization Studies 14 (3): 375-94.

Doh, Jonathan P. 2001. "Can Leadership Be Taught? Perspectives From Management Educators." Academy Al Management Learning and Education 2 (1): 54-67.

Du Pré, Roy. 2010. Universities of Technology in the Context of the South African Higher Education L Andscape. Kagisano. https://doi.org/10.1002/jor.20079.

El-Khawas, E. (2001). Who's in charge of quality? The governance issues in quality assurance. Tertiary Education and Management, 7(2), 111-119.

El-Khawas, E. (2002). Quality assurance for higher education: Shaping effective policy in developing countries. In D. W. Chapman \& A. E. Austin (Eds.), Higher education in the developing world: Changing contexts and institutional responses. Westport, CT: Greenwood Press.

El-Khawas, E. (2006). Accountability and quality assurance: New issues for academic inquiry. In J. F. Forest \& P. G. Altbach (Eds.), International handbook of higher education (pp. 23-37). Dordrecht, Netherlands: Springer.

FAO 2012. World Agriculture Towards 2030 2050, The 2012 Revision. Nikos Alexandratos and Jelle Bruinsma, ESA Working Paper No. 12-03, June 2012.

Foster-Fishman, P.G., Nowell, B., \& Yang, H. (2007). Putting the System Back into Systems Change: A Framework for Understanding and Changing Organizational and Community Systems. American Journal of Community Psychology, 39, 197-215.

Freeman, S., S. L. Eddy, M. McDonough, M. K. Smith, N. Okoroafor, H. Jordt, and M. P. Wenderoth. 2014. "Active Learning Increases Student Performance in Science, Engineering, and Mathematics." Proceedings of the National Academy of Sciences 111 (23): 8410-15. https://doi.org/10.1073/pnas.1319030111. 
Ghana Ministry of Employment and Social Relations. n.d. "Ghana Labour Market Information System." http://glmis.gov.gh/.

Hahn, Karola, and Damtew Teferra. 2013. "Tuning as Instrument of Systematic Higher Education Reform and Quality Enhancement: The African Experience." Tuning Journal for Higher Education, no. 1: 127-63.

Halbrooks, Mary C. 2003. "DACUM as a Model for Horticulture Curriculum Development and Revision: A Case Study." Horttechnology 13 (2): 569-76.

Havlik, P., et al 2015. "Climate Change Impacts and Mitigation in the Developing World: Integrated Assessment of Agriculture and Forestry Sectors." Background paper to the World Bank report "Climate Change and Poverty." Washington, D.C. in World Bank (2015).

Hayward, F.M. and D.J. Ncayiyana 2014. Confronting Challenges of Graduate Education in Sub-Saharan Africa. International Journal of African Higher Education.

Heinrich, W., Cherchiglia, L., Abalo, T.A., Bonnell, J. (in press) "Learning to Innovate: How a Malawian Faculty of Agriculture Improved Food Systems with Human Centered Design" International Journal of Agricultural Education and Extension.

Helie, Sebastien, and Ron Sun. 2010. "Incubation, Insight, and Creative Problem Solving: A Unified Theory and a Connectionist Model." Psychological Review 117 (3): 994-1024. https://doi.org/10.1037/a0019532.

IAGRI. n.d. "Tanzanian Universities Trained to Provide Digital Library Services." http://iagri.org/stories/tanzanianuniversities-trained-to-provide-digital-library-services/.

IFPRI 2018. Advancing Policy Innovation and Reforms in Africa's Agricultural Sector, Ousmane Badiane, Presentation to The World Bank, February 2018, Paris.

International Network for Quality Assurance Agencies in Higher Education. (2018). [Web page] Retrieved from http://www.inqaahe.org/

Johanson, Richard K., and Arvil V. Adams. 2004. Skills Development in Sub-Saharan Africa. World Bank Regional and Sectoral Studies. https://doi.org/10.1038/ncomms5346.

Jongbloed, Ben, and Hans Vossensteyn. 2001. "Keeping up Performances: An International Survey of Performance-Based Funding in Higher Education." Journal of Higher Education Policy and Management 23 (2): 127-45.

Kenya Ministry of Labour and Social Protection. n.d. "Kenya Labour Market Information System." https://www.labourmarket.go.ke/.

Kirkland, John, and Patrice Ajai-Ajagbe. 2013. "Research Management in African Universities: From Awareness Raising to Developing Structures." London.

Koch \& Weingart (2016) - Ask Amy for this reference

Kraybill, D.S.;, J.M.; Erbaugh, I.J.; Minde, and D.O. Hansen. 2017. "Improving the Capacity of Agricultural Higher Education Institutions to Contribute to Food Security: The IAGRI Experience and Lessons Learned" 2 (1): 1-10.

Lam, Alice. 2010. "Tacit Knowledge, Organizational Learning and Societal Institutions: An Integrated Framework." Organization Studies 21 (3): 487-513. https://doi.org/10.1177/0170840600213001.

Larsen, Carl Erik Schou. 2016. "Reflections on the Incentive Structures at African Universities and Their Impact on the Direction and Performance of the Continent's Development" 1 (2): 127-37. 
Levy, D. C. (2009a). Growth and typology. In S. Bjarnason, K. M. Cheng, J. Fielden, M. J. Lemaitre, D. C. Levy, \& N. V. Varghese (Eds.), A new dynamic: Private higher education (pp. 7-27). Paris, France: UNESCO.

Levy, D. C. (2009b). Sub-Saharan Africa's Private and Public Higher Education Shares 2002-2009. [Data file]. Retrieved from http://www.albany.edu/dept/eaps/prophe/data/international.html

Linton, Richard H., Abbey Nutsch, David McSwane, Justin Kastner, Tejas Bhatt, Sheryl Hodge, Kelly Getty, et al. 2011. "Use of a Stakeholder-Driven DACUM Process to Define Knowledge Areas for Food Protection and Defense." Journal of Homeland Security and Emergency Management 8 (2). https://doi.org/10.2202/15477355.1768.

Mapila, M. A. T. J., Kirsten, J. F., \& Meyer, F. (2012). The Impact of Agricultural Innovation System Interventions on Rural Livelihoods in Malawi. Development Southern Africa, 29(2), 303-315.

Marx, Axel, and Jadir Soares. 2013. "South Korea's Transition from Recipient to DAC Donor: Assessing Korea's Development Cooperation Policy." International Development Policy 4.2.

Masters, W., N. Rosenblum, and R. Alemu (2018). Agricultural transformation, nutrition transition and food policy in Africa: Preston Curves reveal new stylized facts. Journal of Development Studies,54(5), 788-802.

Materu, P. (2007). Higher education quality assurance in sub-Saharan Africa: Status, challenges, opportunities and promising practices. Washington, D.C.: World Bank.

Mcguire, Michael, and Ed Gerrish. 2016. "The Impact of Performance Management on Performance in Public Organizations: A Meta-Analysis." Public Administration Review 76 (1): 48-66.

https://doi.org/10.1111/puar.12433.48.

Mohamedbhai, G. 2014. Massification in Higher Education Institutions in Africa: Causes, Consequences, and Responses. International Journal of African Higher Education.

Mozambique Ministry of Labor. n.d. "Moz Trabalha." https://moztrabalha.co.mz/.

Nakkazi, Esther. 2016. "Academic Network Launches New Research Training Programme." University World News Africa Edition, 2016.

Mundial, B. (1994). Higher education: The lessons of experience. Washington, DC: The World Bank.

National Research Foundation. 2018. "South African Research Chairs Initiative (SARChI ): Framework and Funding Guide."

Neave, G. R., \& van Vught, F. (1994). Government and higher education relationships across three continents: The winds of change. Tarrytown, NY: Pergamon.

Nguthuri, Javan Mwiti, Andrew K Maringa, and Gongera Enock George. 2013. "An Evaluation of the Performance Contracting on Organisation Performance: A Case of Kenyatta University, Kenya." European Journal of Business and Management 5 (21): 94-108.

Norton, Robert E. 2009. "Competency-Based Education via the DACUM and SCID Process : An Overview." The Ohio State University.

Okebukola, Peter, ed. 2015a. Towards Innovative Models for Funding Higher Education in Africa. Accra: Association of African University.

- - - 2015b. "Towards Models of Creatively Funding Higher Education in Nigeria." In Towards Innovative Models for Funding Higher Education in Africa. Accra: Association of African Universities. 
Oketch, M. O. (2003). The growth of private university education in Kenya: The promise and challenge. Peabody Journal of Education, 78(2), 18-40.

Oketch, M. O. (2004). The emergence of private university education in Kenya: Trends, prospects, and challenges. International Journal of Educational Development, 24(2), 119-136.

doi:10.1016/j.ijedudev.2003.10.005

Reardon, T., R. Echeverria, J. Berdegué, B. Minten, S. Liverpool-Tasie, D. Tschirley, D. Zilberman. (2018). Rapid transformation of food systems in developing regions: Highlighting the role of agricultural research \& innovations. Agricultural Systems.

Reinhard, Karin, Anna Pogrzeba, Rosemary Townsend, and Carver Albertus Pop. 2016. "A Comparative Study of Cooperative Education and Work Integrated Learning in Germany, South Africa, and Namibia." Asia-Pacific Journal of Cooperative Education 17 (3): 249-63. https://doi.org/10.1016/j.jmpt.2004.08.005.

Rivera. (2008). Transforming Post-secondary Agricultural Education and Training by Design: Solutions for SubSaharan Africa. Washington, D.C.: World Bank.

Rodrik, Dani. 2008. One Economics, Many Recipes: Globalization, Institutions, and Economic Growth. Princeton University Press.

Schomburg, Harald. 2003. Handbook for Tracer Studies. Centre for Research on Higher Education and Work, University of Kassel. https://doi.org/10.1017/CBO9781107415324.004.

Senge, P.M. (1990). The Fifth Discipline: The Art \& Practice of the Learning Organization. New York: Currency Double Day.

Senge, Peter M.; 2006. The Fifth Discipline: The Art and Practice of the Learning Organization. New York: Doubleday.

Shabani, Juma, Peter Okebukola, and Olusola Oyewole. 2014. "Quality Assurance in Africa : Towards a Continental Higher Education and Research Space." International Journal of African Higher Education 1 (1): 13971.

Shulock, N. (1999). The Paradox of Policy Analysis: If It Is Not Used, Why Do We Produce So Much of It? Journal of Policy Analysis and Management, 18(2), 226-244.

Simon, Leslie A., Jacqui D. Haygood, Cindy L. Akers, David L. Doerfert, and Chad S. Davis. 2005. "Master's Level Agricultural Communications Curriculum: A National Delphi Study." Journal of Agricultural Education 46 (3): 5669. https://doi.org/10.5032/jae.2005.03056.

Spielman, D.J., Ekboir, J., Davis, K., \&Ochieng, C.M.O. (2008). An innovation systems perspective on strengthening agricultural education and training in Sub-Saharan Africa.Agricultural Systems, 98(1), 1-9.

Swanepoel F. Ofir Z. and Stroebl A. eds. 2014. Towards Impact and Resilience. Cambridge University Scholars Publishing.

Tagg, John. 2007. "Double Loop Learning in Higher Education :" Change 39 (4): 36-41.

Teece, David J. 2018. "Managing the University: Why 'Organized Anarchy' Is Unacceptable in the Age of Massive Open Online Courses." Strategic Organization 16 (1): 92-102. https://doi.org/10.1177/1476127017732760.

Tettey, Wisdom J. 2006. "Staff Retention in African Universities: Elements of a Sustainable Strategy." Washington DC. 
Tien, Flora F. 2000. "To What Degree Does the Desire for Promotion Motivate Faculty To Perform Research? Testing the Expectancy Theory." Research in Higher Education 41 (6): 723-52.

Toguebaye, Bhen Sikina. 2015. "Performance Contracts in Public Universities in Senegal." In Towards Innovative Models for Funding Higher Education in Africa, edited by Peter Okebukola, 77-92. Accra: Association of African Universities.

Tschirley, D., J. Snyder, M. Dolislager, T. Reardon, S. Haggblade, J. Goeb, M. Kondo (2015). Africa's Unfolding Diet Transformation: Implications for Agri-Food System Employment. Journal of Agribusiness in Developing and Emerging Economies, 5 (2), 102-136.

UNESCO. (1998). World declaration on higher education for the twenty-first century. Paris, France: UNESCO.

USAIN. n.d. "Resources for Librarians in Developing Countries." https://usain.org/Resources-for-Librarians-inDeveloping-Countries.

Webb, Steven Benjamin. 2008. Public Sector Reform: What Works and Why? An IEG Evaluation of World Bank Support. The World Bank.

World Bank. (2006). Enhancing Agricultural Innovation: How to go beyond the Strengthening of Research Systems. Washington, D.C.: Author. Retrieved from http://siteresources.worldbank.org/INTARD/Resources/Enhancing_Ag_Innovation.pdf

World Bank 2014. Turn Down the Heat. Confronting the New Climate Normal

World Bank, Elsevier. 2014 A Decade of Development In Sub-Saharan African Science, Technology, Engineering \&Mathematics Research.

World Bank 2015a. Plenary Presentation to 12th Agricultural Science Congress, Karnal, India. February 4, 2015. World Bank, 2015. Future of Food, Washington, D.C: World Bank

World Bank 2016. Reaping Richer Returns, Public Spending Priorities for African Agricultural Productivity Growth. Aparajita Goyal and John Nash.

World Bank. (2017). Sharing Higher Education Beyond the Few in Africa.

World Resources Institute (WRI) 2013, Land Use, Land Use Change and Forestry.

Yusuf, Shahid, William Saint, and Kaoru Nabeshima. 2009. Accelerating Catch-Up: Tertiary Education for Growth in Sub-Saharan Africa. Washington, DC.

Zeleza, P. T. (2016). The Transformation of Global Higher Education, 1945-2015. New York: Palgrave Macmillan

Zito, Paola. 2011. "Labour Market Information Systems in Ivory Coast, Morocco and Peru : Comparative Report." Turin, Italy. 


\section{ANNEX 1 CORE DEVELOPMENT CHALLENGES IN HIGHER EDUCATION IN AFRICA: SUMMARY OF FINDINGS FROM COUNTRY STUDIES}

1. This annex summarizes country specific findings relating to each of the core challenges discussed in the main report. These issues are grouped under four themes: (i) Institutional Structure including the role of private universities, specialized and non-specialized universities and countries response to increasing demand for higher education; (ii) Leadership and Management; (iii) Relevance and Quality and (iv) Collaboration between universities and with other actors in the AIS.

\section{InSTITUTIONAL STRUCTURE}

2. This section describe how the institutional architecture of higher education institutes is evolving in each country to meet changing demands. The difficulty that countries are having meeting increasing demand while improving the quality and relevance of teaching, underlines the importance of developing a long-term institutional strategy for higher agricultural education in each country that provides greater certainty around which universities can plan, and defines the countries long-term needs for agricultural graduates, the role of specialized agricultural universities, non-specialized universities and private universities, and the financial resources that will be made available to implement the strategy.

\section{Responding to Rising Demand}

\section{Balancing Access and Quality}

3. Universities are responding to rapidly expanding demand in a limited-resource environment. Institutions often face a difficult choice: either expand student numbers in response to rising demand but sacrifice quality or restrict student intake to maintain quality of student teaching or. Countries have taken different approaches to addressing this challenge.

4. Ethiopia adopted the former approach and expanded the number of undergraduate students by 30 -fold over the past two years, which has unsurprisingly resulted in a serious deterioration of the quality of instruction and supervision.

5. Malawi adopted the latter approach and student intake has been severely restricted. Every year, approximately 15,000 students qualify for post-secondary education, however due to capacity constraints only 4,000 are accepted into higher education. Currently about 2000 students are receiving some sort of vocational training related to agriculture. This leaves 9,000 admissible students each year unable to obtain a post-secondary education or vocational training.

6. In areas of higher education where Malawi has expanded maintaining quality has been challenging. LUANAR is now expanding enrollment numbers very rapidly, which creates significant management challenges for faculty. While the new modes of offering courses have expanded access, faculty members indicated that they have had to expand their teaching loads significantly to accommodate the new programs (ODL, City Campus, and weekend programs at NRC) without much 
support or additional compensation. The university has hired tutors and teaching assistants to help with grading and tutorials, however, students have expressed concerns with the quality of assistants' work.

7. In Mozambique the government expanded teaching programs and enrollment but has not given any additional support to build new classrooms or laboratory equipment. The University is clearing its laboratories to make them into classrooms which means there is no facilities for practical lab related courses and the faculty is left with no choice but to offer less practical oriented courses.

8. Kenya partly responded to increased demand by adopting a policy that supported the creation of parallel universities with distinct mandates within the higher education system (Ng'ethe, Subotzky, \& Afeti, 2007). The strategy supported the upgrading of polytechnics to technical universities offering "skills degrees" and training programs to the highest level possible. Traditional universities would then focus on research and the awarding of "knowledge degrees".

Exploiting the Emergence of Private Universities

9. Private universities, have begun to offer agricultural programs in response to rising demand. While additional institutions offer greater access, private delivery of education is often difficult to regulate and costly; thus, many of these newer private universities lack quality programs due to lack of qualified staff and in some cases, students are not able to access financial resources to attend them.

10. However, there is potential to take advantage of the expanded capacity provided by private universities in several ways through strengthening their faculty, accreditation and reform of student funding arrangements.

11. In Mozambique, in addition to the major university for agriculture - the Eduardo Mondlane Universidad, there are six other private universities offering agricultural courses. These universities faculties could be upgraded by linking them to major universities and their commitment to quality increased by subjecting them to accreditation.

12. Malawi has recently extended access to government-funded student loans to those enrolling in accredited private university programs, which has expanded enrollment and helped to reduce attrition rates.

13. In Kenya, as a result of the 2012 Higher Education Act in Kenya, the Higher Education Loans Board (HELB) allows students to apply for government-funded loans to private institutions. Kenya private universities have been scrutinized since 1985 by the country's quality assurance agency. As a result, the country boasts some of the most reputable private universities in the region such as Strathmore University and United States International University. Both have new programs and centers in agri-business with industry engagement that have high rates of alumni employment upon graduation. 


\section{Taking Advantages of General and Specialized Agricultural University Models}

14. In conceptualizing how to expand higher agricultural education, one of the long-term strategic choice decision makers face is whether to deliver education from a specialized agricultural university or faculty or whether to integrate agriculture within existing faculties.

15. There are both advantages and disadvantages in having agriculture as an agricultural focus versus a science focus. An advantage of ESA's narrow focus is that agriculture remains central to the academic mission, making it relatively easy both administratively and intellectually to collaborate with external agricultural stakeholders and external agricultural universities and institutes.

16. Nevertheless, there are potential disadvantages in a sole focus on agriculture, a major one being that agricultural teachers and researchers may be isolated from scientific developments in nonagricultural fields of knowledge that have potential relevance for agriculture.

17. An advantage of the broad scientific focus, such as that at University Felix Houphouet-Boigny (UFHB) and University Nangui Abrogoua (UNA) in Cote D'Ivoire, is that synergy can more easily emerge between agriculture and non-agricultural domains of knowledge. A disadvantage is that the practical problems of agriculture science may be less prestigious and therefore less attractive to teachers and researcher concerned with establishing and maintaining their reputations as researchers in the fundamental sciences of biology, chemistry, physics, or economics.

18. In Cote D'Ivoire, of the three universities with agricultural programs, only the École Supérieure d'Agronomie (ESA) at INPHB has an academic administration devoted solely to agriculture. The Director of ESA, roughly equivalent to a dean in the Anglophone academic system, is an agriculturalist. Most of ESA's degrees are specific to agriculture. Coordination of agricultural programs is the primary responsibility of the Director of ESA. This coordination function is important both for advancing agriculture within the institution and for liaising with donor and external collaborators focused on agriculture.

19. In contrast, UFHB and UNA have no administrative unit or administrator devoted solely to agriculture. Instead, agriculture is one of multiple scientific domains and multiple sectors of the economy addressed by these institutions. Though some of the degrees offered by UFHB are specific to agriculture, many of them are not. From discussions with various members of the Biosciences Unit at UFHB, the university tends to address agriculture through the lens of science rather than through the lens of agricultural expertise per se. UNA follows a pluralistic science approach to agriculture similar to UFHB.

\section{LEADERSHIP AND MANAGEMENT}

20. This section address some of the challenges that the leadership of Universities face in transforming their universities. Some challenges are external to universities and beyond the immediate control of university leadership, including the regulatory framework that while being an important tool for improving quality can also constraint the flexibility with which universities can implement change. 
Other challenges are internal and require changes to faculty incentives, adoption of specific tools to make universities more responsive to industry needs and changes in approaches to leadership. This suggest that investments to strengthen higher education in agriculture should address both the external challenges, that are generally related to the broader higher education system are not specific to higher agricultural education and internal issues that are specific to each university.

\section{Regulation}

21. In all five countries, universities are regulated by a Ministry of Education or regulatory agency. This section describes the arrangements for regulation of agricultural universities and the expansion of quality assurance and then discusses resulting challenges to change management in universities including in relation to curricula development, financial independence and performance-based management.

\section{Institutional Arrangements for Regulation}

22. In Cote D'Ivoire, the current legal framework for higher education in Côte d'Ivoire was established by an act of Parliament, known as the Education Law, in 1995. Public universities in Côte d'Ivoire are heavily regulated with respect to enrollment and finances. The government determines the level of enrollment at each public institution, sets tuition fees, and requires universities to turn over internally generated revenue to the national treasury (World Bank, 2017, p. 12). Universities with agriculture programs are regulated by the Ministry of Higher Education and Scientific Research (MESRS), just like all other universities in the country.

23. In 1985, Kenya created the Commission for Higher Education to regulate the quality of private universities. In 2010, the Higher Education Act in Kenya renamed this agency, now the Commission for University Education, and reconstituted its mandate to assure quality not only in the private but also public institutions, which otherwise had no external accountability.

24. In Ghana, tertiary education is governed by the Ministry of the Education (MOE) with regulatory support from the National Council for Tertiary Education (NTCE) and the National Accreditation Board (NAB). Universities are established through acts of parliament and are governed by councils. Councils at the various universities are constituted by the vice chancellor, government appointees, council appointees, convocation members, student representatives and representatives of tertiary education related associations.

25. The National Council for Tertiary Education (NCTE) was established by an Act of Parliament which enjoins it to: (i) advise the Minister of Education on the development of tertiary education institutions in Ghana; (ii) recommend national standards and norms including standards and norms on staff, costs, accommodation and time utilization, for approval of the Minister of Education; (iii) monitor the implementation of any approved national standards and norms by the institutions; and to publish information on tertiary education in Ghana and (iv) oversee university curriculum and accreditation. 
26. In Malawi, public universities including LUANAR fall under the purview of the Ministry of Education, but LUANAR, as an agricultural university, is also connected to the Ministry of Agriculture, Irrigation, and Water Development.

27. In Mozambique, The Ministry of Science and Technology, Higher Education and Vocational Training is responsible for managing the universities in the country. The Ministry of Education is responsible for tertiary education standards, curriculum, and accreditation. The National Council of Higher Education is supposed to guide the universities. Though national guidelines exist, there is limited capacity to successfully implement these guidelines.

\section{Quality Assurance}

28. Global trends in quality assurance echo across Africa at national and regional levels. Increasing numbers of African governments have created national quality assurance agencies in just the last thirty years. The African Quality Assurance Network, established by the Association of African Universities, now lists quality assurance bodies in 34 countries, including Cameroon, Ghana, Kenya, Malawi, Mozambique (AfriQAN, 2018). In some countries, these agencies regulate not only private, but also public universities such as in Kenya as discussed above.

29. At the regional level, national quality assurance agencies are teaming up to standardize programs, among other reasons, to facilitate the mobility of students across borders. For instance, the Inter-University Council of East Africa, strives to "facilitate maintenance of internationally comparable education standards in East Africa so as to promote the region's competitiveness in higher education" (IECUA, 2018). IUCEA member university institutions has grown from 33 in 2000 to more than 100 at present.

30. In Côte D'Ivoire, MESRS created a Quality Assurance Department in 2016 but operation was begun only recently. Universities are required to have quality assurance units though most institutions in the country do not have a functioning unit yet. New degree programs must be approved by MESRS but once programs are created, the higher education institutions take control of the own curricula, including the schedule for curricular revision.

31. In Malawi, The National Council for Higher Education in Malawi oversees quality assurance at the national level for tertiary institutions. They are in charge of registering and accrediting higher education institutions in Malawi which includes institutional assessment as well as capacity building within institutions on what is required for evaluating quality assurance. LUANAR has its own quality assurance unit.

32. In Ghana, universities have implemented efforts to improve quality. At the University of Ghana, a Departmental Teaching Assessment Committee (DTAC) assesses and evaluates the performance of lecturers in conformity with international standards. At the Kwame Nkrumah University of Science and Technology (KNUST), internal periodic assessment of the teaching curriculum by the faculty provides quality assurance for tertiary agricultural education. At the University of Cape Coast (UCC), the 
Directorate of Research, Innovation and Consultancy (DRIC) ensures a thematic approach to all research conducted in the university. The directorate also provides regular support for competencebased activities by the various departments in the university.

33. In Kenya, stakeholders underlined the importance of understanding the center-universitynational context in higher education. National quality assurance standards seem to them to be prioritized over center-level standards. When a center's goals, processes, and especially Directorate of Research, Innovation and Consultancy (DRIC) monitoring and evaluation plans are not aligned with the broader expectations from Kenya's Commission for Higher Education for the host university, then ongoing center assessment is challenging.

34. The experience of the African Centers of Excellence (ACE) in Kenya demonstrates that the national quality assurance standards are powerful levers of change and that retrofitting brings undesired complexities. Initiatives to support universities are more likely to be successful if they design evaluation and quality assurance mechanisms that complement the demands, trends, metrics, and political dynamics of national and regional quality.

35. In Mozambique, The Higher Education, Science and Technology (HEST) project funded by The World Bank has sought to address these challenges. It helped to streamline the accreditation process and to create policies related to research quality, managing higher education statistics, and managing monitoring and evaluation (M\&E) system for higher education.

\section{Challenges to Change Management Created by Regulation}

36. While sound regulation is necessary and an important tool to help ensure the quality of higher agricultural education provided, it is important to understand the challenges that it creates in designing and implementing change in Universities. Specifically, these challenges relate to (i) reforming governance arrangements; (ii) changing leadership; (iii) changing curricula and research programs; (iv) improving university finances.

\section{(1) Reforming governance arrangements.}

37. In trying to improve the relevance of University education to the private sector, Universities may wish to reform the composition of their executive, including to bring in greater private sector representation from the agri-business sector. It would be important to examine the regulatory constraints to such initiatives and agree on solutions with regulators. For example, in Cote D'Ivoire, higher education institutions, both public and private, are created through a unique Presidential decree for each institution. The internal governing structure of higher education institutions is specified in brief in the Education Law and spelled out in detail in the decree. Under the law, each university must have a University Council presided over by the President of the institution. The institution's decree of establishment specifies the composition of the University Council, which consists primarily of representatives of various government ministries. In the university establishment decrees examined, the private sector was represented on the university's councils by the Chamber of Commerce and 
Industry and by the General Confederation of Enterprises of Côte d'Ivoire but not by individual companies.

\section{(2) Changing leadership.}

38. The extent to which parent ministries or regulators have control over changes in university leadership and the extent to which universities' governing body are politically appointed, both, influence how easily changes in university leadership can be implemented which is likely to be critical to efforts to reform higher agricultural education.

39. For example, in Malawi, universities appear to have a high level of independence in most hiring decisions but the ultimate decision on changes in leadership lies with politically appointees. Most decisions of the institution (including curriculum, hiring decisions, and other programmatic considerations) have final approval at the University Council which is politically appointed. For hiring decisions, these are made internally at the department level and then recommended to the faculty level, the VC level, and then Council endorses the decision. University Council makes decisions about the appointment of university leadership.

\section{(3) Changing curricula and research programs.}

40. The extent to which Universities are given flexibility to revise curricula varies between countries. For example, in Côte D'Ivoire, MESRS gives universities the flexibility to revise curricula after their initial creation and approval by MESRS. However overall, Deans and department chairpersons who were interviewed suggested that curricular revisions typically are initiated only every 4-6 years, impose additional demands on faculty, and require lengthy approval procedures which may add an additional year or two to the revision process.

(4) Improving university finances.

41. Regulation aims to ensure good value for money and therefore necessarily involves some regulation of University finances. However, reduced financial independence of a University, creates disincentives and obstacles to Universities identifying alternative sources of revenue or to design innovative financing arrangements that attract new students or to differentiate fees between different types of students to bring about greater inclusion from diverse backgrounds. The case of Côte D'Ivoire where government sets enrollment levels, tuition fees, and requires universities to turn over internally generated revenue to the national treasury, appears to quite restrictive, so any financial initiatives would need to be agreed with MESRS at an early stage in its conception that the University could reap the full benefits of its initiative.

\section{Performance Based Funding and Staff Contracts}

42. Performance based university funding and staff contracts are in their infancy in the countries studied. Potentially they provide an important incentive for faculty staff to align their efforts with university objectives. They could for example provide the necessary incentive for staff to refocus their 
efforts from research, which has traditionally driven promotion, to delivering high quality teaching which has reaped fewer rewards for staff in the past.

43. In Côte D'Ivoire, the government has not implemented performance-based contracts (PBCs) with higher education institutions, though the idea has been under discussion for several years. MESRS is now in the process of developing plans and procedures for PBCs. If implemented, the new system would require institutions to negotiate performance targets with the government and funding of higher education institutions would be based on the extent to which the institution achieves its targets.

44. One of the barriers to adoption of performance-based contracts in Côte D'Ivoire is that members of academic staff in Côte d'Ivoire's public universities, including UFHB and INPHB, are employees of the Ministry of Higher Education and Scientific Research and are represented by one or more unions, thus giving them substantial independence from university deans, directors, and presidents. This independence weakens the capacity of university administrators to bring about change. However, performance-based contracting, if implemented, can help overcome the weak commitment of university employees to their own institution and its goals and thus provide a compelling rationale for change in organizational culture, or mindset.

45. Performance based contracting could also help to address the burden placed on universities by the pursuit of supplemental income by members of academic staff which is a major diversion from core teaching and research responsibilities in Côte d'Ivoire. Many lecturers and professors supplement their base salaries by taking on a teaching load in excess of the normal load within their own institution or at another institution. It is also common for members of academic staff to operate their own private schools and universities, especially the private grandes écoles, as a source of income. Because of its concentration of population, Abidjan offers more opportunities for "moonlighting" than Yamoussoukro, and therefore it is expected that distractions from core university responsibilities are likely to be greater at UFHB than at ESA.

46. In Malawi, LUANAR has recently adopted a performance management system and it in its first year of rolling out. Under this new system, they are beginning to institute performance-based salaries, but this is not yet in place. There is currently a general evaluation of performance on contributions to science (publications and outreach), resource mobilization, and seniority which influences salary decisions.

47. The new performance evaluation system at LUANAR would require staff to set performance targets in the areas of teaching, research, outreach, and resource mobilization for each semester which include specific deliverables. These would be negotiated by the staff member and their manager. Staff will be evaluated every six months through a participatory appraisal process (between the staff member and their manager) with results being submitted to human resources for review. The overall performance management system was adopted from the private sector, and some staff members expressed the need to ensure it is adequately adapted to an academic context which may require more 
flexibility and different incentives. In addition to salary and promotion incentives, there was indication that benefits like staff development opportunities would also be considered.

\section{Relevance And Quality}

48. There is a consensus among alumni and agribusiness companies in that current university agriculture education tends to be overly theoretical, unapplied, and/or outdated. This section address some of the challenges universities face in responding to calls from industry for students who are better equipped to apply their academic knowledge in practice and who have the soft skills to operate within businesses teams. In the countries studied, these are well recognized challenges and efforts have been made to respond to them. Nevertheless, the systematic use of analytical tools to assess agri-food sector skills needs and feedback into the design of curricula and research programs is inadequate and there is clearly a need to strengthen arrangements for implementation of experiential learning and internships.

\section{Designing More Relevant Courses}

49. The first challenge in enhancing the relevance of university education is to understand the fields in which students are being employed, what tasks and responsibilities they will have in those jobs and what skills they will need to be successful in these jobs. Tracer studies that track where students are employed when they graduate and occupational studies to provide a detailed understanding of the task involved in specific jobs would greatly inform efforts to increase the relevance of higher agricultural education but such a rigorous approach appears to be uncommon. A second challenge is to bring expertise from the private sector into curricula design and delivery to help ensure that the content is sufficiently relevant and to provide a private sector perspective to course delivery.

50. In Côte D'Ivoire, there are no official statistics on the rates of employment or unemployment of higher education graduates. None of the higher education institutions in the country have conducted tracer studies of graduates in recent years, according to various informants interviewed for this report. The Director of ESA reported that approximately $80 \%$ of its graduates are employed. UFHB has no statistics on employment of its agricultural graduates.

51. In Malawi LUANAR collect labor market information in several ways. It conducted an alumni tracer study of their 2013 and 2014 graduates which was published in 2016 and used as data when putting together their new strategic plan. It also has a process in place for stakeholder engagement into curricular reform (although this has been done differently in different departments/fields with varying results).

52. Regarding curricula design in Malawi, the nutrition department at LUANAR has done significant work to engage with stakeholders around program decision and curriculum. They are actively involved in a stakeholder committee at the national level which provides a platform for engagement amongst those based at LUANAR and external stakeholders.

53. In Kenya, efforts have been made to strengthen capacity for curricula design to enhance relevance and quality. The University of Nairobi recently established a Center for Pedagogy and 
Andragogy launched in 2015. The center's mandate is to "train academic staff in pedagogy which include provision of knowledge and skills in the areas of curriculum development, effective teaching in higher education, incorporation of mentorship in teaching and, assessment and evaluation of learning outcome" (UoN website). Center staff are endeavoring to create a unique approach and methodology of pedagogies which will be branded as the "University of Nairobi Approach."

54. Looking beyond existing students, Text Box 24 describes efforts in Kenya to make education more relevant to communities who might not otherwise access it.

\section{Text Box 24 Non-traditional academic engagement in Kenya}

Private universities in Kenya are using new mechanisms to make education more relevant to communities who may not otherwise access their campuses. Many of these individuals are involved in agri-food businesses.

Strathmore University: Faculty from Strathmore's renowned business school recently launched a 'Street MBA' program. The program contextualizes business theory and entrepreneurial practices for small-business owners in the informal markets of the Kibera neighborhood just nearby campus. English curriculum was translated in Kiswahili, contextualized with local illustrations, and taught by faculty and advanced grad students. Many of the street MBA participants operate agri-food business. Program evaluation shows significantly improved business productivity for program participants.

United States International University: USIU recently launched an interdisciplinary capacity building program for medium and small microenterprise owners. The program was designed with government partnership so as to provide evidence for policy, which is presented via periodic 'Evidence to Action' workshops with policymakers. Also, in partnership with the World Bank, USIU recently launched the Kenya Youth Employment Opportunities project, which provides out-of-school youth training in life skills and business skills, and provides seed funding for start-up ventures, many of which are agribusiness. To incentivize support in this non-traditional academic engagement, USIU leaders are 'retooling' faculty and developing a new faculty evaluation framework that includes more targeted metrics and higher weight for industry and civil society engagement and supporting applied research opportunities.

\section{Experiential Learning and Internships}

55. Inadequate practical internship opportunities has been cited by higher agricultural educationists as the major reason for weak university-private sector linkages. Although the various universities ensure students undertake industrial attachments at the undergraduate level, there is inadequate supervision of students under internship. This is due to the high cost associated with effective student supervision during internship periods.

56. In Cote D'Ivoire good progress has been made in providing students with practical experience in entrepreneurship including through internships, business incubators and a university farm. In 2016, ESA began an agribusiness Master's program that includes entrepreneurship and UFHB has a Master's program in entrepreneurship on its main campus. At ESA, bachelor students in all degree programs are required to do a two-month internship in the first year, a one-month internship in the second year, and a six-month internship in the third year. ESA has a mixed farm of 77 hectares for teaching, research and development, short-term workshop training, and income generation. At UFHB, bachelor students enrolled in programs in the Biosciences Department are required to do a one-month internship, some of which take place in private firms. 
57. ESA has an incubator, begun in 2017 and financed by the African Development Bank, to help student entrepreneurs from INPHB and other universities and outsides, to analyze the market opportunities, prepare a business plan, and launch small enterprises. Guidance on entrepreneurship is provided by both faculty members at INPHB and owners and managers of businesses in Côte d'Ivoire. In 2018, ESA was selected to host the pilot phase of Enable Youth Côte d'Ivoire, a youth agribusiness entrepreneurship initiative developed by the International Institute of Tropical Agriculture that provides practical experience through businesses incubators and helps students source start-up new businesses. UFHB has had a business incubator at the Bingerville campus since 2013 financed by Cote d'Ivoire government in part to generate funds for the university. It supports business planning, prototyping, commercialization, and marketing.

58. In Malawi, practical training opportunities are built into all diploma and degree programs at LUANAR, however, the quality of the opportunities and their integration into the rest of the curriculum varies widely. Some of those hosting interns reported that they had had positive experiences and regularly interacted with the students' mentor. Others stated that the attachments were poorly supervised and students were not properly evaluated (e.g., the host organization supervisor had little opportunity to communicate performance to the LUANAR mentor). They also indicated that students were not appropriately prepared for the internship. Most came with little to no practical knowledge of the sector and some had had no guidance on professional behavior (showing up on time, professional attire, etc.). The AfDB Jobs for Youth program is currently undertaking research to potentially design a national internship program.

59. At the University of Ghana, second year students undertake a compulsory 6-week 3 credit hour practical agriculture program. Students visit the Forest and Horticultural Crops Research Center (FOHCREC), Livestock and Poultry Research Center (LIPREC) and Soil and Irrigation Research Center (SIREC) for practical tuition and examination. At the Kwame Nkrumah University of Science and Technology (KNUST), first year students undertake a compulsory practical course on the university farms. In the second year, they embark on a mandatory supervised industrial internship program to promote university-private sector linkage. Similarly, at the University of Cape Coast (UCC), second year agriculture students undertake a compulsory supervised industrial attachment with agribusiness firms.

60. Text Box 25 discusses some of the suggestions to improve experiential learning from faculty, students and employers during the country studies. 


\section{Text Box 25 Improving Student Internships in Agrifood Industry}

Findings from the country studies reveals the overwhelming need and value for university students to gain updated, practical training. The most common mode of delivery is internships and attachments. Faculty, students, and employers all shared ideas to improve student internships:

- $\quad$ Faculty share the time-intensive supervisory roles with advanced graduate students, who are betterpositioned to give and receive transparent feedback with students in cultures with high power distance.

- Increase communication between supervisors, typically one is from industry, the other from university. Invite IT students to create a mobile application for supervisors and students alike to share observations, industrybased challenges, proposed solutions.

- $\quad$ Place students in various parts of the value chain to broader exposure across the years of their program (as opposed to repeated placement in the same position)

- Centralize internship administration via a Career Development Center, which could serve as a bidirectional pathway for university and industry engagement.

\section{Collaboration}

61. This section describes the extent to which universities are drawing from and contributing to research and teaching of domestic and international universities and how they are extending their knowledge and ensuring their relevance through collaboration with other actors in AIS including agricultural research organizational, policy research units, ministries of agriculture and the private sector.

62. Universities have benefited from externally funded collaboration with regional and overseas universities such as on teaching masters' degrees, and support to research chairs. Collaboration with other actors in the AIS appears to be quite limited and ad-hoc meaning that the knowledge and expertise within universities is not permeating into the rest of the AIS to the extent that it could and that universities have fewer opportunities to learn from and tailor their teaching and research to the needs of the rest of the AIS.

63. Collaboration between universities and ministries of agriculture appears to be particularly weak, despite the fact that many ministry staff were educated in local agricultural universities. The exception is where agricultural policy units have provided a medium through which academic knowledge can influence policy reform but the development of these units has often been highly dependent on external funding from development agencies.

\section{Collaboration with Ministries}

64. In Côte D'Ivoire, interaction between the universities and the government ministries, aside from the Ministry of Higher Education and Scientific Research, appears to be limited and sporadic.

65. In Malawi, Although LUANR practically produced all the senior officials of the Ministry, the ministry officials do not seem to have full faith in LUANAR as the producer of human resources for their sector. Much less trust exists when it comes to joint research between these organizations. 
LUANAR is seen by the ministry officials as doing research that is not highly relevant for solving the problems of smallholder farmers. Much of the research in LUANAR is seen as donor-driven. Several interviewees stated that LUANAR faculty members are disconnected from relevant ministry departments and do not play a central role in policy formulation, analysis, and/or implementation.

66. In Mozambique, collaboration between UEM and the research department at the Ministry of Agriculture and Food Security is limited. Research collaboration exists on a case by case basis between these organizations.

\section{Collaboration with Policy Units}

67. In Ghana, the Institute of Social Science and Economic Research is affiliated with the University of Ghana; in Kenya the Tegemeo Institute, is affiliated with Egerton University; and in Malawi the Center for Agricultural and Rural Development is affiliated with LUANAR. Affiliations between universities and African agricultural policy research institutes is a mutually beneficial collaboration that can considerably enhance both organizations operations. Household surveys and other data bases collected and shared by agricultural policy research institutes can enhance the quality of research carried out by faculty and students of the affiliated universities and the exchange of researchers between university departments and policy institutes can contribute exchange of ideas and methods to the programs of both organizations.

68. Text boxes 26 and 27 provide insight into some of the challenges of establishing such collaboration with reference to two country examples that followed different collaboration models: Tegemeo Institute in Kenya, that was initially established within Egerton University and the Indaba Agricultural Policy Research Institute in Zambia, that was established as an autonomous organization but collaborating closely with UNZA.

69. These examples underline the importance of the collaboration in terms of (i) the university providing a supply of highly qualified researchers to the policy research institutions; (ii) the importance of data gathered by the policy research institutes for university research; (iii) creation of opportunities for university academics to apply their academic knowledge to the policy issues of the day and make them more relevant to decision makers and (iv) the important role of the university in advocating for the policy research institutes interests to government and donors and securing funding. They also draw attention to some of the challenges of such collaboration including: (i) achieving independent policy research while being affiliated with a public university; and (ii) dealing with tensions created by pay differentials between the two organizations sometimes driven by donor funding on policy research institutes and short-term consulting opportunities.

\section{Collaboration with Research Institutes and Extension Services}

70. In Cote D'Ivoire, between universities and the national agricultural research system, the National Center for Agricultural Research (CNRA), there is a great deal of interaction involving the post-graduate training of students from ESA, UFHB, and UNA. Interaction between the universities and the agricultural extension agency (ANADER) appears limited. 
71. In Ghana, the Planting for Food and Jobs program was initiated in 2017 to facilitate national economic transformation. The policy seeks to promote research extension linkages by providing linkage between researchers and farmers in mitigating risks and threats and refining current agronomic practices. The program secretariat is collaborating with the University of Ghana, KNUST, UDS and various research institutions to breed high-yielding maize and soybean seeds to distribute to program beneficiaries.

72. In Malawi, TVET came out as an area where there is significant, largely untapped, opportunity for impact in the agri-food sector. There is significant interaction between Malawi's TVET system and LUANAR's Natural Resources College around curriculum development on climate smart agriculture and agro-processing.

\section{Collaboration between Local Universities}

73. In Cote D'Ivoire, the most frequent interaction among Côte d'Ivoire universities, including UFHB and ESA, occurs through individual teachers teaching courses in other universities. This interaction is generally not the result of planned inter-institutional collaboration but is rather a response to the mismatch between demand and supply of instructors within institutions. Both UFHB and ESA report that they collaborate with each other on research projects, especially large ones, though the number of researchers involved in inter-university collaborations appears to be very small.

\section{Collaboration with Universities in the Region}

74. The high costs of training Africans in most "northern" universities means that roughly seven graduates could be produced in African universities for the cost of one graduate educated in the US or UK. External priorities and resources are shifting to redirect African graduate students from the US and UK to less expensive options, such as in China and African universities themselves. So, incentives for faculty (including emeritus faculty) in non-African universities can be explored to relocate international expertise at African universities as a means of maintaining quality education at much lower costs per student enrolled.

75. In Cote D'Ivoire, both ESA and INPHB report that they collaborate with other university in the West Africa region through enrollment of students from other countries, student exchanges, joint degree programs, faculty exchanges, and research.

76. ESA is part of a collaborative Master's program in agribusiness with a university in Benin (Abomey-Calavi) and a university in Niger. The program brings students those countries to the ESA campus for coursework. ESA also participates in a program that brings students to the school from Congo, Comores Islands, and other countries, financed by their governments.

77. UFHB reports having collaborated with universities and research institutes in Benin, Burkina Faso, Senegal, Senegal, Conakry, and Togo. 


\section{ANNEX 2 SKILLS DEMANDED BY AGRIBUSINESS FIRMS: SURVEY RESULTS}

1. This annex presents the results of a survey conducted to assess agribusiness skills needs. A fivequestion survey was implemented to representatives of agribusiness firms operating in three countries: Kenya, Cote d'Ivoire and Malawi. Most questions used a Likert scale of 1 to 5, with 5 being most important and 1 being not important. Results presented in this section are based on 44 respondents. Of these, 35 operated in or were based in Kenya. Nine respondents represented firms that operated in multiple countries including Kenya, Malawi, Nigeria, Rwanda, South Africa, Tanzania, Uganda and Zambia. Five respondents represented firms based in Cote d'Ivoire, while one respondent was based in Malawi.

2. Table 2 describes the types of agribusiness firms responding to the survey. Seed and agro-input suppliers and members of business associations were the most frequently represented. Eight respondents represented firms involved in agricultural production. Seven respondents were wholesalers and processors in the downstream stages of the food system.

Table 2 Composition of businesses surveyed

\begin{tabular}{ll}
\hline Type of business & number surveyed \\
\hline Producer & 8 \\
Wholesaler & 2 \\
Processor & 5 \\
Seed or agro-input Supplier & 12 \\
Agricultural finance & 1 \\
Other & 3 \\
Business Association & 13 \\
\hline Total & 44 \\
\hline
\end{tabular}

Note: the question in the survey was "please indicate the nature of your business?"

3. Table 3 provides a ranking of respondents' views about the relative importance of various skill sets to agribusiness firms. The highest rankings were given to "ability to communicate effectively" and "soft skills" (good work habits, show up on time, reliable, adaptability, team player, etc.). These responses indicate that firms' most important trait in prospective employees are not necessarily related to technical expertise but rather good communications skills, work ethics, and adaptability. Undergraduate courses along the lines of "succeeding in the business world" or opportunities for mentorship from successful business people in HAE institutions could be considered to shore up these skills among students. 
Table 3 Agribusiness firm respondent's ranking of importance to the question: "Over the next decade, which kind of employee skills will be most highly valued by your business?"

\begin{tabular}{llccc}
\hline Skill type & Min & Max & Mean & $\begin{array}{l}\text { Std } \\
\text { Dev }\end{array}$ \\
\hline Ability to communicate effectively & 2 & 5 & 4.29 & 0.73 \\
Agri-business management skills & 1 & 5 & 4.12 & 1.02 \\
Economics analysis and market projections skills & 1 & 5 & 4.06 & 1.14 \\
Ag technical /vocational/extension skills / "how to" skills & 1 & 5 & 4.06 & 1.17 \\
$\begin{array}{l}\text { Ag science skills: e.g., seed breeding, agro-biology/chemistry, other kinds } \\
\text { of R\&D }\end{array}$ & 1 & 5 & 3.58 & 1.36 \\
Food science, handling and processing technologies & 1 & 5 & 3.25 & 1.32 \\
Computer skills for data analysis (spreadsheets, statistical packages, etc.) & 1 & 5 & 3.79 & 1.2 \\
"Soft" skills (good work habits, show up on time, reliable, etc.) & 2 & 5 & 4.28 & 0.84 \\
\hline
\end{tabular}

4. Other skills deemed important, on average, were related to agribusiness management, economic analysis and market projection skills. Not all firms ranked these skills highly, but they received more "highly important" rankings than "ability to communicate effectively". These responses indicate a demand for employees that can scan the environment to identify profitable business investments in agrifood systems, and skills in running aspects of a business. The importance attached to these skills is not considered surprising, and many HAE institutions already focus on providing these skills. However, these skills were considered most difficult to find among university graduates. In response to the question "Which of these skills is most difficult to find among university under-graduates for agrifood system related jobs in this region?", effective economic and market projection analytical skills received highest score, with business acumen and soft skills receiving the next highest scores.

5. The private sector respondents also highly ranked "how to" skills in agricultural operations, such as expertise in cultivation, soil management, vocational and technical skills that are imparted through TVETs. Unfortunately, many African countries have very few and often poorly functioning agricultural technical, vocational, and extension training schools. University efforts to contribute to the formation and functioning of TVETs may be an area for consideration for future support initiatives.

6. Somewhat less important, but still valued by many respondents, were skills related to agricultural sciences (seed breeding, agro-biology/chemistry, other kinds of R\&D), food science, handling and processing technologies, and computer skills for data analysis.

7. Table 4 shows the distribution of scores in response to the question "Over the next decade, which kind of employee skills will be most highly valued by your business?" While effective communication received the highest average rankings, the highest percentage of " $5=$ most important" 
responses were given to soft skills, agribusiness management, and hands-on practical skills in agricultural operations.

Table 4 Over the next decade, which kind of employee skills will be most highly valued by your business?

\begin{tabular}{|c|c|c|c|c|c|}
\hline Skill category & $\begin{array}{l}\text { Least } \\
\text { Important } \\
(1)\end{array}$ & 2 & $\begin{array}{l}\text { Somewhat } \\
\text { Important } \\
\text { (3) }\end{array}$ & 4 & $\begin{array}{l}\text { Most } \\
\text { Important } \\
(5)\end{array}$ \\
\hline Ability to communicate effectively & $0.0 \%$ & $5.9 \%$ & $0.0 \%$ & $58.8 \%$ & $35.3 \%$ \\
\hline Agri-business management skills & $5.9 \%$ & $0.0 \%$ & $5.9 \%$ & $35.3 \%$ & $52.9 \%$ \\
\hline Economics analysis and market projections skills & $6.3 \%$ & $6.3 \%$ & $6.3 \%$ & $37.5 \%$ & $43.8 \%$ \\
\hline $\begin{array}{l}\text { Ag technical /vocational/extension skills / "how } \\
\text { to" skills }\end{array}$ & $6.3 \%$ & $6.3 \%$ & $6.3 \%$ & $31.3 \%$ & $50.0 \%$ \\
\hline $\begin{array}{l}\text { Ag science skills: e.g., seed breeding, agro- } \\
\text { biology/chemistry, other kinds of R\&D }\end{array}$ & $12.5 \%$ & $12.5 \%$ & $6.3 \%$ & $37.5 \%$ & $31.3 \%$ \\
\hline $\begin{array}{l}\text { Food science, handling and processing } \\
\text { technologies }\end{array}$ & $18.8 \%$ & $6.3 \%$ & $37.5 \%$ & $18.8 \%$ & $18.8 \%$ \\
\hline $\begin{array}{l}\text { Computer skills for data analysis (spreadsheets, } \\
\text { statistical packages, etc.) }\end{array}$ & $5.9 \%$ & $11.8 \%$ & $11.8 \%$ & $35.3 \%$ & $35.3 \%$ \\
\hline $\begin{array}{l}\text { "Soft" skills (good work habits, show up on time, } \\
\text { reliable, willingness to cooperate, team player, } \\
\text { etc.) }\end{array}$ & $0.0 \%$ & $5.9 \%$ & $5.9 \%$ & $35.3 \%$ & $52.9 \%$ \\
\hline
\end{tabular}

To assess specific fields, respondents were asked "Which specific knowledge competency areas would you like to see more emphasis placed on in higher education to prepare graduates to work in your business?" Table 5 presents the descriptive results. The most important fields based on mean scores were related to agricultural extension services, water and soil fertility management, ability to use information communication technologies (ICTs), consumer and market demand trends, adaptation to climate change, and post-harvest storage technologies. The lowest scores for greater focus in university education were in hands-on skills (e.g., ability to utilize and repair machinery, possibly because this is perceived to be the domain of agricultural TVETs, and not higher education) and food science/nutrition. 
Table 5 Which specific knowledge competency areas would you like to see more emphasis placed on in higher education to prepare graduates to work in your business?

\begin{tabular}{|l|l|l|l|l|}
\hline Field & Min & Max & Mean & Std Dev \\
\hline Plant breeding & 1 & 5 & 3.53 & 1.29 \\
\hline $\begin{array}{l}\text { Ability to utilize and repair machinery in agriculture } \\
\text { (e.g., tractors, irrigation equipment, dryers, processing) }\end{array}$ & 1 & 5 & 3.24 & 1.52 \\
\hline Extension services for farmers & 1 & 5 & 4.31 & 1.04 \\
\hline Water and soil fertility management & 2 & 5 & 4.31 & 0.85 \\
\hline Consumer and market demand trends & 2 & 5 & 4.19 & 0.88 \\
\hline Business/economics/accounting skills & 1 & 5 & 3.69 & 1.1 \\
\hline Financial, insurance and market risk management tools & 1 & 5 & 3.93 & 1.24 \\
\hline Food science, food technology and human nutrition & 1 & 5 & 3.4 & 1.36 \\
\hline Adaptation to climate change & 1 & 5 & 4.2 & 1.22 \\
\hline Post-harvest storage technologies & 1 & 5 & 4.2 & 1.17 \\
\hline Human resource management & 1 & 5 & 3.2 & 1.28 \\
\hline ICTs in agriculture and food systems & 2 & 5 & 4.25 & 0.83 \\
\hline
\end{tabular}

8. Table 6 shows the dispersion of 1-5 scores for these fields. The insight from this table is that every single field received a " $5=$ most important" response from at least a few agribusiness firms. And most of the identified fields, even the ones ranked highest on average, were considered of only limited importance by at least a few firms. We conclude from this that agribusiness firms are diverse in their work force needs. While soft skills were generally ranked as very or highly important, the technical needs of agribusiness firms differed widely depending on their specific type of business. 
Table 6 Which specific knowledge competency areas would you like to see more emphasis placed on in higher education to prepare graduates to work in your business?

\begin{tabular}{|c|c|c|c|c|c|}
\hline \multirow{4}{*}{ Skill area } & \multicolumn{5}{|l|}{ Loss } \\
\hline & \multicolumn{4}{|l|}{ Emphasis } & \multirow{3}{*}{$\begin{array}{l}\text { Most } \\
\text { Emphasis } \\
\text { Needed (5) }\end{array}$} \\
\hline & Needed & & & & \\
\hline & $(1)$ & 9. $\quad-2$ & 10. -3 & 11. -4 & \\
\hline Plant breeding & $11.76 \%$ & $5.88 \%$ & $29.41 \%$ & $23.53 \%$ & $29.41 \%$ \\
\hline $\begin{array}{l}\text { Ability to utilize and repair } \\
\text { machinery in agriculture (e.g., } \\
\text { tractors, irrigation equipment, } \\
\text { dryers, processing, etc.) }\end{array}$ & $23.53 \%$ & $5.88 \%$ & $23.53 \%$ & $17.65 \%$ & $29.41 \%$ \\
\hline Extension services for farmers & $6.25 \%$ & $0.00 \%$ & $6.25 \%$ & $31.25 \%$ & $56.25 \%$ \\
\hline $\begin{array}{l}\text { Water and soil fertility } \\
\text { management }\end{array}$ & $0.00 \%$ & $6.25 \%$ & $6.25 \%$ & $37.50 \%$ & $50.00 \%$ \\
\hline $\begin{array}{l}\text { Consumer and market demand } \\
\text { trends }\end{array}$ & $0.00 \%$ & $6.25 \%$ & $12.50 \%$ & $37.50 \%$ & $43.75 \%$ \\
\hline $\begin{array}{l}\text { Business/economics/accounting } \\
\text { skills }\end{array}$ & $6.25 \%$ & $12.50 \%$ & $6.25 \%$ & $56.25 \%$ & $18.75 \%$ \\
\hline $\begin{array}{l}\text { Financial, insurance and market } \\
\text { risk management tools }\end{array}$ & $6.67 \%$ & $6.67 \%$ & $20.00 \%$ & $20.00 \%$ & $46.67 \%$ \\
\hline $\begin{array}{l}\text { Food science, food technology and } \\
\text { human nutrition }\end{array}$ & $13.33 \%$ & $13.33 \%$ & $20.00 \%$ & $26.67 \%$ & $26.67 \%$ \\
\hline Adaptation to climate change & $6.67 \%$ & $6.67 \%$ & $6.67 \%$ & $20.00 \%$ & $60.00 \%$ \\
\hline Post-harvest storage technologies & $6.67 \%$ & $0.00 \%$ & $20.00 \%$ & $13.33 \%$ & $60.00 \%$ \\
\hline Human resource management & $6.67 \%$ & $26.67 \%$ & $33.33 \%$ & $6.67 \%$ & $26.67 \%$ \\
\hline $\begin{array}{l}\text { ICTs in agriculture and food } \\
\text { systems }\end{array}$ & $0.00 \%$ & $6.25 \%$ & $6.25 \%$ & $43.75 \%$ & $43.75 \%$ \\
\hline
\end{tabular}

12. The last question asked respondents to "please rate the importance of the following ways of developing a work force with the skills most valued by your business" (Table 7). On-the-job training received the greatest proportion of "most important" responses. Further analysis is needed to determine the extent to which on-the-job training is considered important because job skills are so context specific that on-the-job training is essential no matter how well HAE institutions prepare their graduates, and 
the extent to which on-the job training is considered necessary remedial action to address deficiencies in skills that could or should have been conferred in HAE institutions.

13. The HAE institutions receiving the greatest proportion of "most important" responses were TVET schools, signifying the importance of hands-on practical implementation skills associated with operating farms and agricultural businesses. Better quality undergraduate education was considered either highly or extremely important by about 80 percent of respondents. Relatively less importance was directly attached to primary or secondary school education. We hypothesize that these results may differ if greater numbers of informal sector agribusiness firms were included in the sample, given that most small and medium-scale enterprises in African agrifood systems employ people with only primary or secondary school educations.

Table 7 Please rate the importance of the following ways of developing a work force with the skills most valued by your business.

\begin{tabular}{llllll}
\hline & $\begin{array}{l}\text { Least } \\
\text { Important } \\
\text { (1) }\end{array}$ & (2) & $\begin{array}{l}\text { Somewhat } \\
\text { Important } \\
(3)\end{array}$ & (4) & $\begin{array}{l}\text { Most } \\
\text { Important } \\
\text { (5) }\end{array}$ \\
\hline $\begin{array}{l}\text { Better quality primary and } \\
\text { secondary school education }\end{array}$ & $12.5 \%$ & $0.0 \%$ & $37.5 \%$ & $25.0 \%$ & $25.0 \%$ \\
$\begin{array}{l}\text { Better quality undergraduate } \\
\text { university education }\end{array}$ & $0.0 \%$ & $0.0 \%$ & $12.5 \%$ & $37.3 \%$ & $56.5 \%$ \\
$\begin{array}{l}\text { Ag technical, vocational, and } \\
\text { education training (TVET) schools }\end{array}$ & $0.0 \%$ & $0.0 \%$ & $20.0 \%$ & $13.5 \%$ & $66.5 \%$ \\
$\begin{array}{l}\text { On-the-job training within your } \\
\text { firm }\end{array}$ & $0.0 \%$ & $0.0 \%$ & $0.0 \%$ & $33.3 \%$ & $72.8 \%$ \\
$\begin{array}{l}\text { Internships, university or TVET } \\
\text { students volunteering their time in } \\
\text { exchange for mentorship and skill } \\
\text { training by members of your firm }\end{array}$ & $0.0 \%$ & $6.3 \%$ & $18.8 \%$ & $39.5 \%$ & $41.5 \%$ \\
\hline
\end{tabular}

To summarize these results, agribusiness firms are seeking a wide variety of diverse skills from prospective employees. Good communications and soft skills are highly valued by almost all private sector firms. Many of them view skills offered by agricultural technical, TVET schools as particularly important because of their hands-on relevance. But many other firms seek strong training in business management, economics, and agricultural sciences. On-the-job training is considered most important, which might reflect a view of some deficiencies in the current university and/or TVET systems. 


\section{ANNEX 3 APPROACH TO UNIVERSITY TRANSFORMATION}

1. This section presents a conceptual framework of organizational learning for transformation of African universities, followed by description of a practical mechanism for universities to "learn how to learn" as organizations. The goal of organizational learning in the higher education context is for universities to develop the ongoing capacity to know the evolving skill, knowledge, and technology needs of their students and external stakeholders and to develop the capacity to meet those needs through teaching, research, and outreach.

\section{A Framework for Conceptualizing University Transformation}

2. The country background studies for this study revealed a "relevance gap" between the training and research provided by local universities and the needs of the economy. African universities can reduce this gap by developing the capacity for organizational learning, defined here as a continuous process of adapting systemically to internal and external forces that stand in the way of a university achieving economic relevance and academic excellence in its programs. Many types of organizations have adopted organizational learning to make internal improvements over the past two decades, but the discussion here focuses on its application in the higher education context (Tagg 2007; Senge 2006; Dodgson 1993).

3. Nearly all African universities are teaching organizations in the sense that teaching is their primary activity. Many universities on the continent also aspire to be research organizations and some have increased their research productivity to the point that they are now recognized globally. Few African universities, however, are learning organizations, as defined above, with processes in place for the university to systematically assess whether its students are acquiring the knowledge and skills expected by employers and whether its research is addressing and helping to solve the most pressing problems of the local economy and society.

4. A university that strives to be a learning organization no longer adopts the traditional approach to classroom instruction in which curricular planning and class preparation is teacher-centric, focusing on "what teachers teach". Instead, instructional planning by both the university and the individual instructors is learner-centric, focusing on "what students learn". Planning for course content and instructional methods begins with specific learning objectives and ends with assessment of whether the student has actually mastered the targeted knowledge and skills. For example, if employability of graduates is a goal of the academic program, learning objectives are developed through careful analysis based on frequent dialogue with employers and tracer studies of graduates to ensure that the content is adequate for achieving that goal. If students are failing to reach a defined standard of learning, internal feedback mechanisms within the instructional program are in place for shifting to more effective pedagogical methods. A university with a learning-organization orientation also has feedback mechanisms in place for systemically guiding and assessing its research to ensure both relevance and scientific rigor. 
5. For a university to become a learning organization requires internal transformation in mindsets and other aspects of internal culture. For universities to become learning organizations, they must develop ongoing processes to listen to their stakeholders, especially students and employers, and bring them into the ecosystem of learning as active partners. This requires more than just occasional interaction. Universities should develop the capacity to elicit ongoing and frequent feedback from intended beneficiaries of their programs and to engage in continuous monitoring, improvement, and adjustment to meet stakeholder needs.

6. Organizational learning is not a matter of adopting the "right" plan, curriculum, or program. It cannot be done by merely copying what has been done by other universities, even the most highly respected ones. Instead, organizational learning is experiential learning through search for strategies, structures, programs, and support systems that are "fit for purpose". Organizational learning leads to local managerial and programmatic relevance and competence, a deeper and more enduring kind of capacity building than is acquired through mimicry of external solutions. Though a university with a learning organization orientation may examine external solutions to expand its awareness of options, it probes outside solutions methodically, experiments with them, and adapts them so they fit the local context and so the tacit knowledge needed for implementing them successfully can be developed by persons within the university.

7. The diagram below, Figure 17, shows three styles of leadership in higher education, each responding to a different set of concerns. Leaders are defined here as persons who are formally appointed or elected as well as persons who lead informally through their influence on others. Leaders exert control or influence over administration, infrastructure, teaching, research, outreach, and all other aspects of a university. 


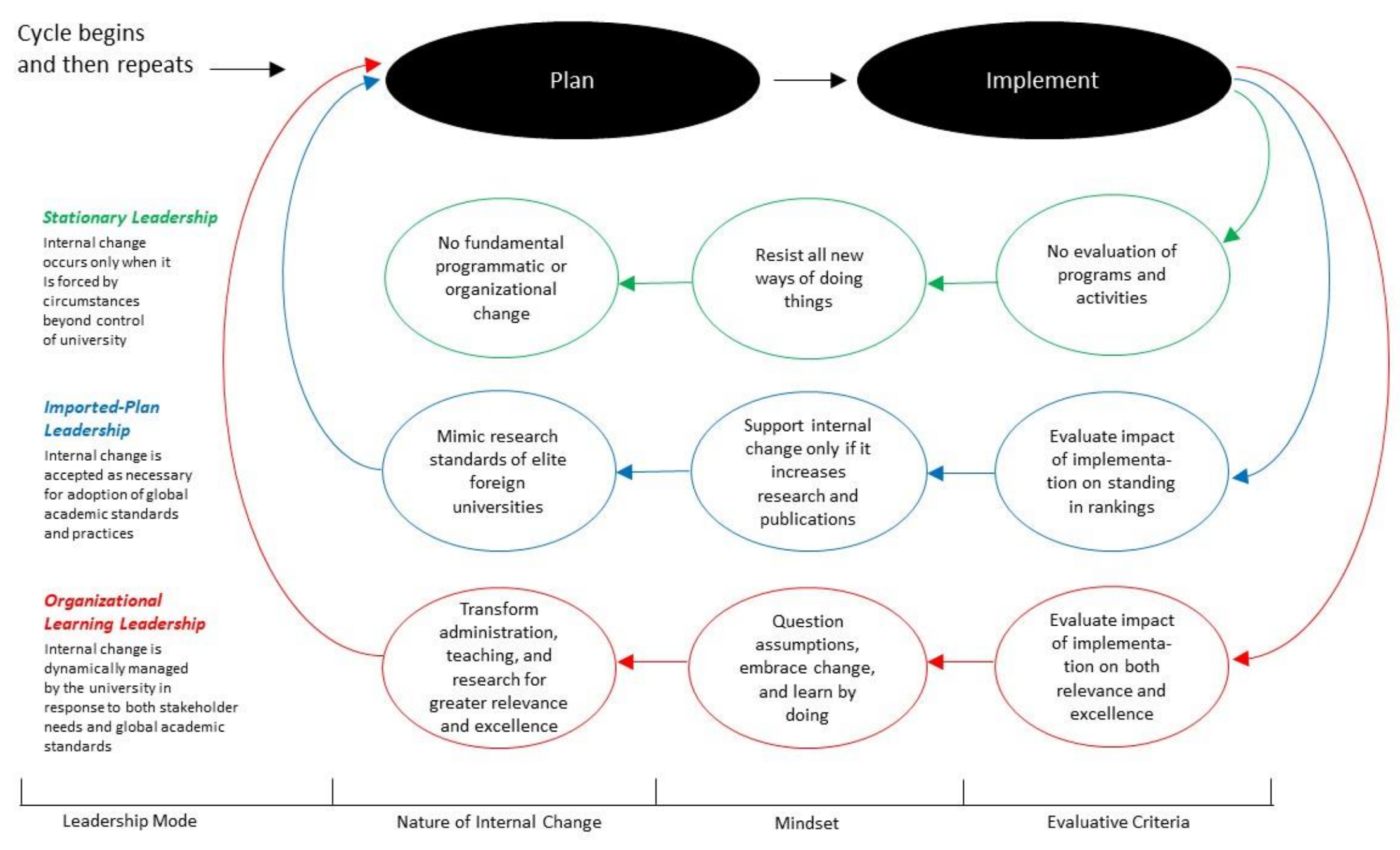

Source: David Kraybill 
8. A university with a stationary leadership style resists internal change until it is forced by circumstances, which can be external, internal, or both. Generally, such a university invests little or nothing in planning capacity and processes. When change becomes unavoidable, planning efforts are focused on keeping things as similar to the past as possible. Implementation of change is haphazard with little attention to accountability. During and following implementation, no attempt is made to evaluate the efficiency, effectiveness, or impact of the implementation effort. The mindset of leaders is to resist new ways of doing things. Change is not accepted willingly and therefore no organizational learning takes place. Any internal changes that are allowed to occur are minor and seldom correct the problems that motivated the change. No new planning is undertaken until it is forced upon the university.

9. In contrast, a university with imported-plan leadership accepts and even embraces a limited set of internal changes as long as those changes are consistent with the types of plans and programs adopted from other universities or outside experts. Implementation of planned change is evaluated according to whether it improves the university's standing in international, continental, regional, or national university rankings, most of which emphasize research rather than teaching or community engagement. University leaders operating in the imported-plan leadership style pay relatively little attention to local relevance of either teaching or research. Instead, the imported-plan university aspires to be a faithful importer of the organizational and programmatic models adopted by leading global research-oriented universities.

10. A university with organizational learning leadership embraces internal change in pursuit of goals it has chosen through dialogue with stakeholders, including students, staff, employers, alumni, government, international academic partners, and donors. Both local needs and global academic standards are viewed as important. Instead of trying to adopt the "right plan" and follow it rigidly, leaders of the university adopt flexible processes of planning and experimentation that facilitate systems thinking and team learning. The leaders aspire for both individual employees and the university as an organization to acquire experience and wisdom about how to plan and implement academic programs and activities. Feedback, evaluation, and opportunities to correct weaknesses are built into the design of programs and activities. Leaders promote a mindset that encourages people throughout the university to question the standard assumptions, scan the horizon for innovations, and experiment with new ways of doing things. They view all academic and administrative activities of the university as laboratories where lessons can be learned with the aim of improved teaching and research and better management of people and resources.

11. Changing higher education requires advanced leadership skills given the decentralized organizational nature of universities. Worldwide, among the faculty and staff of a typical university, there are multiple and even conflicting aims and goals, multiple approaches to teaching and research, and diffuse and shifting responsibility, leading some organizational 
analysts to refer to universities as "organized anarchies" (Cohen, March, and Olsen 1972). Such an environment, while arguably conducive to scholarship, is an organizational ecosystem in which change cannot be brought about by a heavy hand at the top. The de facto goals of the university and the way those goals are achieved is the result of "multitudinous individual decisions at the level of action" (Birnbaum 1989). University leaders, therefore, can bring about major changes only by enlisting the collaboration of individuals from various levels and parts of the university. Otherwise, change can be resisted and thwarted "at the level of action".

12. Leaders in higher education are nearly always academicians with little or no formal training in leadership theory and practice. Without understanding the range of possible management approaches, many academic leaders adopt the stationary leadership style described earlier in this section, deliberately aiming to make as little change as possible. This leadership style is not an approach that will solve the challenges facing African universities today. Other university leaders are more ambitious, adopting the imported-plan approach to leadership with the aim of copying the strategies and programs observed in globally-recognized university. However, efforts to reform organizations and institutions in developing countries by following imported plans seldom produce the intended results (Rodrik 2008; Webb 2008). Imported plans often fail because they do not fit the local context and because the leadership capacity to carry them out can only be acquired through experience. Both individual leader experience and organizational experience are vital for successful organizational reform.

13. Leadership training in African higher education should build the capability of leaders to transform their universities into learning organizations that can design and implement solutions that are fit for the local context. Teece (2018) contrasts ordinary leadership capabilities with dynamic capabilities. Ordinary capabilities come into play in the day-to-day functions of administration, operations, and governance where tasks and procedures are well delineated. Dynamic capabilities are required when change and uncertainty abound and when strategies, structures, programs, and resources must be reconfigured for organizational survival and revitalization. The dynamic capabilities framework focuses on three capabilities: sensing, seizing, and transforming (Teece 2018). Sensing involves data gathering and analysis, dialogue with internal and external stakeholders, identifying gaps between the university's performance and stakeholder expectations, identifying and prioritizing problems, identifying areas of potential expansion or necessary contraction, identifying alternative sources of revenue, and identifying potential partnerships with external stakeholders and other universities. Seizing is mobilization of people and resources to carry out the activities targeted through sensing. Seizing includes the design of solutions appropriate to the local context, the catalyzing of collaboration and active participation, and the securing of resources. Transformation is the alteration of organizational culture, the creation of shared values, the legitimizing of experimentation, the embracing of innovation, and the scaling up of change initiated through sensing and seizing. Text box 28 discusses innovation initiatives at LUANAR in Malawi. 


\section{Text Box 26 Innovative Scholars Program - Malawi}

At LUANAR, there have been a significant number of changeovers in leadership, not necessarily at the Vice Chancellor level, but at the DVC, Dean and Director levels where many of the decisions that impact implementation of policy are carried out. As new administrators come in, the trajectory and orientation of the institution can shift significantly.

Overall, LUANAR has introduced a number of new policies and are currently in currently in the process of developing their next strategic plan. They have an expressed desire to improve their rankings and international reputation and many of the reforms in policies and procedures that they are adopting are consistent with models from other universities and outside experts; however, there is major thread of ideas of local relevance that runs through the programming and policy changes underway. They do leave room in their curricular review processes for stakeholder input (more investigation should be done to ensure this input has an impact on the end result), they have requirements for internship or practical engagements for their students (while quality still varies widely across different programs), they have implemented some demand-driven programs in nutrition, veterinary medicine, agriculture extension and others, and there is an expressed desire on all levels of the institution to have a transformative effect on Malawi's agriculture sector (again, more data is needed to determine whether this is playing out on the ground).

In 2016-2017, two dozen administrators and researchers undertook a USAID-funded innovation scholars capacitybuilding program in line with the organizational learning approach. The program utilized human-centered design and systems-thinking frameworks to support the university's mission to equip graduates with the skills and mindset to solve the region's agricultural and natural resource challenges. The ISP had two tracks tailored to the differing needs of faculty members and administrative leaders so as to take a holistic approach to instituting gradual change within the university. The leadership track of the program was a key element. During the design phase the LUANAR ISP design team identified a persistent gap in past capacity development programming - failure to address institutional barriers to innovation. The goal of the program was to promote a process for planning and experimentation with a human-centered design (stakeholder engagement) approach which maps very well onto the "organizational experiment approach". There is some evidence of impact at LUANAR, but administrative turnover was a significant challenge especially with the leadership track. The program is now scaling up to Malawi University of Science and Technology, utilizing LUANAR program graduates as the facilitators of the program to build networking among Malawian institutions and increase the pool of leaders within the country that have this organizational transformation approach.

\section{A Practical Mechanism for Transforming Universities}

\section{Explicit and Tacit Leadership Knowledge}

14. Explicit knowledge of leadership can be transferred through books or workshops but tacit knowledge is know-how that cannot be transferred through words. It can be acquired only through disciplined practice and is the critical determinant of good versus mediocre performance in creative, problem-solving activities such as speaking a language, riding a bicycle, playing a musical instrument, performing surgery, or leading an organization (Helie and Sun 2010). Leadership requires both explicit knowledge and tacit knowledge (Lam 2010); the former can be learned through workshops while the latter requires practice, the effectiveness of which can be enhanced by guided reflection and coaching.

15. A study of institutional reforms, supported by the World Bank and other donors in more than 40 countries, concluded that few imported reforms achieve their goals (Andrews 2013). Neither importation of reform plans nor off-site leadership workshops have a good track record in bringing about organizational or institutional change (Doh 2001). Instead, organizational and institutional reform is best conducted through a process of problem-driven incremental change, 
abbreviated as PDIA (Andrews, Pritchett, and Woolcock 2013). PDIA builds the experience of leaders and their colleagues to solve organizational and institutional problems in the setting in which the problems occur. It begins with identification of a motivating problem and proceeds to development and refinement of solutions through a step-by-step process of experimentation (Andrews 2013). In essence, the target organization or institution becomes a laboratory for selftraining in tacit leadership knowledge and skills that can be acquired only through experience. Trainers facilitate selected aspects of individual and organizational learning but do not teach in the conventional workshop manner. Leadership experience and competence grow with each iteration of problem identification, experimentation, and scaling up. Through this process, leaders develop the dynamic capabilities required for organizational and institutional transformation.

\section{Organizational Experiments for On-site Leadership Self-training}

16. The tacit knowledge which is essential for relevance and excellence in higher education can be developed in African universities through organizational experiments. By solving problems experimentally, members of the university community "learn by doing". Experimentation allows formal and informal leaders to evaluate the merits of particular changes at a small scale before taking the risk of implementing them at a large scale. Based on the experience gained and the lessons learned, the experimental solutions can be expanded and made a formal part of the university.

\section{Protocol for Organizational Experiments}

17. A certain degree of rigor is required for experimentation to produce useful knowledge. A well-defined but flexible protocol should be followed for organizational experiments. Below (Table 8 ) is a description of an organizational experiment protocol originally developed during a transformation initiative at Sokoine University of Agriculture in Tanzania, with further refinements in the protocol made after the end of the project (Kraybill et al. 2017). The protocol has four stages.

18. Stage 1 is the organizing stage in which a formal or informal group of persons who care about an issue engage in a series of conversations to identify a problem within the university. These conversations require time and can take weeks or months to complete. To lead to action, the conversations must address topics that are important to members and central to the overall strategy of the university. It is best for group membership to be voluntary though appointment of one or more known "change agents" from within the university may be necessary to get the conversation started. Relevant information regarding the identified problem should be gathered and analyzed. Stakeholders from outside the university should be brought into the conversation whenever possible to counteract "insider myopia". Based on evidence and logic, the group proceeds to develop a concise statement of the problem. 


\begin{tabular}{|c|c|c|}
\hline Stage & Type & Procedures \\
\hline \multirow[t]{2}{*}{$\begin{array}{l}\text { Stage } 1 \\
\text { Organize }\end{array}$} & Step1 & $\begin{array}{l}\text { With a formal or informal group of persons who care about the issue, engage in } \\
\text { conversations that identify a problem within the university. Include outside stakeholders } \\
\text { where possible. Gather and analyze data regarding the problem and, based on the } \\
\text { evidence, develop a concise statement of the problem. }\end{array}$ \\
\hline & $\begin{array}{l}\text { Step } \\
2\end{array}$ & $\begin{array}{l}\text { Together as a group, agree to conduct an organizational experiment to find a solution to } \\
\text { the problem. Specify who is responsible and who will be involved in the experiment. }\end{array}$ \\
\hline \multirow{4}{*}{$\begin{array}{l}\text { Stage } 2 \\
\text { Experiment }\end{array}$} & $\begin{array}{l}\text { Step } \\
1\end{array}$ & $\begin{array}{l}\text { Brainstorm about potential solutions to the problem. From the candidate solutions, } \\
\text { chose the best one based on evidence and logic. }\end{array}$ \\
\hline & $\begin{array}{l}\text { Step } \\
2\end{array}$ & Develop steps and procedures for the organizational experiment. \\
\hline & $\begin{array}{l}\text { Step } \\
3\end{array}$ & $\begin{array}{l}\text { Identify internal and external challenges to successful implementation of the solution. } \\
\text { Use systems thinking. }\end{array}$ \\
\hline & $\begin{array}{l}\text { Step } \\
4\end{array}$ & $\begin{array}{l}\text { Implement the solution over a period of time. If the solution does not work as expected, } \\
\text { adjust it to improve it. }\end{array}$ \\
\hline \multirow[t]{2}{*}{$\begin{array}{l}\text { Stage } 3 \\
\text { Learn }\end{array}$} & $\begin{array}{l}\text { Step } \\
1\end{array}$ & $\begin{array}{l}\text { Document the final solution and analyze whether or not it works well enough to be scaled } \\
\text { up. If the evaluation is positive, proceed to scale it up. If the evaluation is negative, } \\
\text { analyze why it didn't work. Then, abandon the experiment or refine it further and } \\
\text { continue the experimentation. }\end{array}$ \\
\hline & $\begin{array}{l}\text { Step } \\
2\end{array}$ & $\begin{array}{l}\text { Reflect upon the experience gained by the organization and by individuals as a result of } \\
\text { the experiment. Identify the new knowledge and skills that have been acquired even if } \\
\text { the solution was not deemed successful. Identify additional problems that were } \\
\text { uncovered or better understood during the experiment. Apply these insights to the next } \\
\text { problem you tackle. }\end{array}$ \\
\hline \multirow{4}{*}{$\begin{array}{l}\text { Stage } 4 \\
\text { Scale-up }\end{array}$} & $\begin{array}{l}\text { Step } \\
1\end{array}$ & $\begin{array}{l}\text { Develop policies and procedures to make the solution part of the formal system of the } \\
\text { university. }\end{array}$ \\
\hline & $\begin{array}{l}\text { Step } \\
2\end{array}$ & $\begin{array}{l}\text { Identify units or individuals within the university who will be responsible for } \\
\text { implementation of the scaled-up solution and establish accountability criteria. }\end{array}$ \\
\hline & $\begin{array}{l}\text { Step } \\
3\end{array}$ & $\begin{array}{l}\text { Find a way to fund the scaled-up solution even if it is not possible to make it part of the } \\
\text { regular university budget (if funding is required). }\end{array}$ \\
\hline & $\begin{array}{l}\text { Step } \\
4\end{array}$ & $\begin{array}{l}\text { Evaluate the scaled-up solution before the next university budget is prepared. If } \\
\text { warranted by the evaluation, make the solution a part of the next funding cycle of the } \\
\text { university budget. }\end{array}$ \\
\hline
\end{tabular}

Source: developed by the author and others during the iAGRI project in Tanzania and further refined since then by the author.

19. Stage 2 is the experiment stage, in which potential solutions are identified and evaluated and the solution most likely to solve the problem while being scalable given available resources 
is chosen for implementation. Because an organizational experiment is an innovation, it may push against existing policies or norms. In this case, the support of the organization's formal leaders is especially important. Smallness is valuable at this stage because leaders may be willing to bend existing rules for a small-scale experiment though they would have not been willing to do so for a large-scale innovation. Furthermore, it is less costly to adjust and improve the solution while it is small.

20. Stage 3 is the learning stage in which the final and improved version of the solution is examined for potential scaling up. If the evaluation is positive, leaders can scale it up and support it with confidence that it will work. If the evaluation is negative, the experiment will end and the university will have been spared the cost and stress of an otherwise large failure. Whether it succeeds or fails, the lessons learned through the effort are valuable for the university and the individuals involved. Reflection on these lessons can help in tackling subsequent problems.

21. Stage 4 is the scaling-up stage in which the experimental solution, if successful, is made a formal part of the university. This often requires new policies or changes in existing policies. The evidence demonstrated by a successful experiment plays a vital role in facilitating the administrative and mindset changes required for scaling up. During this stage, the scaled-up solution must be assigned to a unit of the university for it to become permanent, and individuals must be assigned responsibility for implementation and monitoring. Funding must be found for implementation. If possible, it is best to fund the scaled-up solution from the university budget from the start. However, if this is not possible initially, temporary funding can be used and funding for it can be included during the next budget cycle. 


\section{ANNEX 4 INTERNATIONALIZATION AND SHIFTS IN THE DYNAMICS OF NORTH-SOUTH PARTNERSHIPS - DRIVING THE DEMAND FOR AFRICAN-LED SOLUTIONS}

1. It is widely acknowledged that quality higher education and research are key to development in Sub-Saharan Africa (SSA). In 2014, the World Bank initiated the Partnership for Applied Science, Engineering and Technology (PASET), to support efforts by African governments and their partners to strengthen the role of applied science, engineering, and technology in the development agenda. Makhtar Diop, World Bank's Vice President for the Africa Region, speaking at a higher education forum in March 2014 said: "To be more competitive, expand trade, and remove barriers to enter new markets, Africa must expand knowledge and expertise in science and technology...Building human capital in science and technology is critical to empower Africa to take advantage of its strengths". With agriculture still the main source of livelihoods in rural Sub-Saharan Africa (Davis et al. 2017) it is vital that agricultural and related STEM research is not neglected in this agenda, both as a way to strengthen the local knowledge base and capacity and to bring much needed technology transfer and innovation to improve smallholder agriculture in the field.

2. A joint report by the World Bank and Elsevier, "A decade of development in SubSaharan African Science, technology, engineering \& mathematics research" published in 2014, gives interesting pointers to the underlying issues affecting development of STEM and agricultural research in the different regions of SSA. The report shows that from $2003-2012$, SSA greatly increased both the quantity and quality of its research output with all three SSA regions (East, West and Central, and Southern Africa, excluding South Africa) more than doubling their yearly research output from 2003 to 2012. Indeed, SSA's share of global research increased from $0.44 \%$ to $0.72 \%$ during the decade examined. While the increase is impressive, this still accounts for less than $1 \%$ of global output for $12 \%$ of the global population. Unsurprisingly, considering the region's health challenges and the associated input of government and international funding, the majority of research output during this period has been in the Health Sciences, representing 45\% of all SSA research. STEM research on the other hand is lagging behind, representing only $29 \%$ of SSA research and a relative citation impact, considered to be a proxy for quality, 32\% lower than the global average. Agricultural research represents $32 \%$ of SSA's output during the same period. 
Figure 18 : Percentage of total article output by subject groupings for Africa regions and comparator countries 2012. Source: SCOPUS

\begin{tabular}{|c|c|c|c|c|c|c|}
\hline & $\begin{array}{l}\text { Southern } \\
\text { Africa }\end{array}$ & $\begin{array}{c}\text { East } \\
\text { Africa }\end{array}$ & $\begin{array}{c}\text { West \& Central } \\
\text { Africa }\end{array}$ & $\begin{array}{l}\text { South } \\
\text { Africa }\end{array}$ & Malaysia & Vietnam \\
\hline Physical Sciences \& STEM & $28.0 \%$ & $25.3 \%$ & $32.3 \%$ & $44.7 \%$ & $69.2 \%$ & $67.9 \%$ \\
\hline Agriculture & $33.4 \%$ & $34.4 \%$ & $28.2 \%$ & $22.9 \%$ & $15.3 \%$ & $22.0 \%$ \\
\hline Health Sciences & $44.8 \%$ & $47.8 \%$ & $43.1 \%$ & $26.5 \%$ & $13.1 \%$ & $16.5 \%$ \\
\hline Social Sciences \& Humanities & $17.5 \%$ & $15.4 \%$ & $14.0 \%$ & $21.8 \%$ & $19.4 \%$ & $8.4 \%$ \\
\hline Life Sciences & $15.7 \%$ & $15.0 \%$ & $15.2 \%$ & $8.7 \%$ & $5.1 \%$ & $8.6 \%$ \\
\hline
\end{tabular}

3. The three regions' impact in STEM and Agriculture, measured by Field-Weighted Citation Index (FWCI) is much lower than their overall average for all research subjects. For instance, Southern Africa's overall FWCI in 2012 was 1.39, but its FWCI in the Physical Sciences \& STEM was 0.94, just below the world average. Similarly, while the impact of research output in Agriculture grew at roughly the same rate as their overall research impact, the baseline impact for Agriculture was much lower than average.

4. However, data from the same report, this time using downloads from Science Direct as a more immediate measure of impact than citation, tell a slightly different story. Articles in STEM and in Agriculture are downloaded more often than the overall average across subjects and more so than articles in Health Sciences.

Figure 19: Downloads per article by subject grouping relative to regional averages for SSA regions and comparator countries, 2008-2012. Source: ScienceDirect.

\begin{tabular}{|c|c|c|c|c|c|c|}
\hline & \multirow{2}{*}{\multicolumn{2}{|c|}{ Physical }} & & \multicolumn{3}{|c|}{ Social } \\
\hline & & & & Health & Sciences \& & Life \\
\hline & All & Sciences & Agriculture & Sciences & Humanities & Sciences \\
\hline East Africa & 1.00 & 1.17 & 1.07 & 0.82 & 1.10 & 0.87 \\
\hline Southern Africa & 1.00 & 1.07 & 1.17 & 0.91 & 0.92 & 0.93 \\
\hline West \& Central Africa & 1.00 & 1.16 & 1.11 & 0.76 & 0.99 & 1.27 \\
\hline South Africa & 1.00 & 0.93 & 1.11 & 1.09 & 0.90 & 1.26 \\
\hline Malaysia & 1.00 & 0.94 & 1.41 & 0.89 & 1.39 & 1.30 \\
\hline Vietnam & 1.00 & 0.92 & 1.32 & 1.01 & 1.18 & 1.24 \\
\hline
\end{tabular}

8. Yet corporate users, whom we can consider to be potential future funders of R\&D, download Health research articles significantly more than Agriculture and STEM implying a paucity of knowledge transfer and collaboration between African academics in these latter disciplines and the corporate sector.

9. Data from the report support the view that research outputs are greatly determined by targeted international and national funding for research institutions with increased disciplinary allocation logically resulting in an increase in discipline-related research output. STEM seems to have particularly suffered from a lack of dedicated funding in contrast to health research which has benefitted considerably from a bias in funding in its favour resulting in a significant increase in its quantity and impact. 
10. The number of researchers in each discipline tends to mirror the flow of resources. In the majority of SSA countries the share of researchers in medical science and health far exceeds the share of researchers in engineering and technology though Kenya stands out as having significantly more researchers in agriculture than in health sciences. For STEM disciplines, the lack of research infrastructure and access to international databases and scientific literature can also be considered an important obstacle to progress in these areas of scientific research in SSA.

11. Sub-Saharan research is characterised by a very high level of international collaboration. According to the report, in $201279 \%, 70 \%$ and $45 \%$ of all research by Southern Africa, East Africa, and West \& Central Africa, respectively, was conducted through international collaboration. These collaborations were between 3.23 and 3.82 times as impactful as those respective regions' institutional collaborations underlining the key role of international collaboration in raising the citation impact of SSA scientific publications.

Figure 20: Level of international collaboration for SSA regions and comparator countries, 2003-2012. Source: Scopus

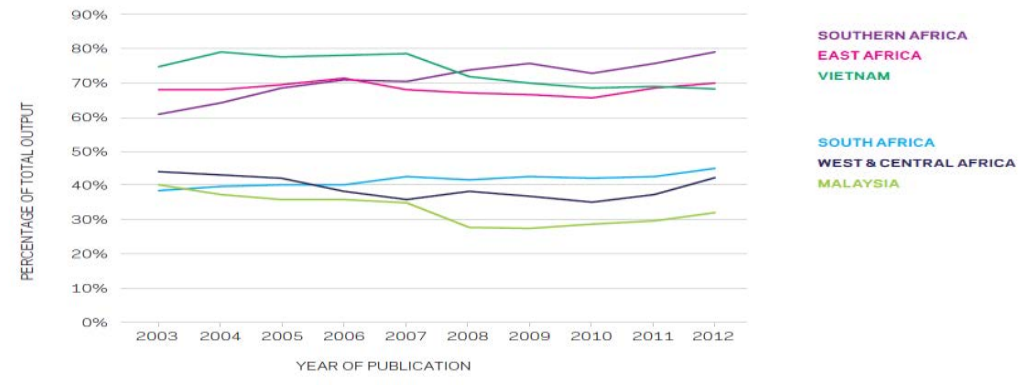

Figure 21: Adjusted Field Weighted Citation Index associated with different types of collaboration (e.g., FWCI for single-authored, intra-regional, and international collaboration normalized against FWCI of institutional collaboration) for SSA regions and comparator countries, 2012. Source: Scopus.

$\begin{array}{lcccc} & \text { Single Author } & \text { Institutional } & \text { Intra-regional } & \text { International } \\ \text { East Africa } & 1.08 & 1.00 & 1.03 & 3.23 \\ \text { Southern Africa } & 1.07 & 1.00 & 1.24 & 3.82 \\ \text { West \& Central Africa } & 1.13 & 1.00 & 0.92 & 3.64 \\ \text { South Africa } & 0.95 & 1.00 & 1.12 & 2.67 \\ & & & & \\ \text { Malaysia } & 0.62 & 1.00 & 0.93 & 1.34 \\ \text { Vietnam } & 1.18 & 1.00 & 1.02 & 1.92\end{array}$

12. International research collaboration is often catalysed by researcher mobility and indeed African researchers are highly mobile. The World Bank-Elsevier report found that transitory researchers - those who spend less than 2 years in or outside the region - comprise $57.2 \%$ and $65 \%$ of East Africa's and Southern Africa's total researcher base. A high percentage of SSA researchers are both non-local and transitory, spending less than 2 years at institutions in SSA. $39 \%$ and $48 \%$ of all East and Southern African researchers, respectively, fall into this category. 
The research productivity and impact of these mobile African researchers, including visiting faculty, is markedly higher than those of sedentary African researchers with sedentary researchers producing research that is between $33 \%$ and $57 \%$ less impactful than mobile researchers.

13. The high level of researcher mobility is likely to result from inadequate research infrastructure, fewer opportunities for $\mathrm{PhDs}$ and postdoctoral researchers, shortages in local funding, and international funding targeting international researchers. One particularly concerning consequence of this transient mobility is the lack of time to build meaningful collaboration with local companies and government.

14. West \& Central Africa displays a different pattern of researcher mobility with a higher share of sedentary researchers and a lower share of its research conducted through international collaboration. This situation may be explained by a Francophone research environment, when most international scientific collaboration is conducted in English, and regional political instability.

15. International research collaboration in SSA is marked by a strong North-South axis with very low levels of inter-regional collaboration within SSA. When no additional South African or international partner is present the level of inter-African collaboration is even lower, comprising only $0.9 \%$ of research in West \& Central Africa, 2\% in East Africa and 2.9\% in Southern Africa. International partners, and particularly OECD partners, thus seem to act as important brokers for inter-regional collaboration.

\section{Recommendations}

16. For Africa to realise its full potential as an innovator in African-led solutions for agriculture there is a need to develop durable local capacity, infrastructure and coordinated funding instruments in both agricultural research and supporting STEM disciplines to counter the current heavy dependence on international collaboration. Whilst agriculture already receives a significant percentage of funding compared to STEM in many SSA countries, it is vital that governments and development agencies accelerate support for STEM to ensure locally-relevant innovative and technological solutions are transferred to agricultural practice.

17. International collaboration, as the main driver of African research, should continue to be nurtured but funding organisations should be encouraged to support a broader range of disciplines, specifically in agricultural and STEM research. Wherever possible international funding programmes for research should include some measure of collaboration with local industry and government so that local legacy is guaranteed.

18. Similarly, academic mobility in STEM and agricultural research should be encouraged as a way of strengthening skills and maintaining the exchange of ideas and practice. However, the 
mechanisms of mobility should favour the return of African researchers to build local capacity in the long-term.

19. Sectoral transformation must also include improvements to basic STEM education and increased capacity and infrastructure for agricultural and STEM-related higher education which will be key to ensuring a pipeline of well-trained researchers.

20. The fragmentation of SSA's research capacity and lack of inter-regional collaboration constitutes a serious obstacle to the development of African-led solutions and tends to reinforce and perpetuate the current pattern of North-South collaboration and mobility. The pooling and coordination of regional resources and infrastructure should therefore be prioritized.

21. Finally, all policies must take into account the high level of heterogeneity across SSA, and specifically within Francophone Africa, ensuring country level analyses are drawn upon. 